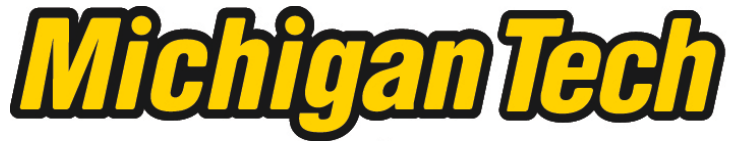 \\ Michigan Technological University Create the Future Digital Commons @ Michigan Tech
}

Dissertations, Master's Theses and Master's Reports - Open

Dissertations, Master's Theses and Master's

Reports

2012

\section{Mechanical modeling of Intraneural Ganglion Cyst}

Puneet Soman

Michigan Technological University

Follow this and additional works at: https://digitalcommons.mtu.edu/etds

Part of the Mechanical Engineering Commons

Copyright 2012 Puneet Soman

\section{Recommended Citation}

Soman, Puneet, "Mechanical modeling of Intraneural Ganglion Cyst", Master's Thesis, Michigan Technological University, 2012.

https://doi.org/10.37099/mtu.dc.etds/410

Follow this and additional works at: https://digitalcommons.mtu.edu/etds

Part of the Mechanical Engineering Commons 


\title{
MECHANICAL MODELING OF INTRANEURAL GANGLION CYST
}

\author{
By \\ Puneet Soman
}

\begin{abstract}
A THESIS
Submitted in partial fulfillment of the requirements for the degree of MASTER OF SCIENCE (Mechanical Engineering)
\end{abstract}

MICHIGAN TECHNOLOGICAL UNIVERSITY

2012

Copyright (C) 2012 Puneet Soman 
This thesis, "Mechanical Modeling of Intraneural Ganglion Cyst," is hereby approved in partial fulfillment of the requirements for the Degree of MASTER OF SCIENCE IN MECHANICAL ENGINEERING.

Department of Mechanical Engineering - Engineering Mechanics

SIGNATURES:

THESIS ADVISOR:

DR.GREGORY ODEGARD

DEPARTMENT CHAIR:

DR.WILLIAM PREDEBON

DATE: 


\section{TABLE OF CONTENTS}

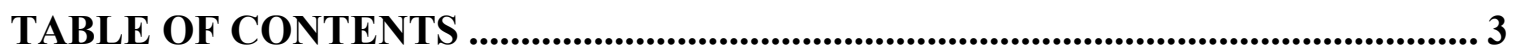

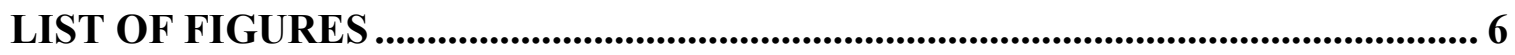

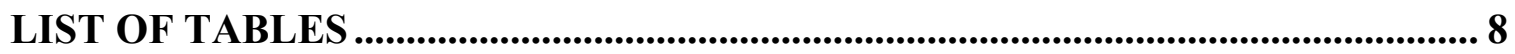

ACKNOWLEDGEMENTS ............................................................................................ 9

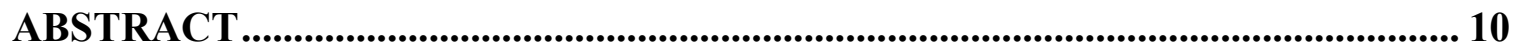

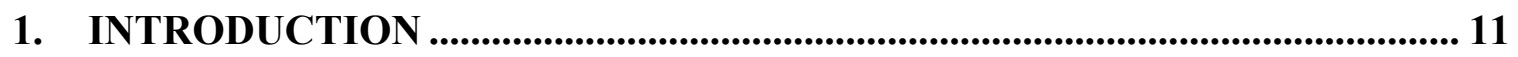

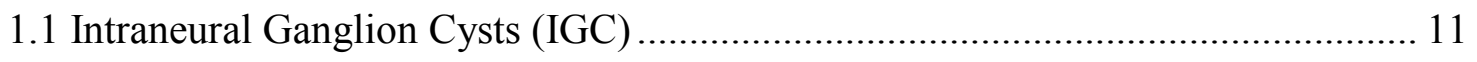

1.2 Finite Element Analysis (FEA) in Biomechanics .................................................. 16

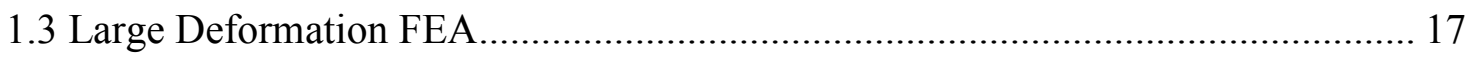

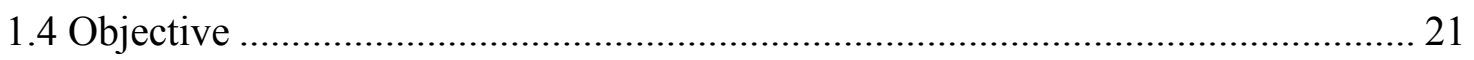

2. FINITE ELEMENT MODEL OF NERVE CROSS SECTION................................ 23

2.1 Finite Element Model of Affected CPN cross section .......................................... 23

2.2 Homogeneity and linear elasticity assumption...................................................... 25

3. ELEMENT FREE GALERKIN METHOD (EFGM) ............................................... 27

3.1 Difference between FEM and EFGM: ............................................................. 27

3.2 Basics of Element Free Galerkin Method (EFGM) ................................................ 30

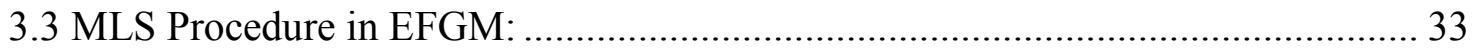

3.4 Formulation of system equations by EFGM ……………………...................... 35

3.5 Modeling of plate with a hole model in EFGM …………..................................... 44

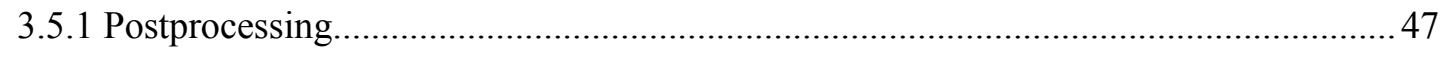

3.6 Results - Plate with a hole using EFGM.......................................................... 48

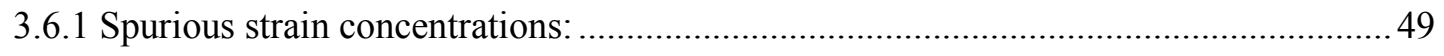


3.7 Modeling of Nerve cross section using EFGM …….......................................... 50

3.8 Results: Ganglion Cyst propagation in CPN ...................................................... 51

4. EULERIAN ANALYSIS IN ABAQUS/EXPLICIT .................................................. 54

4.1 Methods used for approaching mechanics problems ........................................... 54

4.2 Eulerian Approach for modeling ganglion cyst propagation .................................. 56

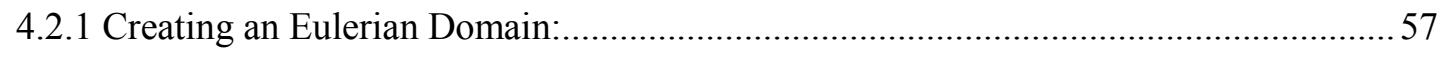

4.2.2 Creating an Eulerian Nerve part: ........................................................................ 58

4.2.3 Assembling and merging of instances: ................................................................. 59

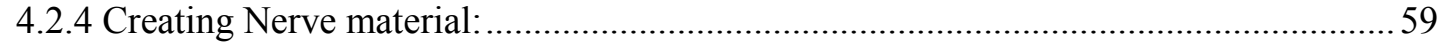

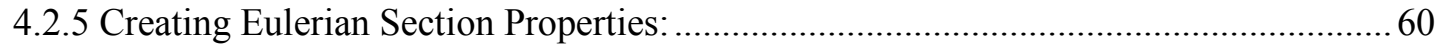

4.2.6 Creating sets for specifying material volume fractions:.................................................. 62

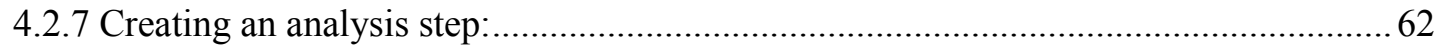

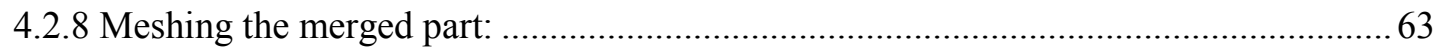

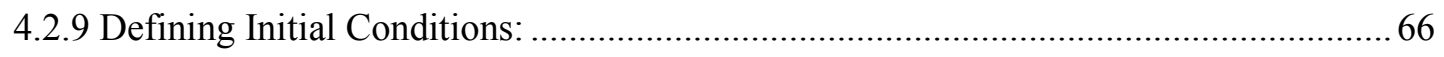

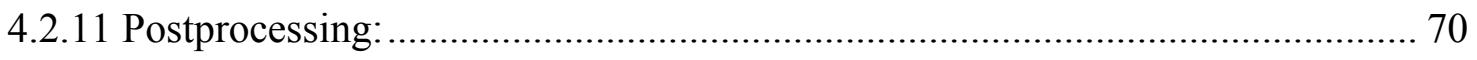

4.3 Results - Eulerian Analysis: ............................................................................ 71

4.3.1 Signet Ring Correlation.............................................................................. 75

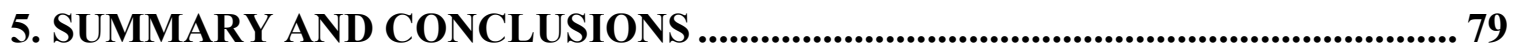

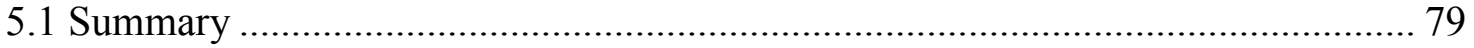

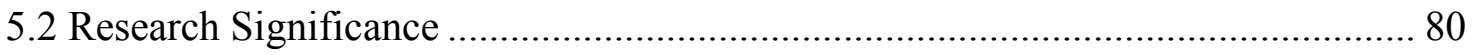

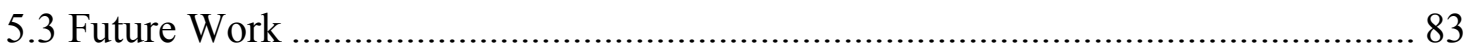

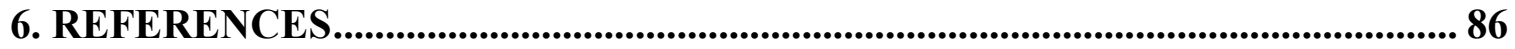

7. APPENDIX A - COPYRIGHTS/PERMISSIONS ..................................................... 89

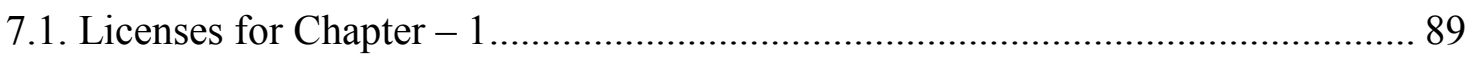

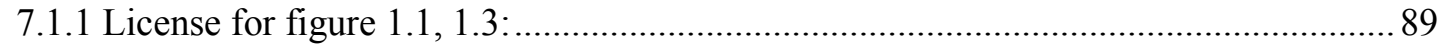

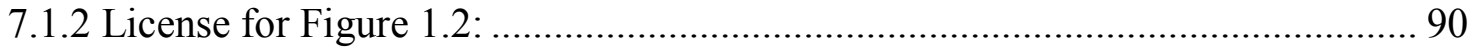

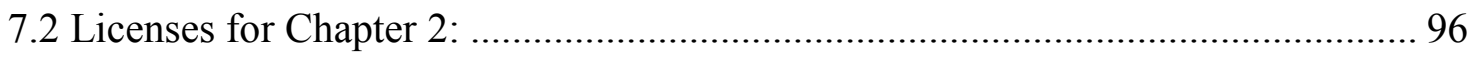




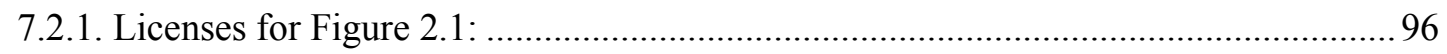

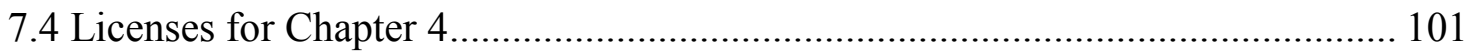

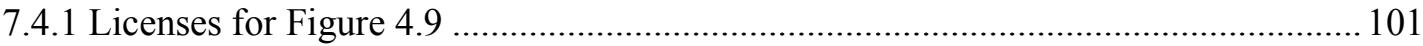

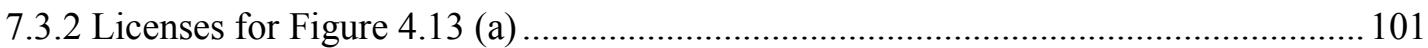




\section{LIST OF FIGURES}

Figure Page

1.1. Composite drawing showing constituents of major peripheral

1.2. Dispersion of Compression stresses by epineurial tissue........... 12

1.3. Composite Drawing showing the stages of intraneural ganglia.... 14

1.4. MRI image of cross section of affected nerve at Fibular neck showing cystic enlargement of articular branch................. 15

2.1. Schematic drawing of the internal topography of cross section of the $\mathrm{CPN}$ and its branches at the fibular neck

2.2. Finite Element Model of affected CPN at fibular neck............ 25

3.1. Flow chart specifying difference between FEM and EFGM...... 29

3.2. (a) Smoothed boundary discretized into triangular elements as in FEM;(b) Smoothed boundary discretized into a cloud of nodes as in EFGM

3.3 Overlapping of support domains showing variable connectivity...

3.4. EFGM formulations for calculation of field variables

3.5. Preprocessed model of Plate with a hole subjected to internal pressure

3.6. Deformation of plate with a hole model showing principal strain contours.

3.7. Preprocessed model of a Peroneal Nerve cross section at fibular neck

3.8. Deformation of affected Peroneal Nerve cross section at fibular neck with principal strain contours.

4.1. Movement of Lagrangian nodes subjected to deformation.........

4.2. Movement of eulerian nodes subjected to deformation.

4.3. Eulerian domain containing peroneal nerve model 
4.4. 3D peroneal nerve model in Abaqus 6.9..................... 59

4.5. Merged part representing different regions for specifying material volume fractions................................ 60

4.6. Edit Section dialog box in Abaqus 6.9....................... 61

4.7. Plot of circumferential strain v/s number of elements............ 65

4.8. Defining material volume fractions in predefined fields......... 66

4.9. Anatomy of Common Peroneal Nerve with its branches at Superior tibiofibular joint.................................. 67

4.10. Application of Boundary conditions and loads to the Eulerian domain.................................................... 69

4.11. Isosurface view cut dialog box in Abaqus 6.9............... 70

4.12. Deformation of CPN due to expansion of IGC for subsequent time intervals............................................... 73

4.13. Signet ring sign correlation............................. 76

4.14. Plot of circumferential strain against time interval............. 77 


\section{LIST OF TABLES}

Table

Page

4.1. Key features of Lagrangian and Eulerian mesh.................

56 


\section{ACKNOWLEDGEMENTS}

First and foremost, I would like to express my gratitude to my advisor Dr. Odegard who has always inspired me throughout this research with his knowledge and experience. He always encouraged me to strive towards the goals of this research. I believe without his encouragement, guidance and faith in me my Master's Thesis would not have been possible. I am also very thankful to Profs Tolou Shokuhfar and Devin Harris for their invaluable suggestions on my work and taking time to serve on my Master's thesis defense. I am extremely grateful to Shreehari Elangovan whose support, suggestions, knowledge and experience on this project helped me enormously and made me achieve this task. I am also greatly obliged to my collaborators Robert Spinner M.D, MarieNoelle Herbert-Blouin M.D and Huan Wang M.D., Ph.D. from the Mayo Clinic, Rochester, MN for explaining and discussing important concepts on this clinical problem and providing the data required to develop the FEA model. I would like to extend my special thanks to my Research group members whose valuable inputs during the weekly seminar series helped me accomplish this goal. I extend my heartfelt thanks to my friends at Michigan Tech who were always there to support and guide me with their knowledge and for making my 2 year stay in Houghton extremely fun filled. I would like to notably mention about my parents: Mr. Surendra Soman and Mrs. Meghana Soman for their immense moral and financial support during my Masters at Michigan Tech. Their constant encouragement and curiosities in this Research during our conversations revitalized me to achieve these targets. I feel blessed to have a brother like Rohit Soman, who has always been an inspiring figure in my life. Without him and my sister in law Aparna, I would not have reached the finish line. Last but not the least, I wish to extend

my heartfelt thanks to my soon to be fiancée Devashree for being there with me during these tough times of thesis writing and making this task easy and amenable. 


\section{ABSTRACT}

Intraneural Ganglion Cyst is a 200 year old mystery related to nerve injury which is yet to be solved. Current treatments for the above problem are relatively simple procedures related to removal of cystic contents from the nerve. However, these treatments may result into neuropathic pain and recurrence of the cyst. The articular theory proposed by Spinner et al., (Spinner et al. 2003) takes into consideration the neurological deficit in Common Peroneal Nerve $(\mathrm{CPN})$ branch of the sciatic nerve and affirms that in addition to the above treatments, ligation of articular branch results into foolproof eradication of the deficit. Mechanical Modeling of the Affected Nerve Cross Section will reinforce the articular theory (Spinner et al. 2003). As the cyst propagates, it compresses the neighboring fascicles and the nerve cross section appears like a signet ring. Hence, in order to mechanically model the affected nerve cross section; computational methods capable of modeling excessively large deformations are required. Traditional FEM produces distorted elements while modeling such deformations, resulting into inaccuracies and premature termination of the analysis. The methods described in this Master's Thesis are effective enough to be able to simulate such deformations. The results obtained from the model adequately resemble the MRI image obtained at the same location and shows an appearance of a signet ring. This Master's Thesis describes the neurological deficit in brief followed by detail explanation of the advanced computational methods used to simulate this problem. Finally, qualitative results show the resemblance of mechanical model to MRI images of the Nerve Cross Section at the same location validating the capability of these methods to study this neurological deficit. 


\section{INTRODUCTION}

\subsection{Intraneural Ganglion Cysts (IGC)}

Intraneural Ganglion Cysts (IGC) are lesions or defects occurring in nerves and causing a neurological deficit. These lesions contain mucin as a primary substance and are believed to be seen around joints. As the name suggests, the cystic lesions occur inside the nerve and as the cyst propagates, the cyst expands due to intraarticular pressures from the joint mechanics and compresses material around it. The material being compressed consists of nerve fascicles and epineurium. Nerve fascicles contain a bundle of nerve fibers enclosed by protective sheathing made up of connective tissue called perineurium. Several such nerve fascicles are bundled together and are surrounded by a layer of connective tissue called epineurium which forms the constituents of a major peripheral nerve.

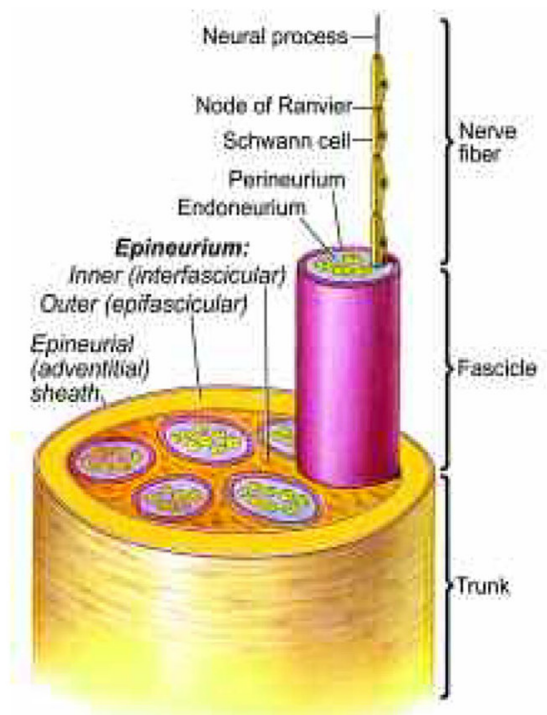

Figure 1.1 Composite drawing showing constituents of major peripheral nerve (Figure 1.1 is copyrighted and used with permission of the Mayo foundation for medical education and research, all rights reserved, see Appendix - A) 
As shown in figure 1.1, nerve fascicles contain nerve fibers carrying sensory or motor signals. Hence, compression of these fascicles results in a loss of sensory or motor signal. Current treatments of the problem include removal of cystic contents from the nerve. However, these treatments are not foolproof and result into postoperative recurrence of the defect. These cysts occur at several locations in human body, but are predominantly seen in nerves of the lower leg. Whenever a nerve is mechanically loaded, epineurial tissue functions as a shock absorber, resulting in dissipation of strain energy set up in the nerve. The dissipation of strain energy increases with increasing amount of epineurial tissue. Figure 1.2 explains the concept of dissipation of strain energy in nerve having a number of fasciculi supported with epineurial tissue interspersed in between the fascicles. Because, Common Peroneal Nerve (CPN) division of a sciatic nerve is composed of large and closely packed fasciculi with little supporting epineurial tissue, it is more susceptible
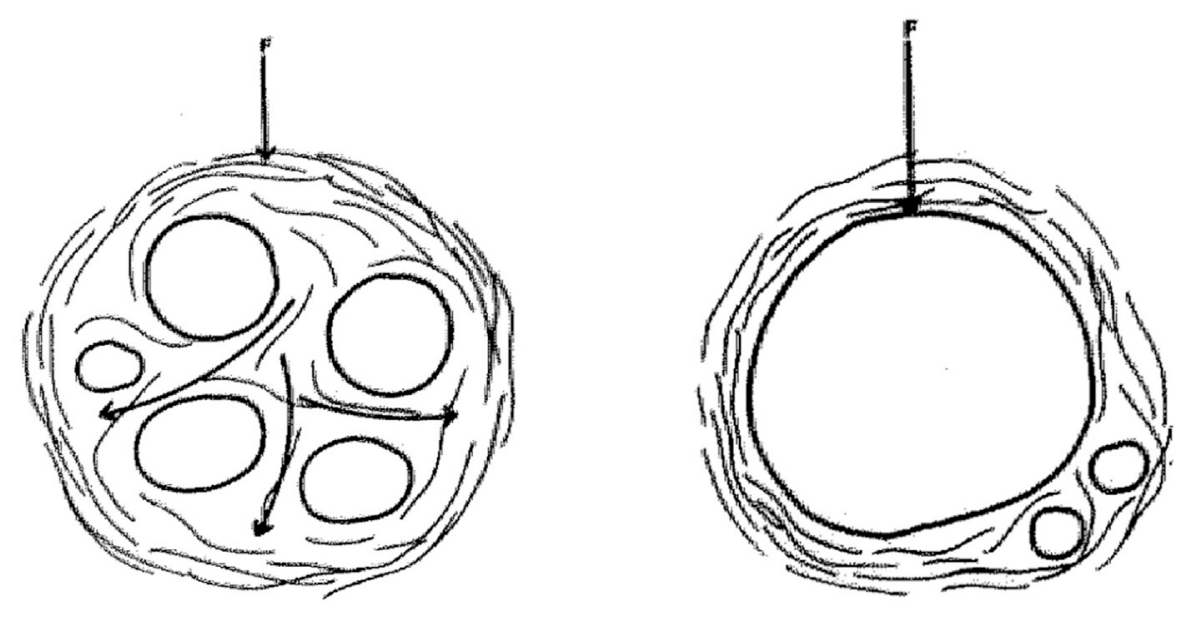

Figure.1.2 Dispersion of Compression stresses by epineurial tissue (Figure 1.2 is copyrighted and used with permission of John Wiley and Sons, all rights reserved, See appendix - A) 
to nerve injury. This thesis focuses on Intraneural Ganglion Cyst occurring in a CPN division of a sciatic nerve. A unifying theory based on the importance of articular branch in the formation and growth of Peroneal Intraneural Ganglion Cyst (IGC) proposed by Spinner et al., (Spinner et al. 2003) explains the involvement of superior tibiofibular joint in the formation of the cyst. The anatomy of CPN and its branches suggest that articular branch connected to the joint serves as a conduit for synovial fluid (joint fluid) to pass through itself and enter the Common Peroneal Nerve. This aberration occurs due to defects in the joint which may have been previously traumatized, degenerated or congenitally weakened. Due to large intra articular pressures, the articular branch becomes remarkably enlarged and results into formation of IGC.

Figure 1.3 shows the anatomy of the CPN and its branches and path of cyst propagation from articular branch to sciatic nerve. It is believed that the fluid follows the path of least resistance and flows proximally up from articular branch to CPN and finally up to the sciatic nerve depending upon the anatomy of CPN and its nerve branches. Due to defect in the joint, the cyst fluid oozes out from the joint and enters the articular branch. The large intraarticular pressures associated with loading and joint mechanics result in cystic appearance of CPN. The predilection of the cyst to propagate proximally depends on the anatomy of articular branch. For this, anatomical study (R. Spinner et al. 2003) of 20 cadaveric limbs was performed which supports the proximal dissection of the cyst from the articular branch to sciatic nerve. Moreover, to understand the cyst pathogenesis, a dye study (R. Spinner, J. Atkinson, et al. 2003) was performed on five specimens concluding that cyst dissects proximally to the sciatic nerve. 
Typically, cyst propagation is categorized into four stages:

Stage I: $\quad$ Cyst fluid flows in the articular branch resulting into mechanical pain.

Stage II: Cyst fluid crosses the trifurcation of the articular branch, DPN and superficial branches resulting in neuropathic pain and neurological deficit in DPN.

Stage III: Cyst fluid enters CPN resulting into motor nerve weakness.

Stage IV: Dissection extends proximal to sciatic nerve bifurcation and enters sciatic nerve resulting into motor and sensory nerve disturbance.

During cyst propagation, cystic fluid under intraarticular pressures compresses the fascicles around it and after reaching Stage IV, simulates an appearance of signet ring. The term 'signet ring sign' was coined by Spinner et al., (Spinner et al. 2006) due to resemblance of MRI image and signet ring.
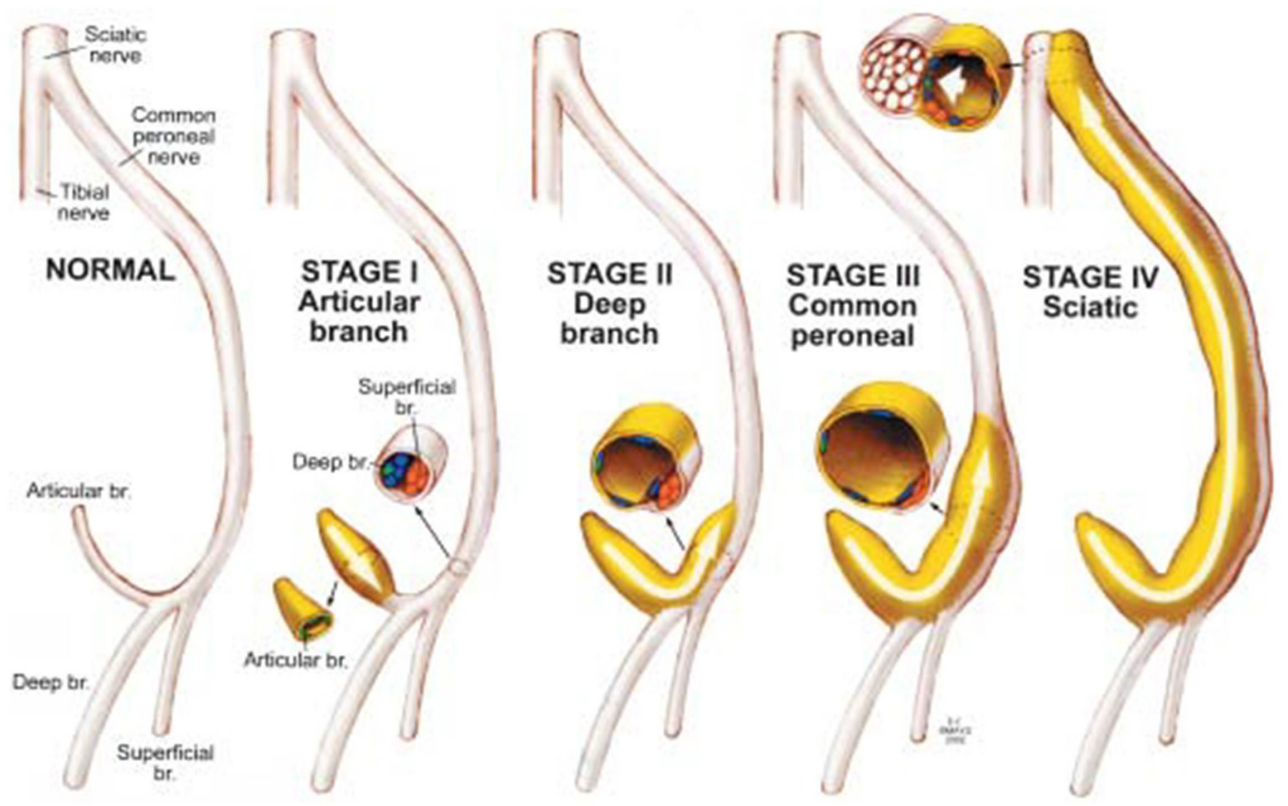

Figure 1.3 Composite Drawing showing the stages of intraneural ganglia.(Figure 1.3 is copyrighted and used with permission of the Mayo Foundation for medical education and research, all rights reserved, see Appendix - A) 
The excessive deformation of fascicles leads to neuropathic pain and loss of motor weakness and/or sensory disturbance. A retrospective study of patients suffering from neuropathic pain and presumably the problem of IGC was done on 16 cases. Figure 1.4 shows the MRI image of the cyst affected cross section. Magnetic Resonance Imaging (MRI) was performed on all the cases to understand this rare entity. MRI images suggest the presence of joint connection to the cyst affected nerve.

Mechanical modeling of the cross section of the affected nerve at the fibular neck and its resemblance with the MRI image of the cross section at the same location reinforces the articular theory proposed by Spinner et al., and improves the understanding of these rare lesions. It also validates the capability of the method to model cyst pathogenesis.

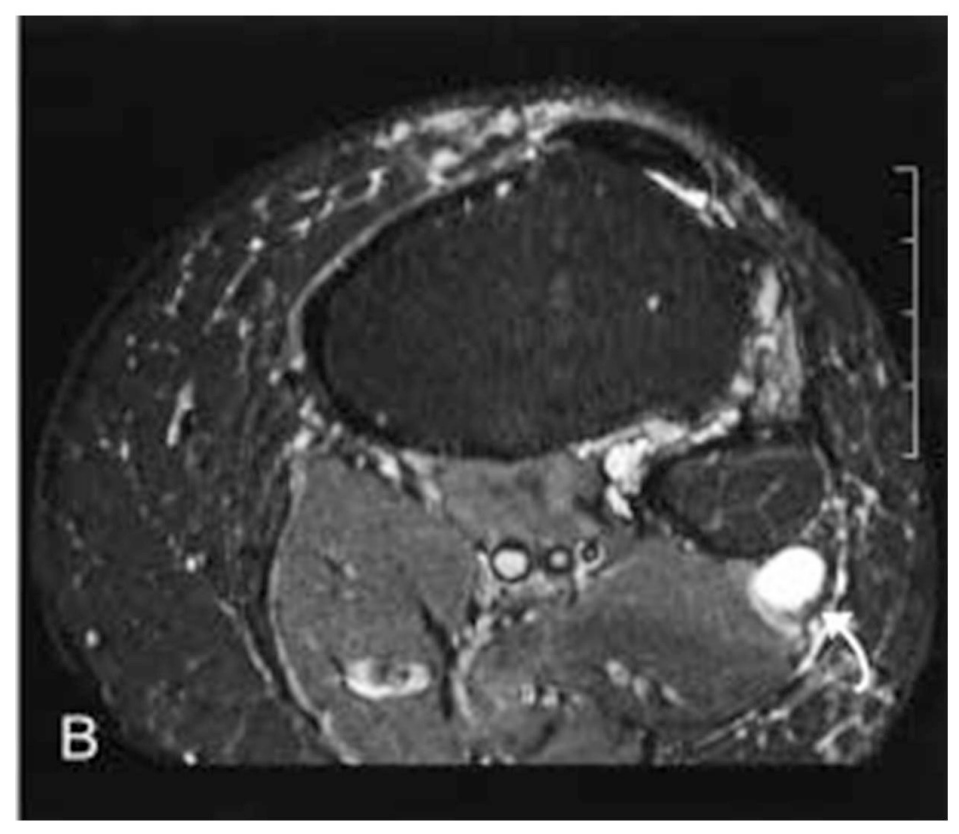

Figure 1.4 MRI of cross section of affected nerve at Fibular neck shows Cystic enlargement of articular branch (Figure 1.4 is copyrighted and used with permission of AANS (American Association of Neurosurgical Sciences with full acknowledgement given to Journal of Neurosurgery. See Appendix - A) 


\subsection{Finite Element Analysis (FEA) in Biomechanics}

Biomechanics is a field of engineering which deals with mechanics of biological materials. Biological materials fall in the class of materials showing inconsistent material behavior in different directions under mechanical loading. Biomechanics involves knowledge of geometry, mechanical properties involved, governing natural laws, mathematical formulation of specific problems, their solutions and validation.

FEM as a concept is a simplification, FEM in Biomechanics also depends on a number of simplifications and assumptions (Gallagher et al. 2006). However, appropriate simplification is a key to good modeling and these appropriate simplifications depend on the hypothesis of the behavior of the system being tested in the model. In general, FEM in Biomechanics has three different aspects:

i. Geometric representation

ii. Material representation (constitutive laws)

iii. Boundary conditions (loading and restraints)

FEM is performed differently in different biological materials namely orthopedic materials, Soft tissues, Bio-fluids etc. as these materials behave differently under mechanical loading. This thesis mainly focuses on a biological defect involving the mechanics of nervous tissue (soft tissue) and finite element modeling of the cross section of the affected nerve at the fibular neck to resemble it with MRI image obtained at the same location. 


\subsection{Large Deformation FEA}

The primary constraint in finite element modeling of IGC is excessively large deformation (greater than $100 \%$ strain) of neighboring fascicles due to cyst expansion. Traditional FEM suffers from problems like excessive element distortions resulting in inaccuracies and premature termination of analyses while modeling such deformations. Hence, special numerical techniques are required to model such large deformations. Research conducted at University of Pittsburgh by Sidorov, is based on finite element modeling of Aneurysm development and growth which is similar to modeling IGC propagation. Here, finite element modeling of Balloon Angioplasty and Fusiform Aneurysm were performed in commercial code Ansys using a multi-mechanism inelastic material model. However, this research was mainly concerned with the observation of stresses at the fully affected aneurysm sites and not with propagation of Aneurysms from its unaffected state to affected state.

Dheeranvongkit and Shimada (Dheeravongkit \& Shimada 2005) maintained the shape quality of elements during large deformation by gaining knowledge about the final deformation boundary and stress state. Then, remeshing of the final deformation boundary was performed to control the mesh shapes and sizes. Finally, mapping of the element was done to undeformed configuration by inverse bilinear mapping. Due to which, the shape quality of elements was preserved throughout the deformation.

To model such large deformations, advanced techniques are required to prevent mesh distortions and inaccuracies. Also, there is additional complexity to model biological 
materials with governing material non linearity and directionality characteristics. Meshless methods are considered as techniques which are capable of modeling excessively large deformations. Due to absence of the mesh, the problem of mesh distortions is avoided and also the computational time and cost due to remeshing techniques is also saved.

Meshless methods were used in biological applications to study the effect of soft tissue deformations during surgical simulations by Horton et al., (Horton et al. 2007). In their study, the Element Free Galerkin Method (EFGM) was used to obtain reaction forces at nodes on the contact surface of a swine brain by assigning prescribed displacements to a set of nodes. A cloud of nodes were used to discretize the problem domain and background cells were used to obtain system matrices. Results obtained were fairly accurate and validated well with the experimental results.

Doblare et al., (Doblare et al. 2004) was another group of researchers that made use of meshless methods in biomechanics. They used the Natural Element Method (NEM) for simulation of adaptive bone remodeling. NEM prevented the formation of checkerboard phenomenon, which was considered to be the main drawback of FEM while modeling bone tissue adaptation. The values of density distribution at the femoral neck and head closely matched with the actual radiographic images of the femur after similar time steps.

Meshless methods are also capable of modeling large deformations in Hyperelastic materials. This type of work was conducted by Kawashima and Sakai, (Kawashima \& 
Sakai 2007). They used Smooth Particle Hydrodynamics (SPH) which is a form of meshless modeling for analyzing large deformations of rubber. SPH was used to simulate the experimental setup of elastic sealant indentation test. Here, a cylindrical material was pushed into an elastic sealant made of polymer resulting into excessive deformations of the sealant. Traditional FEM may result in mesh distortions, leading to inaccuracies or premature termination of the analysis due to large deformation of the elastic sealant. However, due to absence of mesh, SPH was able to simulate the problem with fairly good accuracy.

Due to esoteric nature of meshless methods, very little is known about different types of meshless methods and hence, there are a few commercial software packages namely LSDyna, Pam Crash, MFree 2D etc. capable of analyzing problems using meshless methods. Another method dealing with large deformation analysis is the Eulerian Finite Element (FE) approach which minimizes element distortions and inaccuracies associated with the classical Lagrangian approach.

Generally, the Eulerian FE approach is used to simulate fluid flow problems. Benson (Benson 1992), Gadala and Wang (Gadala \& Wang 1998) first made use of the Eulerian FE approach for simulating excessively large deformations in solids in metal forming, extrusion and die forging applications. This Eulerian FE approach was used by Raczy (Raczy et al. 2004) to simulate deformation state of Copper subjected to orthogonal cutting. They used LS-Dyna for applying the Eulerian technique to study the excessive deformation of copper during the machining process. The strains obtained were of the 
order of 500 to 600 percent. The results validated well with the experimental local stress and strain values.

A detailed study involving Eulerian FE approach and meshless methods was done by Lee (Lee et al. 2005). They studied the effect of dynamic pressure loading on aorta using advanced numerical techniques. Dynamic pressure resulted in excessive strains in the aorta wall and the formation of vortices in the fluid flowing through aorta. They employed Lagrangian, Arbitrary Lagrangian Eulerian (ALE), Eulerian and SPH formulations to simulate the problem. Stresses, strains and velocity of fluid were obtained as output parameters. Comparison of output parameters from each method concluded that SPH gave better results concerning idealized fluid flow, but the Eulerian approach gave fairly accurate results concerning the deformation of aorta wall.

Work related to FE modeling of Intraneural Ganglion Cyst (IGC) was performed by Elangovan, (Elangovan et al. 2009) and (Elangovan 2010). They categorized the IGC propagation into two stages. Stage I considered the propagation of IGC in the articular branch. Modeling of Stage I was performed using a 3 dimensional FE model. Stage II considered the propagation of IGC in Common Peroneal Nerve (CPN) division of the sciatic nerve. Modeling of Stage II was performed using a 2 dimensional FE model. The approach for modeling cyst propagation in both the stages was based on a combined geometrical and physical growth criterion (Huang and Black 1996). In this approach, element separation was performed when the stress value of an element exceeded failure strength of that particular material. However, application of this approach approximates 
propagation of the cyst by failure of neighboring fascicles rather than propagation of cyst by actual deformation of fascicles. The primary constraint involved in modeling of this neurological deficit is the excessively large deformations of fascicles due to expansion of IGC. Hence, a computational method capable of modeling such large deformations is required to model this neurological deficit.

\subsection{Objective}

The primary objective of this research is to mechanically model the growth and propagation of Intraneural Ganglion Cyst in CPN division of Sciatic nerve by using a two dimensional finite element model by actual deformation of fascicles (elements). This thesis mainly focuses on the advanced numerical techniques used to model the cross section of affected CPN at the fibular neck, simulating propagation of the cyst from Stage I to Stage IV (depicted in figure 1.3) to resemble it with MRI image of the affected CPN cross section at the same location. Strain due to deformation of fascicles during cyst growth from Stage I to Stage IV in CPN cross section is expected to be greater than $100 \%$. Hence, advanced numerical techniques capable of modeling strains greater than $100 \%$ are required to simulate cyst propagation.

This thesis report focuses on two techniques capable of modeling excessively large deformations:

i. Element Free Galerkin Method (EFGM)

ii. Eulerian Analysis 
Chapter 2 of this thesis report focuses on the creation of finite element model in Abaqus 6.9 with the information obtained from drawings of histological sections of the sciatic nerve produced by Sunderland and Ray. (Sunderland \& Ray 1948) Chapter 3 initially explains Element Free Galerkin Method (EFGM) (Belytschko et al. 1994) in brief followed by finite element modeling of a simple plate with a hole geometry and nerve geometry using EFGM. Chapter 4 elucidates finite element modeling of IGC propagation in nerve cross sections using Eulerian analysis in Abaqus 6.9. This is followed by discussing the results obtained from both the methods and correlating them with MRI image of the cyst. Finally, based on the results obtained, a suitable method capable of modeling such large deformations and modeling the cyst pathogenesis was proposed. 


\section{FINITE ELEMENT MODEL OF NERVE CROSS SECTION}

\subsection{Finite Element Model of Affected CPN cross section}

Sunderland and Ray, (Sunderland \& Ray 1948) investigated the behavior of fascicles and its intrafascicular mixing forming intraneural plexus formations. For this, they prepared histological sections from segments of sciatic nerve between sciatic notch and tibial malleolus from 40 adult subjects. The sections were enlarged, drawn and arranged in a serial fashion. Thus, several drawings of cross sections of a sciatic nerve were prepared at different locations. The drawing of the nerve cross section at the fibular neck was of primary interest. Figure 2.1 shows the drawing of the cross section of the nerve at fibular neck. According to Spinner et al., 2003, it was believed that cysts arise from the articular branch. The articular branch is located eccentric to the left in the drawing represented by ' $G$ ' shown in figure 2.1. Hence, the cyst in the form of a circular through hole was located in the model eccentric to the left representing the articular branch.

A finite element model was created in Abaqus 6.9 and the cyst arising from articular branch was treated as a hole. The geometry of the outer boundary of the model was scanned and imported in Abaqus 6.9. The dimensions of the FE model were calculated by scaling the model according to the image obtained in Figure 2.1. The major axis of the ellipse ' $a$ ' as shown in figure 2.2 was obtained by experimental data obtained from Spinner et al.,2007 and was $5.7 \mathrm{~mm}$. 


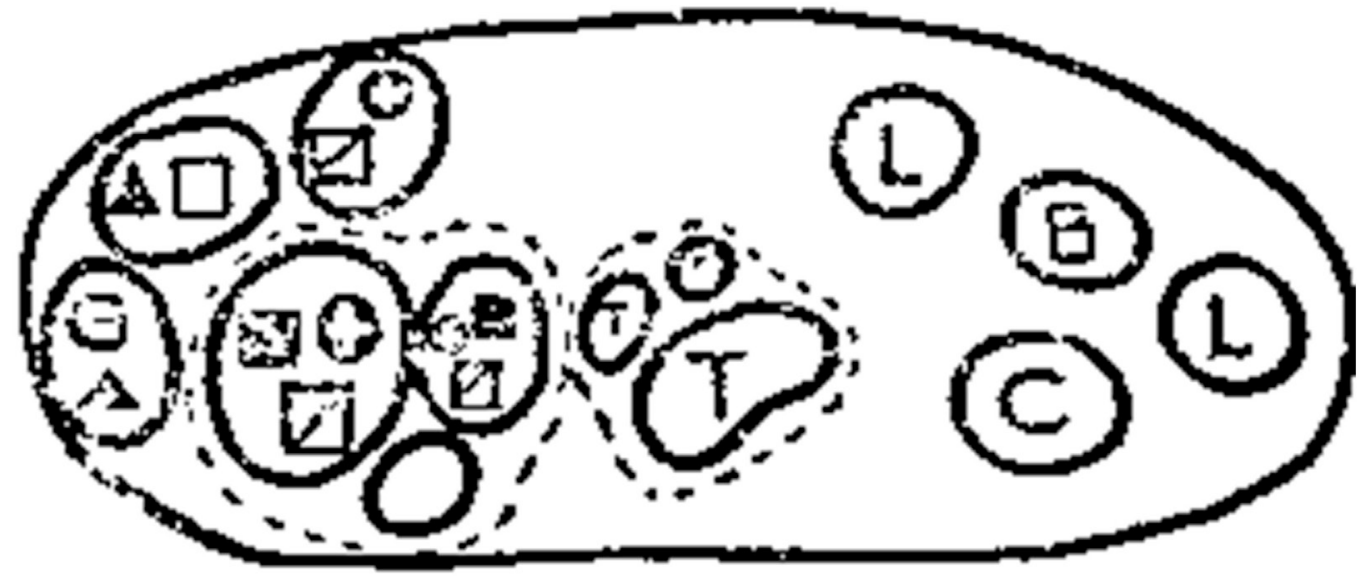

Figure 2.1 Schematic drawing of the internal topography of cross section of the CPN and its branches at the fibular neck (Figure 2.1 is copyrighted and used with permission of Oxford University Press, All rights reserved, See Appendix - A)

The minor axis ' $b$ ' of the ellipse was obtained by equation (2.1.1).

$$
\frac{\text { Major axis obtained from figure 2.1 }}{\text { Minor axis obtained from figure 2.1 }}=\frac{\text { Major axis ' } a \text { ' in FE Model }}{\text { Minor axis ' } b \text { ' in FE Model }}
$$

The minor axis obtained from the above relation was equal to $2.52 \mathrm{~mm}$. Figure 2.2 shows the finite element model of the affected CPN cross section at fibular neck. Due to lack of initial guiding data, the diameter of the cyst was considered to be $0.18 \mathrm{~mm}$. This dimension locates the cyst within the fascicle boundary. Since, intraarticular pressures were responsible for propagation of the cyst; the hole was subjected to internal pressure in radial outward direction to simulate the propagation of the cyst from Stage I to Stage IV. 


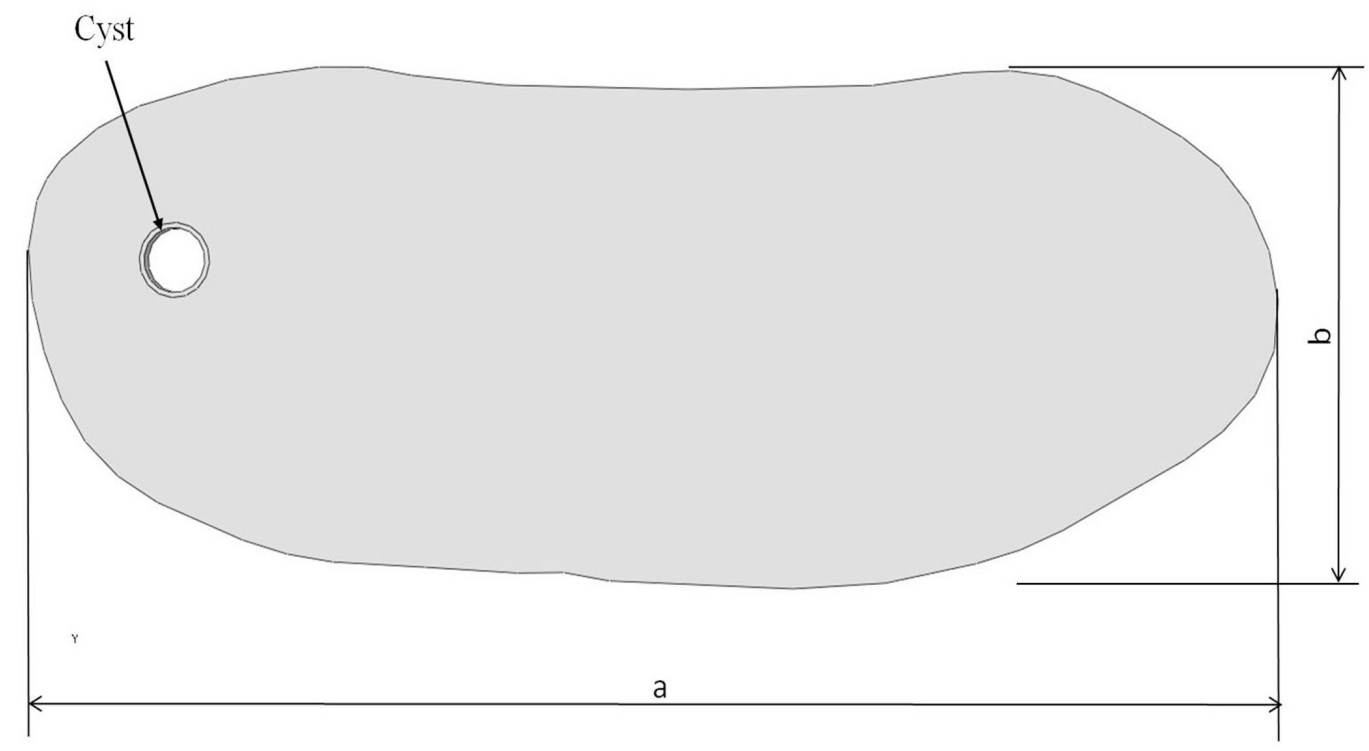

Figure 2.2 Finite Element model of affected CPN at fibular neck (Screenshot from Abaqus 6.9)

\subsection{Homogeneity and linear elasticity assumption}

In order to model the Nerve Cross section for cyst blow out, oval shapes were to be assigned fascicle properties and epineurium material properties to the area interspersed in between the oval shapes shown in figure 2.1. However, large complexities were involved in maintaining the boundaries between fascicle and epineurium during excessive deformation. Hence, for modeling simplicity, the entire area inside the boundary of the nerve was assumed to be a homogenous continuum. Moreover, fascicles and epineurium are anisotropic materials having nonlinear material behavior. Material non linearity creates convergence issues while modeling such large deformations. In addition, incompressibility associated with soft tissues creates further complexities in obtaining an accurate solution. The objective of this research is to mechanically model the propagation 
of ganglion cyst at an affected nerve cross section and correlate it with MRI image of the affected cross section at the same location. Hence, strains are of primary importance in this research. Strains are obtained by differentiating displacements calculated from the numerical solution. Material models are involved only in calculation of stresses. Therefore, the assumption of using a linear elastic material having Elastic modulus similar to the nerve material can be conveniently made in this case.

Elastin and collagen are the major constituents of nerve material and approximately have a linear elastic behavior. Wu et al., 2004 obtained the longitudinal elastic modulus of elastin, cured elastin and native carotid artery by testing dumbbell shaped specimens in tension. Native carotid artery has elastin and collagen as its primary constituents. Hence, Properties of native carotid artery were approximated to be similar to the material properties of CPN. Average Elastic modulus of native carotid artery measured in the experiment was $\mathrm{E}=4.6 \mathrm{MPa}$. Mass Density of human patellar tendon was measured by Hashemi et al. (Hashemi, Chandrashekhar and Slauterback 2005) and equal to $\rho=0.76$ $\mathrm{g} / \mathrm{cm}^{3}$. Since, human patellar tendon contains elastin and collagen as its primary constituents. CPN was assigned a compressible linear elastic material property having $\rho=$ $7.6 \times 10^{-7} \mathrm{~kg} / \mathrm{mm}^{3} ; \mathrm{E}=4.6 \mathrm{MPa}$ and $v=0.3$.

Thus, the finite element model was subjected to boundary conditions and loads in order to simulate a cyst blow out to correlate with MRI image of cyst of the CPN cross section at the fibular neck which is discussed in further sections. 


\section{ELEMENT FREE GALERKIN METHOD (EFGM)}

\subsection{Difference between FEM and EFGM:}

FEM and EFGM are numerical methods used for solving Partial Differential Equations (PDE) governing the physicality of the problem domain. Governing PDE's can be solved by two different methods:-

i) Direct Approach: These are the strong form methods that discretize the problem domain and solve the PDE's directly. Ex: - Finite Difference Method (FDM), Point Collocation Method etc.

ii) Indirect approach: These are the weak form methods that establish an alternative weak form solution of the PDE's, discretizes the problem domain and solves the alternative weak form of PDE. Ex: - FEM, EFGM etc.

Direct approach methods are used normally in fluid flow applications and indirect approach methods are normally used in Solid Mechanics applications. Because, mechanics of nervous tissue involves deformations and force mechanics of solids; it is treated under the category of Solid Mechanics. Hence, it was desirable to use indirect approach methods (FEM, EFGM) to study the neurological deficit of Intraneural Ganglion Cyst.

Solids remain in an equilibrium state at a minimum energy potential. In weak form methods, a displacement field is obtained that satisfies the principle of minimum energy potential forming the basis for best possible approximation of the exact solution. Strains 
and stresses are obtained from the displacement fields by strain displacement equations and constitutive equations respectively. To summarize, there are three basic features of obtaining solutions of PDE's by numerical techniques in weak form methods:

i) Construction of shape functions (for creating displacement functions)

ii) Integration of problem domain for evaluation of energy potentials and system equations

iii) Weak form solution used for creating discrete algebraic equations

The difference between FEM and EFGM lies in construction of shape function and integration of the problem domain. However, FEM and EFGM are both based on Galerkin weak formulation of PDE.

In FEM, the domain is discretized into elements and shape functions are constructed based on those elements in the natural coordinate system. These shape functions are then mapped back to global coordinate system. Mapping of shape functions back to global coordinate system is critical when dealing with complicated geometries. These shape functions are usually predetermined before the analysis starts. Integration over the domain is performed with the use of numerical integration techniques.

In EFGM, (Liu 2003) the domain is discretized into nodes. Even though this is a form of meshfree method, background mesh is required for integration of system equations. A single element in the background mesh is called a background cell. A support domain is selected for a point or cell of interest. Shape functions are constructed on a point or cell 
of interest using local support nodes in the support domain surrounding the point or cell. The shape function is associated with the point or cell of interest and changes according to the point/cell of interest. The construction of a shape function is performed during the analysis. The shape function is constructed in the global coordinate system; hence, no coordinate mapping is required. Fig 3.1 represents a flow chart showing difference between FEM and EFGM.

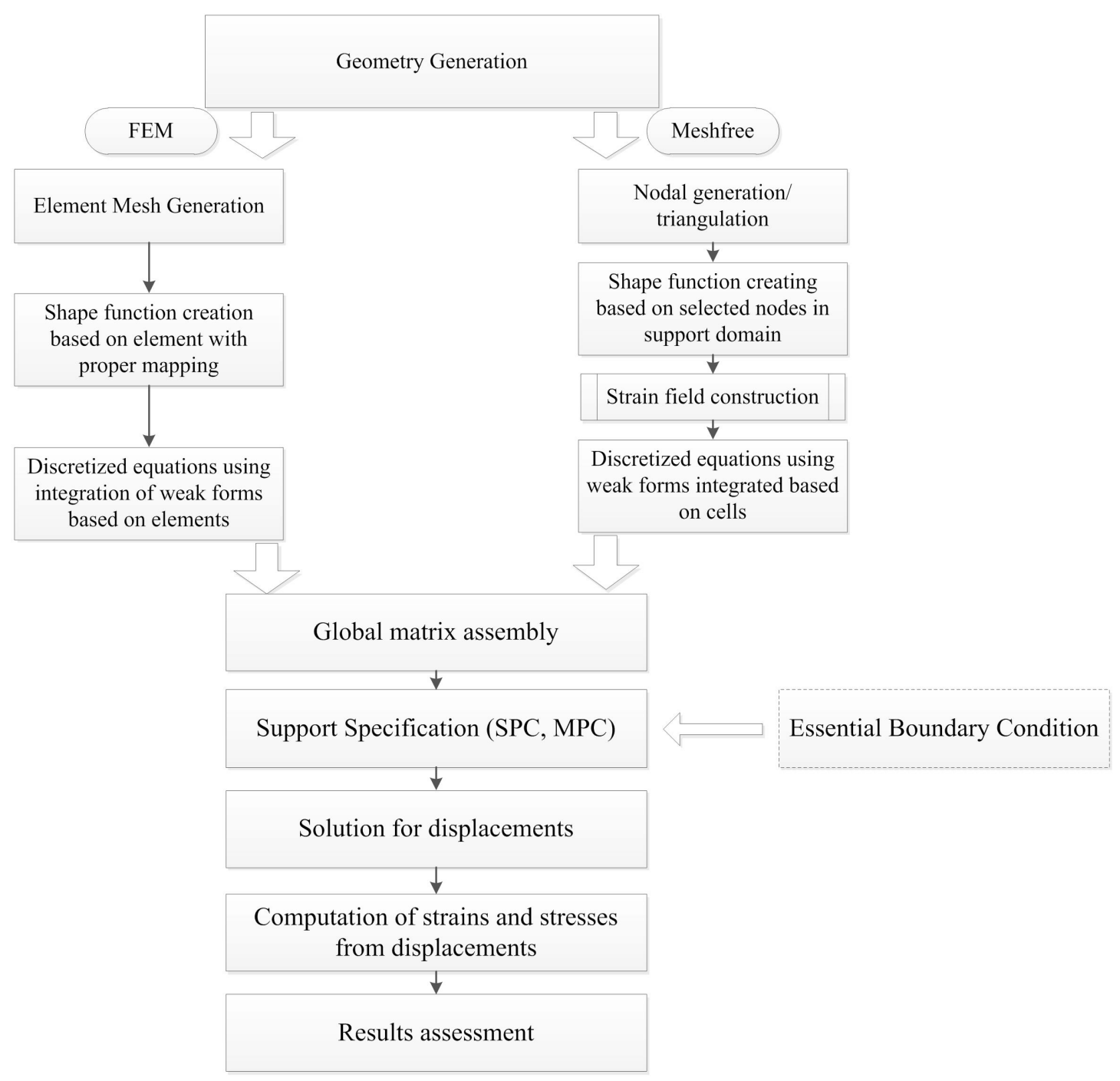

Figure 3.1 Flow chart specifying difference between FEM and EFGM (Liu 2003) 


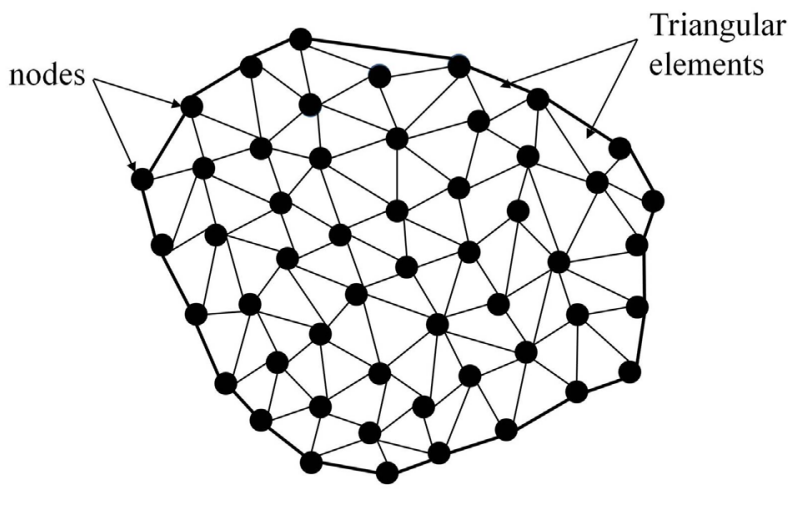

(a)

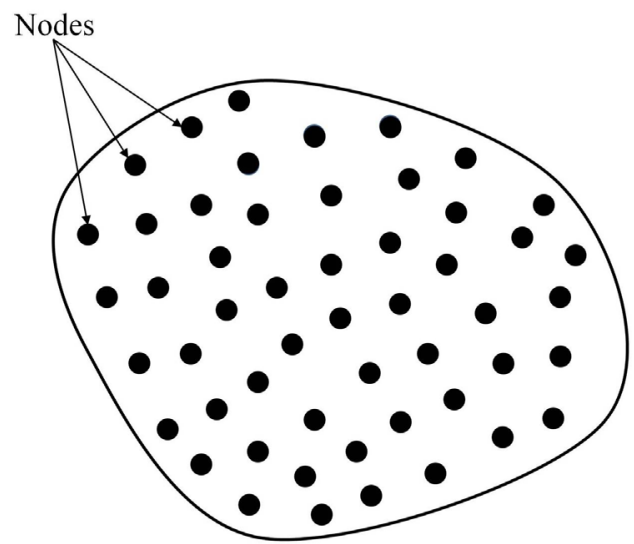

(b)

Figure 3.2 (a) Smoothed boundary discretized into triangular elements as in FEM;

(b) Smoothed boundary discretized into a cloud of nodes as in EFGM (Liu 2003)

The preference of using EFGM over FEM in modeling Intraneural Ganglion Cyst propagation is mainly due to difficulty of FEM in modeling excessively large deformations due to element distortions. In case of EFGM, shape function is constructed on nodes and is independent of element distortion. Since, elements are only used in integration of weak forms. EFGM can be considered capable of modeling excessively large deformations. Figure 3.2 shows difference between FEM and EFGM.

\subsection{Basics of Element Free Galerkin Method (EFGM)}

The basic steps used in EFGM are as follows:

i) Domain Discretization: This is generally performed using Computer Aided Engineering (CAE) preprocessor where the domain is discretized 
into triangular elements considered as triangular background cells in EFGM. The cloud of nodes is also obtained from triangulation.

ii) Displacement Interpolation: Shape functions are constructed using Moving Least Square (MLS) interpolation procedure. A field variable (displacement component) at point of interest at $\mathrm{x}=(x, y, z)$ within the problem domain can be interpolated using the support nodes in the support domain of the point of interest. The concerned point of interest is called as a quadrature point.

$$
\left.u^{h}(x)=\sum_{i \in S_{n}} \phi_{i}(x) u_{i}=\boldsymbol{\wp} x\right) d_{s}
$$

where

$S_{n}=$ support nodes in the support domain of point of interest

$u_{i}=$ nodal field variable of the support nodes

$d_{s}=$ vector collecting local field variables of the support nodes

$\phi_{i}(x)=$ shape function of the ith node created using all the support nodes

in the support domain

$\boldsymbol{\varphi}(x)=$ shape function of the vector collecting local support nodes

The function value at the quadrature point is approximated using the local nodes in the support domain. The support domain is weighted such that the shape function at the boundary of the support domain is zero. The shapes of the support domain can be circular, rectangular, etc. Overlapping of such support domains leads to variable connectivity. In other words, support domains in EFGM are analogous to elements in FEM 
for shape function construction. Figure 3.3 shows overlapping of such support domains.

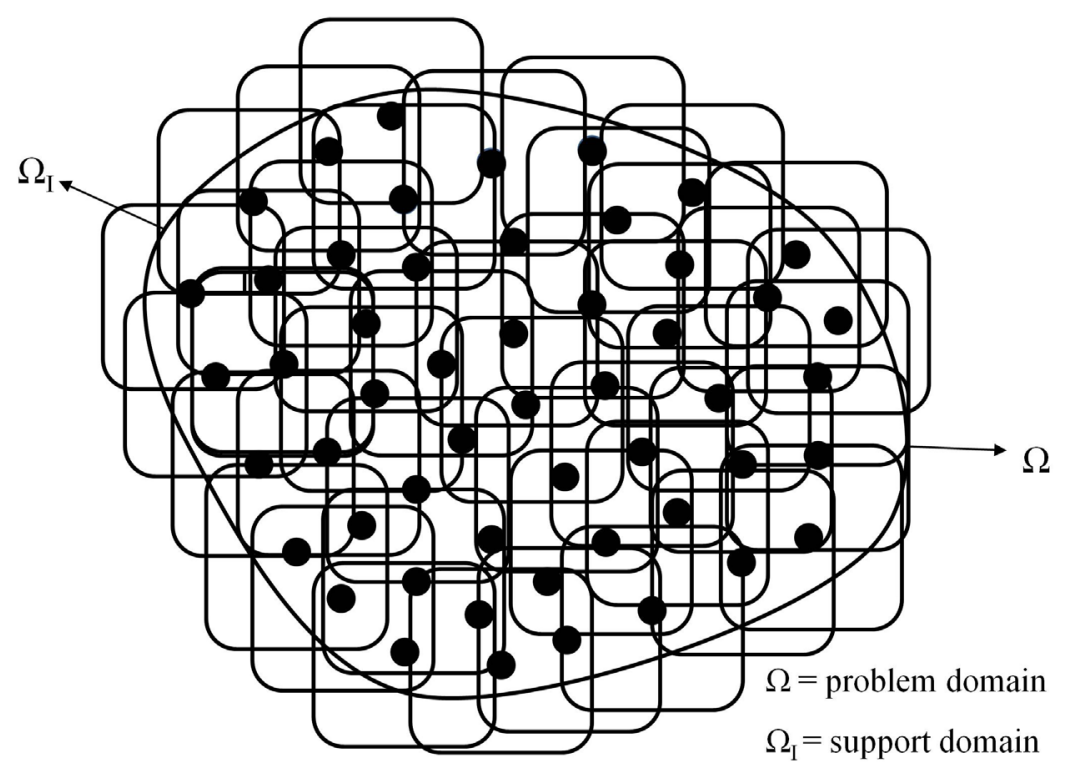

Figure 3.3 Overlapping of support domain showing variable connectivity (Liu 2003)

iii) Formation of system equations: The system equations also known as discrete equations are formulated using integration of the Galerkin weak forms over the background cells.

iv) Solving the global meshfree equations: Finally the global meshfree equations are solved to obtain displacements, Eigen values and Eigen vectors, and time history of displacement, acceleration and velocity for static, vibration and dynamic analysis respectively. 


\subsection{MLS Procedure in EFGM:}

Belytschko et al., (Belytschko et al. 1994) used Moving Least Square (MLS) procedure to construct shape functions in EFGM. The main advantage of a MLS procedure for constructing shape function is the approximated field function is smooth and continuous in the problem domain when sufficient nodes are used.

Consider a problem domain $\Omega$, if $\mathrm{u}(\mathrm{x})$ is the function of field variable in domain $\Omega$ at point $\mathrm{x}, u^{h}(x)$ is the approximation of field variable at point $\mathrm{x}$.

$$
u^{h}(\mathrm{x})=\sum_{j}^{m} p_{j}(\mathrm{x}) a_{j}(\mathrm{x}) \equiv \mathrm{p}^{\mathrm{T}}(\mathrm{x}) \mathrm{a}(\mathrm{x})
$$

where

$\mathrm{m}=$ number of monomials in a polynomial basis

$\mathrm{a}(\mathrm{x})=$ vector of coefficients given by

$$
\mathbf{a}^{T}(\mathrm{x})=\left\{a_{0}(\mathrm{x}) a_{1}(\mathrm{x}) \ldots \ldots a_{m}(\mathrm{x})\right\}
$$

which are functions of $\mathrm{x}$

$\mathrm{p}(\mathrm{x})$ is a vector of polynomial basis functions and it changes according to the dimension of the problem domain.

In 1D space,

$$
\mathbf{p}^{T}(\mathrm{x})=\left\{p_{0}(\mathrm{x}), p_{1}(\mathrm{x}) \ldots \ldots, p_{m}(\mathrm{x})\right\}=\left\{1, x, x^{2}, \ldots . ., x^{m}\right\}
$$

In 2D space,

$$
\mathbf{p}^{T}(\mathrm{x})=\mathbf{p}^{T}(\mathrm{x}, \mathrm{y})=\left\{1, x, y, x y, x^{2}, y^{2} \ldots ., x^{m}, y^{m}\right\}
$$

In 3D space,

$$
\mathbf{p}^{T}(\mathrm{x})=\mathbf{p}^{T}(\mathrm{x}, \mathrm{y}, \mathrm{z})=\left\{1, x, y, z, x y, y z, z x, x^{2}, y^{2}, z^{2} \ldots . ., x^{m}, y^{m}, z^{m}\right\}
$$


Thus, Polynomial basis functions follow the rule of Pascal Triangle.

Now, consider a support domain of $\mathrm{x}$ containing a set of $n$ local nodes $\mathrm{x}_{1}, \mathrm{x}_{2}, \mathrm{x}_{3} \ldots \mathrm{x}_{\mathrm{n}}$

Then,

$$
u^{h}\left(\mathrm{x}, \mathrm{x}_{\mathrm{I}}\right)=\mathrm{p}^{\mathrm{T}}\left(\mathrm{x}_{\mathrm{I}}\right) \mathrm{a}(\mathrm{x}) \quad I=1,2,3 \ldots . n
$$

Each support domain is assigned a weight function. The weightings on the support nodes depend on the distance of the support nodes from the point of interest. Farthest node to the point of interest is assigned a smaller weight while nodes nearer to the point of interest are assigned larger weights. A functional $J$ satisfies the above condition

$$
\begin{gathered}
J=\sum_{I}^{n} \widehat{W}\left(x-x_{I}\right)\left[u^{h}\left(x, x_{I}\right)-u\left(x_{I}\right)\right]^{2} \\
J=\sum_{I}^{n} \hat{W}\left(x-x_{I}\right)\left[\mathrm{p}^{\mathrm{T}}\left(\mathrm{x}_{\mathrm{I}}\right) \mathrm{a}(\mathrm{x})-u\left(x_{I}\right)\right]^{2}
\end{gathered}
$$

where $\hat{W}\left(x-x_{I}\right)$ is defined as the weight function depending on the distance between the local support node and the point of interest.

In MLS procedure, the field approximation is found at the minimization of the functional $J$

$$
\frac{\partial J}{\partial a}=0
$$

resulting into linear system of equations:

$$
\mathrm{A}(\mathrm{x}) \mathrm{a}(\mathrm{x})=\mathrm{B}(\mathrm{x}) \mathrm{d}_{\mathrm{s}}
$$

where A is called as the MLS moment matrix,

$$
\mathrm{A}(x)=\sum_{I}^{n} \widehat{W}_{I}(x) \mathrm{p}^{T}\left(x_{I}\right) \mathrm{p}\left(x_{I}\right)
$$

where 


$$
\begin{gathered}
\widehat{W}_{I}(\mathrm{x})=\hat{W}\left(\mathrm{x}-\mathrm{x}_{I}\right) \\
\mathrm{B}(x)=\left[\mathrm{B}_{1} \mathrm{~B}_{2} \ldots \ldots \ldots \mathrm{B}_{n}\right] \\
B_{I}=\hat{W}_{I}(x) \mathrm{p}\left(x_{I}\right)
\end{gathered}
$$

$d_{s}$ is the vector which collects the nodal parameters of the field variables for all the nodes in the support domain

$$
\mathrm{d}_{\mathrm{s}}=\left\{u_{1} u_{2} \ldots \ldots \ldots u_{n}\right\}^{\mathrm{T}}
$$

Assuming matrix A is invertible; we can calculate the coefficient matrix

$$
\begin{gathered}
\mathrm{a}(\mathrm{x})=\mathrm{A}^{-1}(\mathrm{x}) \mathrm{B}(\mathrm{x}) \mathrm{d}_{s} \\
\therefore u^{h}(x)=\sum_{I}^{n} \sum_{j}^{m} p_{j}(x)\left(\mathrm{A}^{-1}(x) \mathrm{B}(x)\right)_{j I} u_{I} \\
\therefore u^{h}(\mathrm{x})=\sum_{I}^{n} \Phi_{I}(\mathrm{x}) u_{I} \\
\text { where } \Phi_{I}(\mathrm{x})=\sum_{j}^{m} p_{j}(\mathrm{x})\left(\mathrm{A}^{-1}(x) \mathrm{B}(x)\right)_{j I}=\mathrm{p}^{T} \mathrm{~A}^{-1} \mathrm{~B}_{I}
\end{gathered}
$$

\subsection{Formulation of system equations by EFGM}

EFGM developed by Belytschko et al., 1994 is a form of Meshfree method which is based on Galerkin weak formulation. It uses MLS approximation for construction of shape functions and uses background mesh for integration of weak forms. Fig. 3.4 shows flowchart for calculation of field variables using EFGM. 


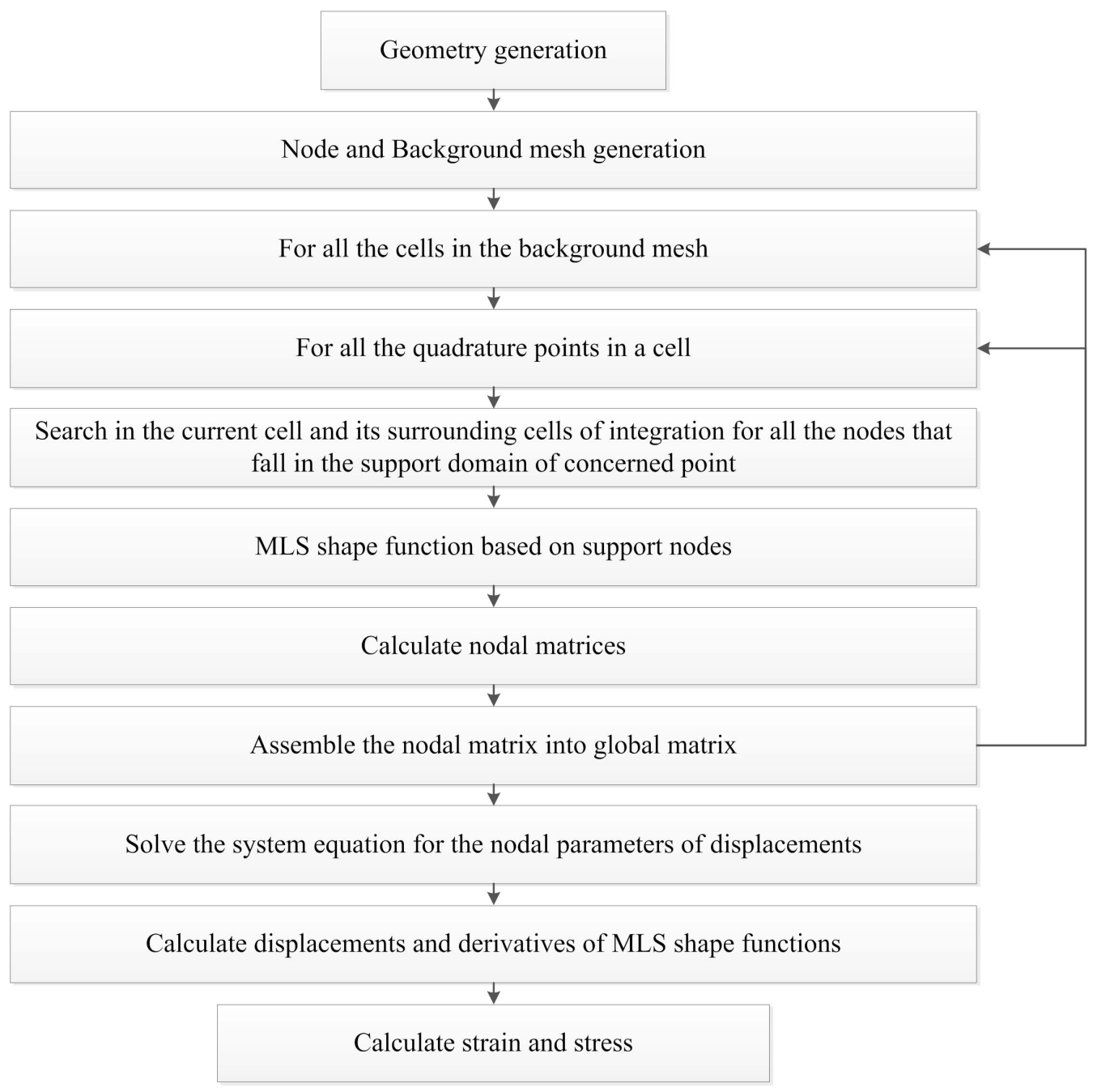

Figure 3.4 EFGM formulations for calculation of field variables (Liu 2003)

Consider a 2D solid mechanics problem. Thus, PDE's and boundary conditions used to represent a solid mechanics problem can be given as:

$$
\begin{gathered}
\nabla \sigma+b=0 \text { equilibrium equation on problem domain } \\
\qquad \begin{array}{c}
\mathrm{u}=\mathrm{u}_{\Gamma} \quad \text { on essential boundary } \Gamma_{u} \\
\nabla_{n} \sigma=\mathrm{t}_{\Gamma} \quad \text { on natural boundary } \Gamma_{t}
\end{array}
\end{gathered}
$$

where 
$\nabla=$ matrix differential operator

$\sigma=$ vector of stress components

$\mathrm{u}=$ vector of displacements

$\mathrm{t}_{\Gamma}=$ traction vector on natural boundary $\Gamma_{\mathrm{t}}$

$\mathrm{u}_{\Gamma}=$ displacement vector at essential boundary $\Gamma_{\mathrm{u}}$

$\mathrm{b}=$ Body force vector

$\nabla_{n}=$ matrix of components of unit vector normal to boundary $\Gamma_{\mathrm{t}}$

A problem domain $\Omega$ is discretized into a set of nodes inside the domain and also on the boundary. MLS procedure is used to approximate the displacement ' $u$ ' at the point of interest with the use of local nodes in the support domain of the concerned point of interest. Galerkin weak formulation is used to construct the discrete equations and background mesh is used to integrate these discrete equations.

The main drawback of EFGM is the displacement obtained after solving the system matrices does not yield the exact value of actual displacement for the nodes at the essential boundary. This is due to failure of EFGM to obey Kronecker Delta property by MLS shape functions. In order to ensure this, Lagrange's multipliers were used to enforce this essential property.

Galerkin weak formulations for the PDE's and Boundary conditions mentioned in Equations (3.4.1) to (3.4.3) with Lagrange's multipliers are given as:

$$
\int_{\Omega} \delta(\nabla \mathbf{u})^{\mathrm{T}}(\mathrm{c} \nabla \mathrm{u}) \mathrm{d} \Omega-\int_{\Omega} \delta \mathrm{u}^{\mathrm{T}} \mathrm{t}_{\Gamma} \mathrm{d} \Gamma-\int_{\Gamma_{\mathrm{t}}} \delta \mathrm{u}^{\mathrm{T}} \mathrm{t}_{\Gamma} \mathrm{d} \Gamma-\int_{\Gamma_{\mathrm{u}}} \delta \lambda^{\mathrm{T}}\left(\mathrm{u}-\mathrm{u}_{\Gamma}\right) \mathrm{d} \Gamma-\int_{\Gamma_{\mathrm{u}}} \delta \mathrm{u}^{\mathrm{T}} \lambda \mathrm{d} \Gamma=0
$$


Equation (3.4.4) is also called as the variational form of the equation. Equation (3.4.4) is formed from equations (3.4.1) to (3.4.3).

Here, $\lambda=$ Lagrange's multiplier used to enforce essential boundary conditions for cases where $u-u_{\Gamma} \neq 0$. Hence, Lagrange's multipliers are forces which enforce the essential boundary condition to be $\mathrm{u}_{\mathrm{L}} \mathrm{u}_{\Gamma}=0$.

From Equation (3.3.9),

$$
u^{h}(\mathrm{x})=\sum_{I \in S_{n}} \phi_{I}^{H}(\mathrm{x}) u_{I}
$$

where $\phi_{I}^{H}(\mathrm{x})$ is given by equation (3.3.10). Similarly, displacement component $v$ can be written as:

$$
v^{h}(x)=\sum_{I \in S_{n}} \phi_{I}^{H}(x) v_{I}
$$

Combining equations (3.4.5) and (3.4.6),

$$
\mathrm{u}^{h}=\left\{\begin{array}{l}
u \\
v
\end{array}\right\}^{h}=\sum_{I \in S_{n}} \underbrace{\left[\begin{array}{cc}
\phi_{I}^{H} & 0 \\
0 & \phi_{I}^{H}
\end{array}\right]}_{\Phi_{I}^{H}} \underbrace{\left\{\begin{array}{l}
u_{I} \\
v_{I}
\end{array}\right\}}_{\mathbf{u}_{I}}=\sum_{I \in S_{n}} \Phi_{I}^{H} u_{I}
$$

where $\Phi_{I}^{H}$ is the matrix of shape functions.

The strains can be calculated by differentiating $\mathrm{u}^{h}$

$$
\nabla \mathbf{u}^{h}=\nabla \sum_{I \in S_{n}} \Phi_{I}^{H} \mathbf{u}_{I}=\sum_{I \in S_{n}} \nabla \Phi_{I}^{H} \mathbf{u}_{I}=\sum_{I \in S_{n}}\left[\begin{array}{cc}
\frac{\partial}{\partial x} & 0 \\
0 & \frac{\partial}{\partial y} \\
\frac{\partial}{\partial y} & \frac{\partial}{\partial x}
\end{array}\right]\left[\begin{array}{cc}
\phi_{I}^{H} & 0 \\
0 & \phi_{I}^{H}
\end{array}\right] \mathbf{u}_{I}
$$




$$
=\sum_{I \in S_{n}}\left[\begin{array}{cc}
\frac{\partial \phi_{I}^{H}}{\partial x} & 0 \\
0 & \frac{\partial \phi_{I}^{H}}{\partial y} \\
\frac{\partial \phi_{I}^{H}}{\partial y} & \frac{\partial \phi_{I}^{H}}{\partial x}
\end{array}\right] u_{I}=\sum_{I \in S_{n}} \mathrm{~B}_{I} u_{I}
$$

where $\mathrm{B}_{I}$ is the strain matrix of node $I$.

But, in EFGM, MLS procedure does not obey Kronecker Delta Property

$$
\begin{aligned}
\text { i.e. } u^{h}\left(x_{I}\right)=\sum_{I \in S_{n}} \phi_{I}^{H}\left(x_{I}\right) & u_{I} \neq u_{I} \\
v^{h}\left(x_{I}\right)=\sum_{I \in S_{n}} \phi_{I}^{H}\left(x_{I}\right) & v_{I} \neq v_{I}
\end{aligned}
$$

This produces a difficulty in imposing essential boundary condition $u_{I}=u_{\Gamma_{I}}$

In order to avoid this difficulty, the last two terms of equation (3.4.4) are used. The Lagrange's multiplier is an unknown factor of coordinates using the nodes on essential boundaries and interpolating using these nodes to obtain a set of discrete equations.

$$
\lambda_{x}=\sum_{I \in S_{\lambda}} N_{I}(s) \lambda_{I}
$$

where

$S_{\lambda}=$ set of nodes on essential boundary

$\mathrm{s}=$ curvilinear coordinate along the essential boundary

$\lambda_{I}=$ Lagrange's multiplier at node I on essential boundary

$N_{I}(s)=$ Lagrange's interpolant used in conventional FEM 
From equation (3.4.11), variation of Lagrange's interpolant can be given as:

$$
\delta \lambda(x)=\sum_{I \in S_{\lambda}} N_{I}(s) \delta \lambda_{I} \quad \mathrm{x} \in \Gamma_{u}
$$

Hence, the vector of Lagrange's interpolant can be given as:

$$
\lambda=\sum_{I \in S_{\lambda}}\left[\begin{array}{ll}
N_{I} & \\
& N_{I}
\end{array}\right]\left\{\begin{array}{l}
\lambda_{u I} \\
\lambda_{v I}
\end{array}\right\}=\sum_{I \in S_{\lambda}} N_{I} \lambda_{I}
$$

Substituting equations (3.4.7) and (3.4.8) in (3.4.4) we get,

$$
\begin{aligned}
& \int_{\Omega} \delta\left(\sum_{I \in S_{n}} \mathrm{~B}_{I} \mathrm{u}_{I}\right)^{T}\left(c \sum_{J \in S_{n}} \mathrm{~B}_{J} \mathrm{u}_{J}\right) d \Omega-\int_{\Omega} \delta\left(\sum_{I \in S_{n}} \Phi_{I}^{H} \mathrm{u}_{I}\right)^{T} \mathrm{~b} d \Omega-\int_{\Gamma_{t}} \delta\left(\sum_{I \in S_{n}} \Phi_{I}^{H} \mathrm{u}_{I}\right)^{T} \mathrm{t}_{\Gamma} d \Gamma \\
& -\int_{\Gamma_{u}} \delta \lambda^{T}\left(\left(\sum_{I \in S_{n}} \Phi_{I}^{H} \mathrm{u}_{I}\right)-\mathrm{u}_{\Gamma}\right) d \Gamma-\int_{\Gamma_{u}} \delta\left(\sum_{I \in S_{n}} \Phi_{I}^{H} \mathrm{u}_{I}\right) \lambda d \Gamma=0
\end{aligned}
$$

Considering first term in the equation:

$$
\begin{aligned}
\int_{\Omega} \delta\left(\sum_{I \in S_{n}} \mathrm{~B}_{\mathrm{I}}^{\mathrm{T}} \mathrm{u}_{\mathrm{I}}^{\mathrm{T}}\right)\left(c \sum_{J \in S_{n}} \mathrm{~B}_{J} \mathrm{u}_{J}\right) d \Omega & =\sum_{I \in S_{n}} \sum_{J \in S_{n}} \delta u^{T} \underbrace{\int_{\Omega} B_{I}^{T} c B_{J} d \Omega u_{J}}_{\mathrm{K}_{I J}} \\
& =\sum_{I}^{n_{t}} \sum_{J}^{n_{t}} \delta \mathrm{u}_{I}^{T} \mathrm{~K}_{I J} \mathrm{u}_{J}
\end{aligned}
$$

Here, $\mathrm{K}_{I J}$ is termed as the nodal stiffness matrix. Every node or point of interest has nodal stiffness matrix. Integration of nodal stiffness matrices of the all the nodes or points of interest in the domain will constitute a Global stiffness Matrix.

In matrix form,

$$
\sum_{I}^{n_{t}} \sum_{J}^{n_{t}} \delta \mathrm{u}_{I}^{T} \mathrm{~K}_{I J} \mathrm{u}_{J}=\delta \mathrm{U}^{\mathrm{T}} \mathrm{KU}
$$


where

$\mathrm{K}$ is termed as global stiffness matrix

$$
\mathrm{K}=\left[\begin{array}{ccccc}
\mathrm{K}_{11} & \mathrm{~K}_{12} & . & . . & \mathrm{K}_{1 \mathrm{n}_{\mathrm{t}}} \\
\mathrm{K}_{21} & \mathrm{~K}_{22} & . & . . & \mathrm{K}_{2 \mathrm{n}_{t}} \\
\cdot & \cdot & \cdot & . & \cdot \\
\cdot & \cdot & . & . & \cdot \\
\mathrm{K}_{\mathrm{n}_{\mathrm{t}} 1} & \mathrm{~K}_{n_{t} 2} & . & . & \mathrm{K}_{\mathrm{n}_{\mathrm{t}} n_{t}}
\end{array}\right]
$$

$\mathrm{U}$ is termed as the displacement vector. Here, $\mathrm{n}_{\mathrm{t}}$ is the number of nodes in the problem domain.

$$
\begin{gathered}
\mathrm{U}=\left\{\begin{array}{c}
\mathrm{u}_{1} \\
\mathrm{u}_{2} \\
\cdot \\
\cdot \\
\mathrm{u}_{\mathrm{n}_{\mathrm{t}}}
\end{array}\right\} \\
u_{I}=\left\{\begin{array}{l}
u_{I} \\
v_{I}
\end{array}\right\}
\end{gathered}
$$

Now, examining the second term in equation (3.4.4)

$$
\int_{\Omega} \delta\left(\sum_{I \in S_{n}} \Phi_{I}^{H} \mathrm{u}_{I}\right)^{\mathrm{T}} \mathrm{bd} \Omega=\sum_{\mathrm{I} \in \mathrm{S}_{\mathrm{n}}} \delta \mathrm{u}_{\mathrm{I}}^{\mathrm{T}} \underbrace{\int_{\Omega}\left(\Phi_{I}^{H}\right)^{T} \mathrm{bd} \Omega}_{\mathrm{f}_{I}}=\sum_{\mathrm{I}}^{\mathrm{n}_{\mathrm{t}}} \delta \mathrm{u}_{\mathrm{I}}^{\mathrm{T}} \mathrm{f}_{I}
$$

where $f_{I}$ is called the nodal force vector due to body force acting on the domain

$$
\therefore \mathrm{f}_{I}=\int_{\Omega}\left(\Phi_{I}^{H}\right)^{T} \mathrm{bd} \Omega
$$


In matrix form,

$$
\sum_{\mathrm{I}}^{\mathrm{n}_{\mathrm{t}}} \delta \mathrm{u}_{\mathrm{I}}^{\mathrm{T}} \mathrm{f}_{I}=\delta \mathrm{U}^{\mathrm{T}} \mathrm{F}
$$

Vector $\mathrm{F}$ is called the global force vector which is formed by assemblage of all the nodal force vectors.

$$
\begin{gathered}
\therefore \mathrm{F}=\left\{\begin{array}{c}
\mathrm{f}_{1} \\
\mathrm{f}_{2} \\
\cdot \\
\cdot \\
\mathrm{f}_{\mathrm{n}_{\mathrm{t}}}
\end{array}\right\} \\
f_{I}=\left\{\begin{array}{c}
f_{x I} \\
f_{y I}
\end{array}\right\}
\end{gathered}
$$

where $f_{I}$ is the nodal force vector having components $f_{x I}$ and $f_{y I}$ in $\mathrm{X}$ and $\mathrm{Y}$ directions respectively.

The third term in equation (3.4.4) gives traction force vector given as:

$$
F_{I}=\int_{\Gamma_{t}}\left(\Phi_{I}^{H}\right)^{T} \mathrm{t}_{\Gamma} d \Gamma
$$

Considering last term of equation (3.4.4):

$$
\begin{aligned}
& \int_{\Gamma_{\mathrm{u}}} \delta\left(\sum_{\mathrm{I} \in \mathrm{S}_{\mathrm{n}}} \Phi_{\mathrm{I}}^{\mathrm{H}} \mathrm{u}_{\mathrm{I}}\right)^{\mathrm{T}} \lambda \mathrm{d} \Gamma=\int_{\Gamma_{\mathrm{u}}} \delta\left(\sum_{\mathrm{I} \in \mathrm{S}_{\mathrm{n}}} \Phi_{\mathrm{I}}^{\mathrm{H}} \mathrm{u}_{\mathrm{I}}\right)^{\mathrm{T}}\left(\sum_{\mathrm{J} \in \mathrm{S}_{\lambda}} \mathrm{N}_{\mathrm{J}} \lambda_{\mathrm{J}}\right) \mathrm{d} \Gamma \\
& =\sum_{\mathrm{I} \in \mathrm{S}_{\mathrm{n}}} \sum_{\mathrm{J} \in \mathrm{S}_{\lambda}} \delta \mathrm{u}_{\mathrm{I}}^{\mathrm{T}} \underbrace{\int_{\Gamma_{\mathrm{u}}}\left(\Phi_{\mathrm{I}}^{\mathrm{H}}\right)^{\mathrm{T}} \mathrm{N}_{\mathrm{J}} \mathrm{d} \Gamma \lambda_{\mathrm{J}}}_{-G_{I J}}=-\sum_{\mathrm{I}}^{\mathrm{n}_{\mathrm{L}}} \sum_{\mathrm{J}}^{\mathrm{n}_{\lambda}} \delta \mathrm{u}_{\mathrm{I}}^{\mathrm{T}} \mathrm{G}_{\mathrm{IJ}} \lambda_{\mathrm{J}}=-\delta \mathrm{U}^{\mathrm{T}} \mathrm{G} \lambda
\end{aligned}
$$


where $\mathrm{n}_{\lambda t}$ is the total number of nodes on essential boundary.

Finally examining fourth term in equation (3.4.4),

$$
\begin{aligned}
\int_{\Gamma_{\mathrm{u}}} \delta \lambda^{\mathrm{T}}\left(\left(\sum_{\mathrm{J} \in \mathrm{S}_{\mathrm{n}}} \Phi_{\mathrm{I}}^{\mathrm{J}} \mathrm{u}_{\mathrm{J}}\right)-\mathrm{u}_{\gamma}\right) \mathrm{d} \Gamma & =\int_{\Gamma_{\mathrm{u}}} \delta\left(\sum_{\mathrm{I} \in \mathrm{S}_{\lambda}} \mathrm{N}_{\mathrm{I}} \lambda_{\mathrm{I}}\right)^{\mathrm{T}} \sum_{\mathrm{J} \in \mathrm{S}_{\mathrm{n}}} \Phi_{\mathrm{I}}^{\mathrm{J}} \mathrm{u}_{\mathrm{J}} \mathrm{d} \Gamma-\int_{\Gamma_{\mathrm{u}}} \delta\left(\sum_{\mathrm{I} \in \mathrm{S}_{\lambda}} \mathrm{N}_{\mathrm{I}} \lambda_{\mathrm{I}}\right)^{\mathrm{T}} \mathrm{u}_{\Gamma} \mathrm{d} \Gamma \\
& =\sum_{\mathrm{I} \in \mathrm{S}_{\lambda}} \sum_{\mathrm{J} \in \mathrm{S}_{\mathrm{n}}} \delta \lambda_{\mathrm{I}}^{\mathrm{T}} \underbrace{\int_{\Gamma_{\mathrm{u}}}^{\mathrm{N}_{\mathrm{I}}^{\mathrm{T}}} \Phi_{\mathrm{J}}^{\mathrm{T}} \mathrm{d} \Gamma \Gamma_{\mathrm{J}}}_{-G_{I J}}-\sum_{\mathrm{I} \in \mathrm{S}_{\lambda}} \delta \lambda_{\mathrm{I}}^{\mathrm{T}} \underbrace{\int_{\Gamma_{\mathrm{u}}} \mathrm{N}_{\mathrm{I}}^{\mathrm{T}} \mathrm{u}_{\Gamma} \mathrm{d} \Gamma}_{-\mathrm{q}_{I}} \\
& =-\sum_{\mathrm{I}}^{\mathrm{n}_{\lambda t}} \sum_{\mathrm{J}}^{\mathrm{n}_{\mathrm{t}}} \delta \lambda_{\mathrm{I}}^{\mathrm{T}} \mathrm{G}_{\mathrm{IJ}}^{\mathrm{T}} \mathrm{u}_{\mathrm{J}}+\sum_{\mathrm{I}}^{\mathrm{n}_{\lambda t}} \delta \lambda_{\mathrm{I}}^{\mathrm{T}} \mathrm{q}_{\mathrm{I}} \\
& =-\delta \lambda^{\mathrm{T}} \mathrm{G}^{\mathrm{T}} \mathrm{U}+\delta \lambda^{\mathrm{T}} \mathrm{q}
\end{aligned}
$$

where $\mathrm{G}$ is given by equation (3.4.26) and vector $\mathrm{q}$ is obtained by assemblage of nodal vector $\mathrm{q}_{I}$

Therefore, Substituting equations (3.4.15), (3.4.20), (3.4.25), (3.4.26) and (3.4.27) in equation (3.4.4) we get,

$$
\delta U^{T}[K U+G \lambda-F]+\delta \lambda^{T}\left[G^{T} U-q\right]=0
$$

Because $\delta U$ and $\delta \lambda$ are arbitrary, the above equation can be satisfied if and only if

$$
\begin{aligned}
& \mathrm{KU}+\mathrm{G} \lambda-\mathrm{F}=0 \\
& \mathrm{G}^{\mathrm{T}} \mathrm{U}-\mathrm{q}=0
\end{aligned}
$$

In matrix form,

$$
\left[\begin{array}{cc}
\mathrm{K} & \mathrm{G} \\
\mathrm{G}^{\mathrm{T}} & 0
\end{array}\right]\left\{\begin{array}{l}
\mathrm{U} \\
\lambda
\end{array}\right\}=\left\{\begin{array}{l}
\mathrm{F} \\
\mathrm{q}
\end{array}\right\}
$$

To summarize,

$$
\mathrm{K}_{\mathrm{IJ}}=\int_{\Omega} \mathrm{B}_{\mathrm{I}}^{\mathrm{T}} \mathrm{cB} \mathrm{J} \Omega
$$




$$
\begin{gathered}
\mathrm{B}_{\mathrm{I}}=\mathrm{L} \Phi_{\mathrm{I}}^{\mathrm{H}}=\left[\begin{array}{cc}
\frac{\partial \Phi_{\mathrm{I}}^{\mathrm{H}}}{\partial \mathrm{x}} & 0 \\
0 & \frac{\partial \Phi_{\mathrm{I}}^{\mathrm{H}}}{\partial \mathrm{y}} \\
\frac{\partial \Phi_{\mathrm{I}}^{\mathrm{H}}}{\partial \mathrm{y}} & \frac{\partial \Phi_{\mathrm{I}}^{\mathrm{H}}}{\partial \mathrm{x}}
\end{array}\right] \mathrm{u}_{\mathrm{I}}=\sum_{\mathrm{I} \in \mathrm{S}_{\mathrm{n}}} \mathrm{B}_{\mathrm{I}} \mathrm{u}_{\mathrm{I}} \\
\mathrm{G}_{\mathrm{IJ}}=-\int_{\Gamma_{\mathrm{u}}} \mathrm{N}_{\mathrm{I}}^{\mathrm{T}} \Phi_{\mathrm{J}}^{\mathrm{T}} \mathrm{d} \Gamma \\
\Phi_{I}^{H}=\left[\begin{array}{cc}
\Phi_{I}^{H} & 0 \\
0 & \Phi_{I}^{H}
\end{array}\right] \\
\mathrm{F}_{\mathrm{I}}=\int_{\Omega}\left(\Phi_{\mathrm{I}}^{\mathrm{H}}\right)^{\mathrm{T}} \mathrm{bd} \Omega+\int_{\Gamma_{\mathrm{t}}}\left(\Phi_{\mathrm{I}}^{\mathrm{H}}\right)^{\mathrm{T}} \mathrm{t}_{\Gamma} \mathrm{d} \Gamma \\
\mathrm{q}_{\mathrm{I}}=-\int_{\Gamma_{\mathrm{u}}} \mathrm{N}_{\mathrm{J}}^{\mathrm{T}} \mathrm{u}_{\Gamma} \mathrm{d} \Gamma
\end{gathered}
$$

Also, nodal stiffness matrix $\mathrm{K}_{\mathrm{IJ}}$ is the basic component of assembling global stiffness matrix of EFGM.

By using symmetric property of c matrix:

$$
\left[\mathrm{K}_{I J}\right]^{T}=\int_{\Omega}\left[\mathrm{B}_{\mathrm{I}}^{\mathrm{T}} \mathrm{cB}_{\mathrm{J}}\right]^{T} d \Omega=\int_{\Omega}\left[\mathrm{B}_{\mathrm{J}} \mathrm{c}^{\mathrm{T}} \mathrm{B}_{\mathrm{I}}\right] d \Omega=\int_{\Omega}\left[\mathrm{B}_{\mathrm{J}}^{\mathrm{T}} \mathrm{cB}_{\mathrm{I}}\right] \mathrm{d} \Omega=\mathrm{K}_{\mathrm{JI}}
$$

In this way, the shape function is constructed using MLS procedure in EFGM.

\subsection{Modeling of plate with a hole model in EFGM}

In order to test the capability of EFGM to simulate the propagation of Intraneural Ganglion cyst, EFGM was initially applied to a simple problem of a circular plate with a 
hole subjected to internal pressure. Figure 3.5 shows a plate with a concentric circular hole subjected to forces acting in radial outward direction at each node on the periphery of the hole. Hypermesh was used as a CAE preprocessor for formation of triangular background cells. These cells were used for integration of system matrices. The cloud of nodes for construction of meshfree shape functions were obtained from the triangulation technique. LS-DYNA has the capability of analyzing FE model using EFGM. Hence, LSDYNA was used as a solver to analyze this problem. Qualitative results were viewed with LS-PrePost.

The triangles displayed for a few nodes on right in figure 3.5 represent zero displacement boundary condition which was used to prevent rigid body motion of the plate and arrows at the centre of the hole represent the forces acting in radial outward direction. Since, LSDYNA is a dynamic solver, the load curve was specified for a period of 15 seconds to approximate a static analysis and save computational costs and time.

The given pre-processed model was exported and opened in LS-Dyna input deck. The input deck contained information about the model, but no information about the type of analysis, time period of the analysis, time step increment of the analysis etc. The input deck was modified for EFGM analysis. The analysis used was dynamic explicit analysis.

Time step was selected to be 0.1 seconds i.e. data was recorded after every 0.1 seconds. Material properties of native carotid artery were used having $\rho=0.76 \mathrm{~g} / \mathrm{cm}^{3} \mathrm{E}=4.6 \mathrm{MPa}$, 


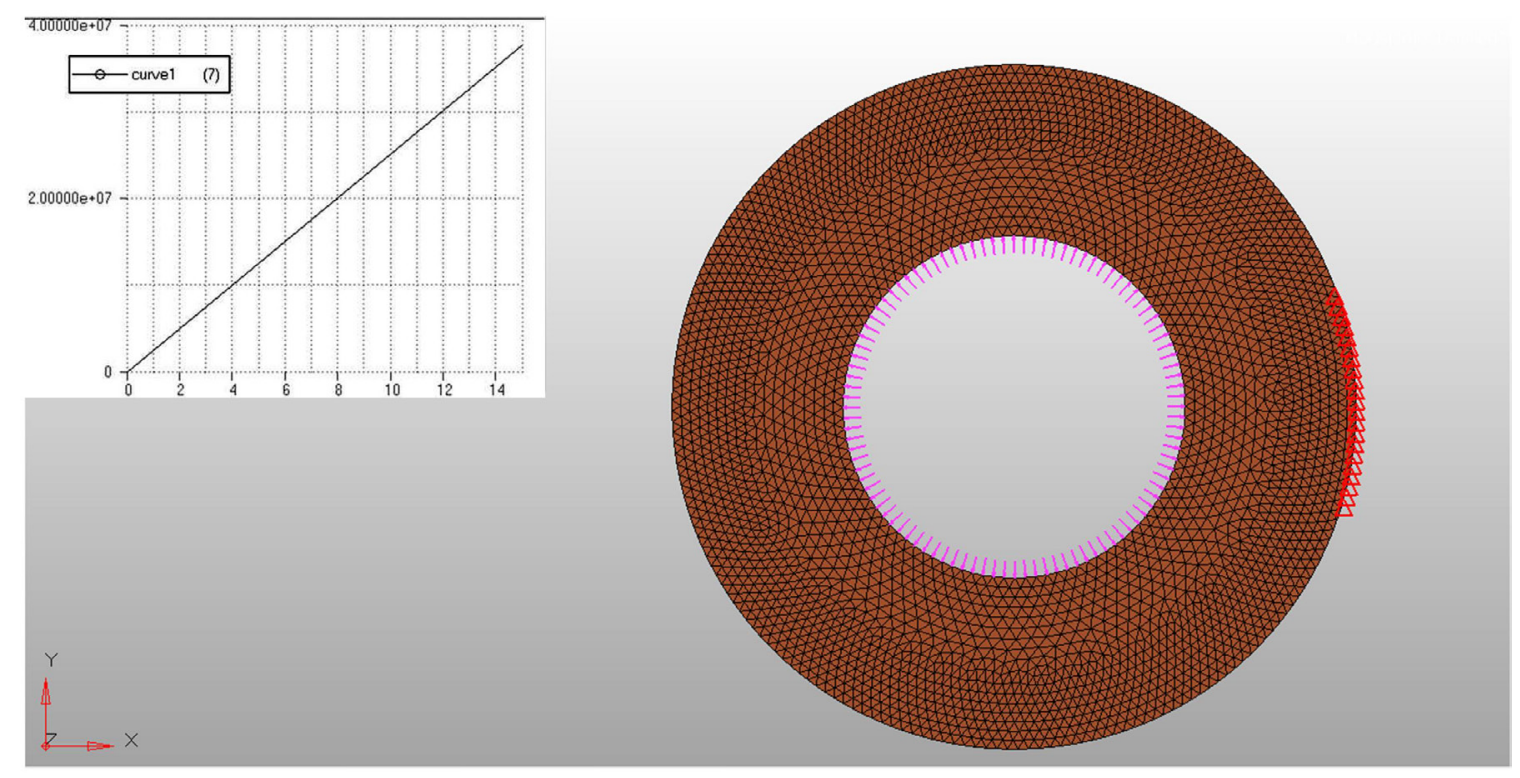

Figure 3.5 Preprocessed model of Plate with a hole subjected to internal pressure (Screenshot from Hypermesh)

$v=0.3$. Due to lack of initial guiding data, the load applied at the first iteration was $10 \mathrm{x}$ $10^{7} \mathrm{~N}$. The applied load was iterated until the plate deformed to its maximum extent up to which the analysis failed to terminate. The maximum load that the plate could withstand without termination of the analysis was $37.5 \times 10^{7} \mathrm{~N}$. The reason for termination of analysis is explained in subsequent sections.

*Section_Shell_EFG was used as the EFG card to define section properties for shell elements. This option defined triangular elements in the preprocessed model as background cells for integration. These elements were not involved in formulation of shape functions. This option treated the nodes obtained from triangular mesh as the cloud of nodes for formulation of shape functions using MLS procedure. LS-DYNA Keyword User's Manual, (2007) was used as reference for inputting analysis parameters in the input deck. According to LS-Dyna Keyword User's Manual, (2007) Element Formulation 
43 was used which represents the Meshfree elements in two dimensions. The thickness of the plate was specified to be $0.1 \mathrm{~mm}$ and normalized dilation parameters for the kernel functions in $\mathrm{X}$ and $\mathrm{Y}$ directions were specified as 1.4. These parameters provide smoothness and compact support properties to Meshfree shape function. All other parameters were used as default.

*Control_EFG card was used which defined control for meshfree computation. A cubic spline function was used as a meshfree kernel function for obtaining accurate results. This spline function acts as a weight function assigned to the support domains at the point of interest as explained in Section 3.2. EFGPACK was used as an optional choice to solve the linear system of equations. All other parameters were used as default. The radial outward load acting at the centre of the hole and the zero displacement boundary condition at the right simulated a blow out which was similar to the blow out of the cyst in $\mathrm{CPN}$.

\subsubsection{Postprocessing}

The LS-Dyna input deck was run which generated a d3plot file storing the stress and strain states after every 0.1 seconds. The binary d3plot file was viewed in commercial postprocessing software LS-PrePost. It showed contour plots of stresses and strains. It has capability to view contour plots of stresses and strains in meshfree computation. This was possible by changing the Part display from mesh to spheres. 


\subsection{Results - Plate with a hole using EFGM}

The model created in section 3.5 was processed and results were viewed in LS-PrePost. Radial outward force was applied at the periphery of the hole and few nodes at the right were constrained to simulate a blow out similar to the one observed in cyst affected CPN. Figure 3.6 shows the deformation of a circular plate with a hole subjected to radial outward forces. Since strains were of primary concern for modeling IGC blow out, the principal strain contour plot was used to interpret the results. Ignoring spurious strain concentrations, the principal strains in the model varied approximately from zero at the zero displacement constraints to 1.4 at the periphery of the hole. As shown in figure, the maximum strain obtained by EFGM for a simple model of plate with a hole ignoring spurious strain concentrations was $140 \%$.
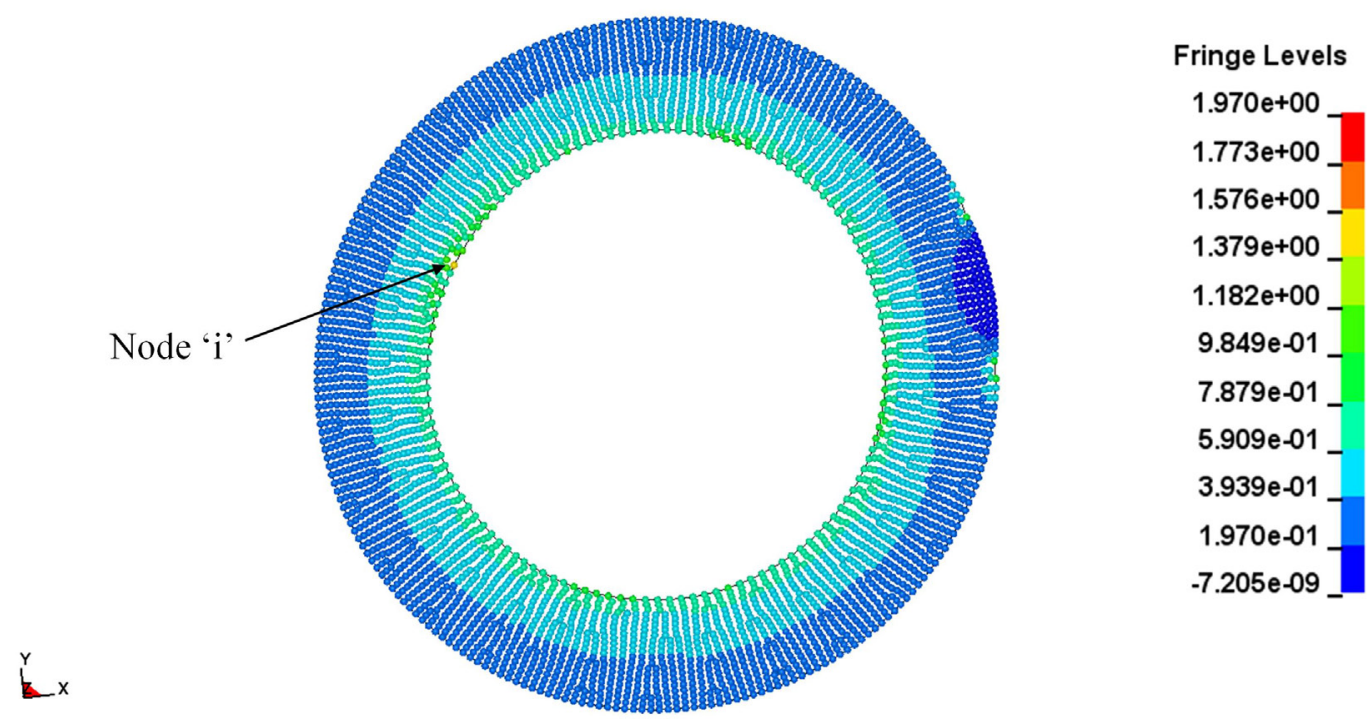

Figure 3.6 Deformation of a plate with a hole model showing principal strain contours (Screenshot from LS-PrePost) 


\subsubsection{Spurious strain concentrations:}

As shown in figure 3.6, spurious strain concentrations or large strain gradients were observed around node 'i' where the principal strains increased from 1.4 to 1.970 showing an approximate $40 \%$ increase in strain. The reason behind such substantial increase in strain was mainly due to lack of control over EFGM in LS-DYNA.

As proposed by Belytschko et al. 1994, stable solutions were obtained at regions in the support domain of the point of interest where

$$
\frac{n_{Q}}{n_{t}}=3
$$

Here,

$n_{Q}=$ quadrature points $=\mathrm{n}_{\mathrm{g}} \times \mathrm{n}_{\mathrm{x}} \times \mathrm{n}_{\mathrm{y}}$

$\mathrm{n}_{\mathrm{g}}=$ number of Gauss sampling points for integration

$\mathrm{n}_{\mathrm{x}} \mathrm{x} \mathrm{n}_{\mathrm{y}}=$ density of background mesh of cells

$n_{t}=$ local nodes in the support domain

EFG card in LS-Dyna treated elements and nodes obtained from triangular mesh as background cells and local support nodes respectively. The user has less control over the selection of the support domains around the point of interest and also over maintaining the optimum ratio of number of quadrature points to number of local nodes in the support domain as mentioned in equation (3.6.1). When the load applied was greater than $37.5 \mathrm{x}$ $10^{7} \mathrm{~N}$, the analysis terminated due to errors. These errors were mainly due to inaccuracies 
resulting from the large strain gradients. Hence, the maximum strain that could be achieved for a plate with a hole model was 1.379 i.e. $137.9 \%$. The deformed plot shown in figure 3.6 suggests that EFGM is capable of modeling the IGC propagation in affected CPN cross section at fibular neck to correlate it with the MRI image of the cyst at the same location. Hence, EFGM was used to simulate the propagation of ganglion cyst in CPN division of sciatic nerve.

\subsection{Modeling of Nerve cross section using EFGM}

A cross section of CPN at the fibular neck was created in Abaqus 6.9 in Section 2.1.The same Abaqus model was imported as an input deck in Hypermesh. The imported model was edited in Hypermesh and assigned boundary conditions and loads similar to modeling the blow out of plate with a hole in Section 3.5. Figure 3.7 shows the preprocessed model of the CPN cross section at the fibular neck.

The nodes at the right end in Figure 3.7 were assigned zero displacement boundary condition to prevent rigid body motion. The load acting in radial outward direction represented the force due to intraarticular pressures of the synovial fluid. Initial guiding data for load acting due to intraarticular pressures was not known. Hence, an initial load of $0.5 \times 10^{7} \mathrm{~N}$ was applied at the edges of the cyst. The load was further iterated until the nerve geometry deformed to its maximum extent up to which the analysis failed to terminate. The maximum load that the model was able to withstand was $12.1 \times 10^{7} \mathrm{~N}$. All the other analysis parameters used were similar to the one used in the model of plate with 


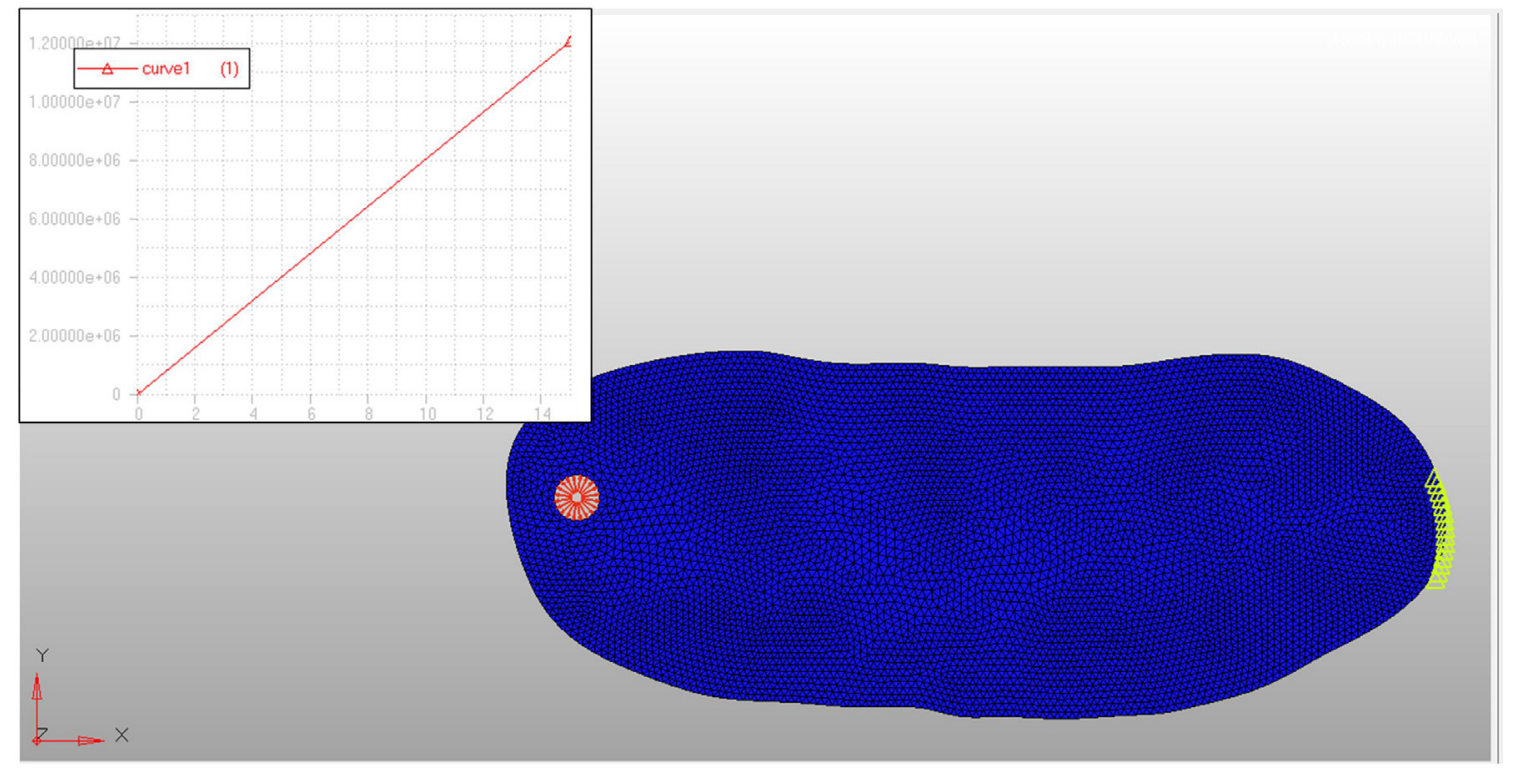

Figure 3.7 Preprocessed model of a Peroneal Nerve Cross section at the fibular neck (Screenshot from Hypermesh)

a hole. Mechanical properties of CPN were assumed to be similar to native carotid artery having $\rho=0.76 \mathrm{~g} / \mathrm{cm}^{3} ; \mathrm{E}=4.6 \mathrm{MPa}$ and $v=0.3$ as explained in Section 2.2. LS-PrePost was used as a post processing tool to view the Principal strain contour plots to interpret the results.

\subsection{Results: Ganglion Cyst propagation in CPN}

Strain obtained from the plate with a hole model was $137.9 \%$ which was substantial and the deformed plot simulated a blow out of the plate. EFGM was applied to the actual cyst affected cross section of CPN. The input parameters used in this case were same as used in the plate with a hole model. The applied load was iterated and the nerve deformed to its maximum extent without termination of analysis at a load of $12.1 \times 10^{7}$ N. Figure 3.8 shows principal strain contours of deformed plot of CPN cross section affected by IGC at 


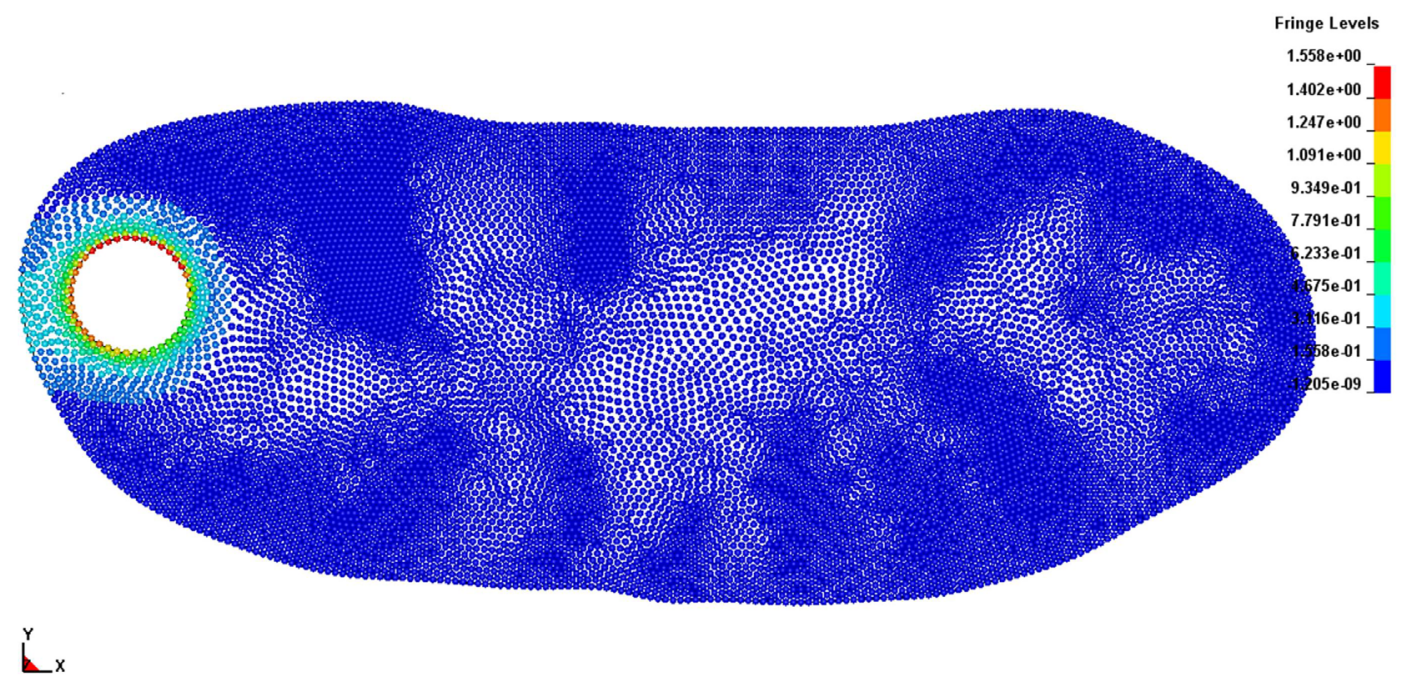

Figure 3.8 Deformation of affected CPN cross section at fibular neck with principal strain contours (Screenshot from LS-PrePost)

articular branch. Preprocessing of the model was explained in section 3.7. As explained in section 3.7 , the radially outward force was iterated until simulation results were obtained without termination of analysis to simulate cyst growth.

As shown by principal strain contours in Figure 3.8, spurious strain concentrations were observed around the hole which was due to reasons explained in section 3.6.1. Ignoring such spurious strain concentrations, the maximum principal strain observed was 1.091 which was approximately $110 \%$. A maximum of $33 \%$ strain can be obtained from traditional FEM technique. Therefore, it was confirmed that the strains obtained using EFGM were certainly greater than those obtained in FEM but were not enough to 
resemble the 'signet ring sign' coined by Spinner (Spinner et al. 2006) obtained from the MRI of the cyst.

Thus, Figure 3.8 showed the capability of EFGM to simulate large strains of the order of $110 \%$. However, the EFG simulation failed to resemble the MRI of cyst affected CPN cross section at the fibular neck. This method though capable of modeling large strains was incapable of modeling strains required to model IGC propagation. Therefore, it was necessary to select a simulation tool capable of producing strains greater than $110 \%$. 


\section{EULERIAN ANALYSIS IN ABAQUS/EXPLICIT}

\subsection{Methods used for approaching mechanics problems}

Based on the types of meshes used, Lagrangian mesh approach, Eulerian mesh approach and Coupled Eulerian Lagrangian (CEL) approach are used to solve mechanics problems. These approaches mainly differ in three main aspects:

i) Description of mesh

ii) Kinematics of the deformation

iii) Kinetics involved in the deformation

In the Lagrangian approach, the mesh deforms along with the body. Nodes move consistent with the material points during deformation. Hence, the position of the nodes relative to the material points remain fixed during deformation. Figure 4.1 explains the movement of Lagrangian mesh with respect to material points subjected to deformation.

In case of Eulerian approach, Eulerian mesh is a background mesh. As the body deforms, the mesh stays fixed and the material flows through the mesh. Hence, the position of the nodes relative to material points changes with motion and deformation of the body. Figure 4.2 shows the movement of the Eulerian nodes with respect to its material points subjected to deformation.

Coupled Eulerian Lagrangian (CEL) approach is used as a combination of both the meshes. It makes use of the advantages offered by both the meshes. 


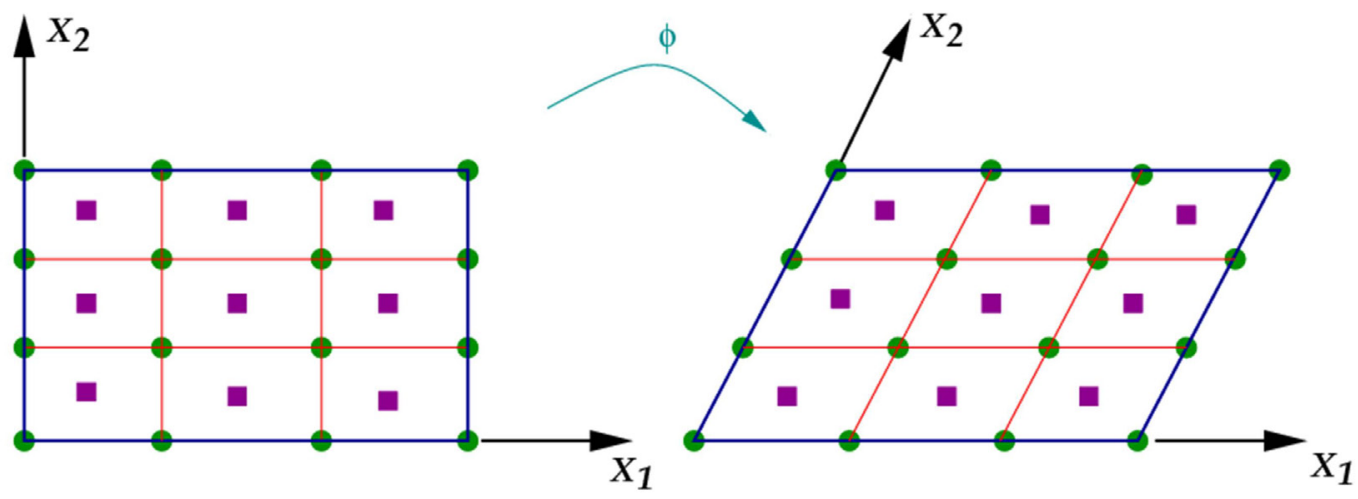

- Material Point

- Grid Node

Figure 4.1 Movement of Lagrangian nodes subjected to deformation (Nonlinear Finite Elements/Lagrangian and Eulerian descriptions n.d.)

As it can be seen from figure 4.2, the grid nodes remain fixed in space as the material points move due to deformation of the body.

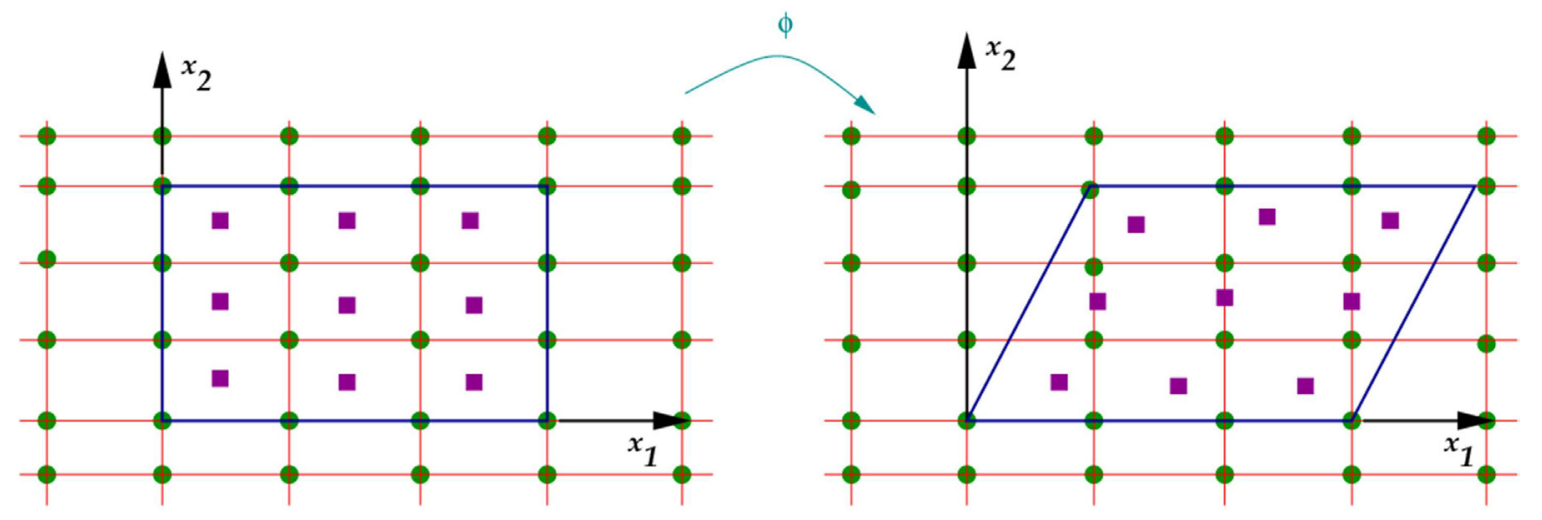

- Material Point

- Grid Node

Figure 4.2 Movement of Eulerian nodes subjected to deformation (Nonlinear Finite Elements/Lagrangian and Eulerian descriptions n.d.) 
Table 4.1 Key features of Lagrangian and Eulerian mesh

\begin{tabular}{|l|l|}
\hline \multicolumn{1}{|c|}{ Lagrangian Mesh } & \multicolumn{1}{c|}{ Eulerian Mesh } \\
\hline $\begin{array}{l}\text { 1. Lagrangian coordinates of nodes move } \\
\text { along with the material. Material } \\
\text { coordinates of material points are time } \\
\text { invariant }\end{array}$ & $\begin{array}{l}\text { 1. Eulerian coordinates of nodes are fixed. } \\
\text { Material moves along with the material } \\
\text { and material points vary with time }\end{array}$ \\
\hline 2. Material moves along with the mesh & 2. Material flows through the mesh \\
\hline $\begin{array}{l}\text { 3. Element Quadrature points remain } \\
\text { coincident with the material points }\end{array}$ & $\begin{array}{l}\text { 3. Material point at a given element } \\
\text { quadrature point changes with time and } \\
\text { motion. This makes dealing with history } \\
\text { dependent materials difficult }\end{array}$ \\
\hline $\begin{array}{l}\text { 4. Boundary nodes remain on the } \\
\text { boundary. Hence, boundary conditions and } \\
\text { loads are easy to apply }\end{array}$ & $\begin{array}{l}\text { 4. Boundary nodes and the material may } \\
\text { not coincide. Therefore, boundary } \\
\text { conditions and loads are difficult to apply }\end{array}$ \\
\hline $\begin{array}{l}\text { 5. Severe mesh distortion occurs in case of } \\
\text { large deformation problems }\end{array}$ & $\begin{array}{l}\text { 5. Since, mesh stays fixed in space and } \\
\text { material flows through the mesh, Mesh } \\
\text { distortion is minimized }\end{array}$ \\
\hline
\end{tabular}

Table 4.1 shows key features, advantages and disadvantages of Lagrangian and Eulerian mesh. During the ganglion cyst propagation, the cyst expands and compresses fascicles around it resulting in excessively large deformation of fascicles. Hence, Eulerian Mesh Approach was preferred for mechanical modeling of Intraneural Ganglion cyst. Abaqus 6.9 was used to model the cyst propagation using Eulerian approach.

\subsection{Eulerian Approach for modeling ganglion cyst propagation}

The eulerian approach in Abaqus Explicit 6.9 was used for modeling ganglion cyst growth in the CPN division of sciatic nerve. It uses Volume of Fluids (VOF) method to 
track material boundaries in the Eulerian domain. In Lagrangian Analysis, material and section properties, boundary conditions and loads are assigned to a part in the FE model. Then, the model is meshed and analyzed for calculating unknown displacements, stresses and strains. However, In Eulerian analysis, since the material points do not remain

coincident with the mesh, the process of analyzing a model is different from traditional Lagrangian analysis. Abaqus 6.9 is incapable of modeling two dimensional Finite Element models using Eulerian Analysis. Hence, a three dimensional Eulerian model having very small thickness was considered. Coupled Eulerian Lagrangian (CEL) Analysis training manual, (2010) was used as reference. The steps for modeling cyst propagation using Eulerian approach in Abaqus 6.9 are explained in following sections:

\subsubsection{Creating an Eulerian Domain:}

In Eulerian approach, material flows through an Eulerian domain that is fixed in space. This requires the Eulerian domain to be large enough to include the nerve model after deformation. Hence, the deformation was predicted in advance and a three dimensional eulerian part named 'Eulerian box' was created using extrusion base feature. This domain was created as a rectangular box having dimensions: $24 \times 24 \times 0.1 \mathrm{~mm}$ with a through hole having dimensions as shown in Figure 4.3. A dependent assembly instance of the Eulerian domain was created named 'Eulerian Box-1'. The nerve was located in such a way that the Eulerian domain encloses the nerve model entirely. It was done in assembly module as explained in later sections. 


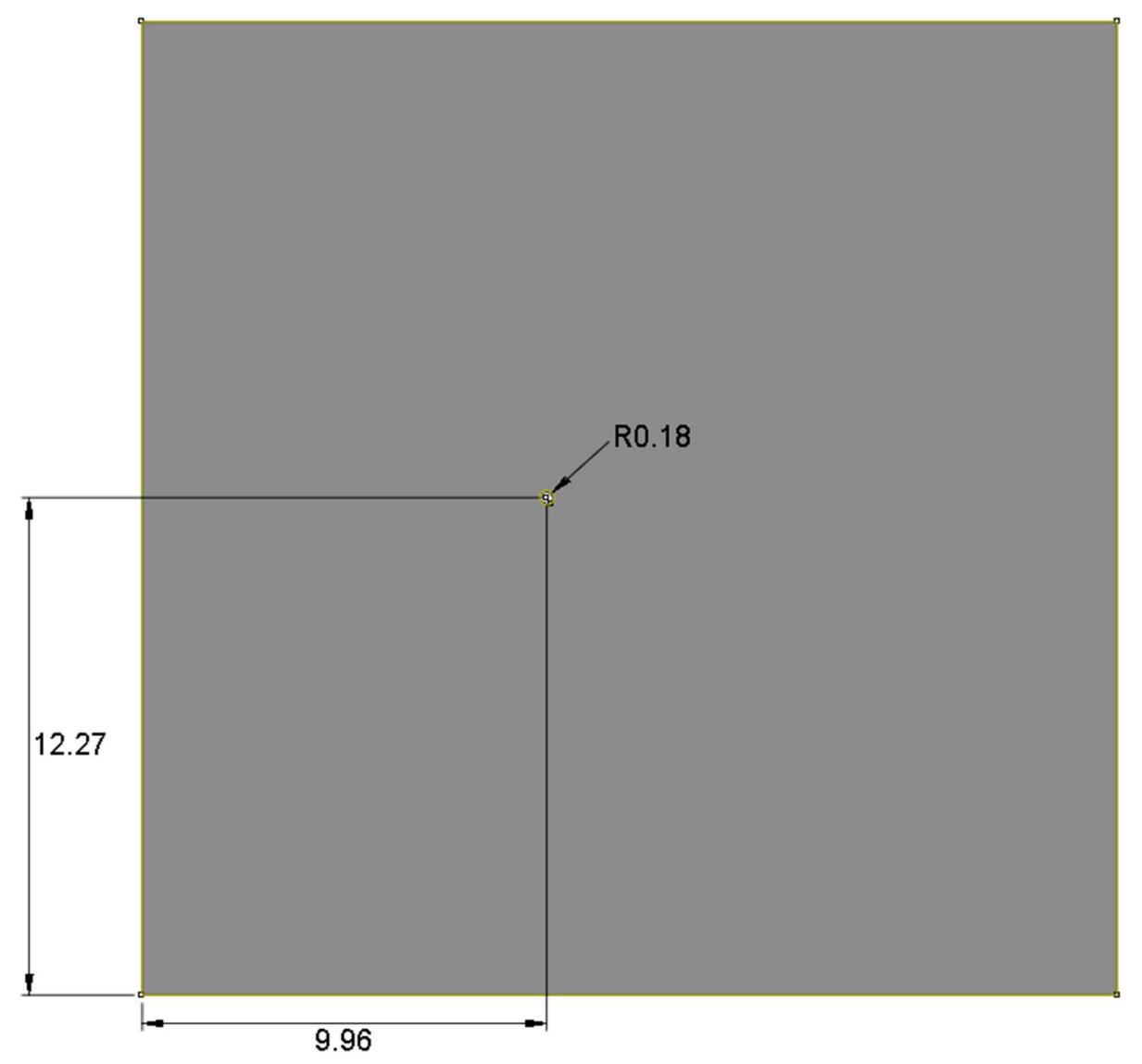

Figure 4.3 Eulerian domain containing peroneal nerve model (Screenshot from Abaqus 6.9)

\subsubsection{Creating an Eulerian Nerve part:}

The Nerve sketch created in section 2.1 was used for creating the 3D Eulerian part. The sketch was imported in the sketcher and extruded to a depth of $0.1 \mathrm{~mm}$. This depth represents the thickness of the nerve and can be approximated to a very thin cross section of CPN at the fibular neck. A dependent assembly instance of the part was created and named as 'Nerve Eulerian-1'. Figure 4.4 shows the Nerve Eulerian part in Abaqus 6.9 with a hole representing the cyst originating from the articular branch. 


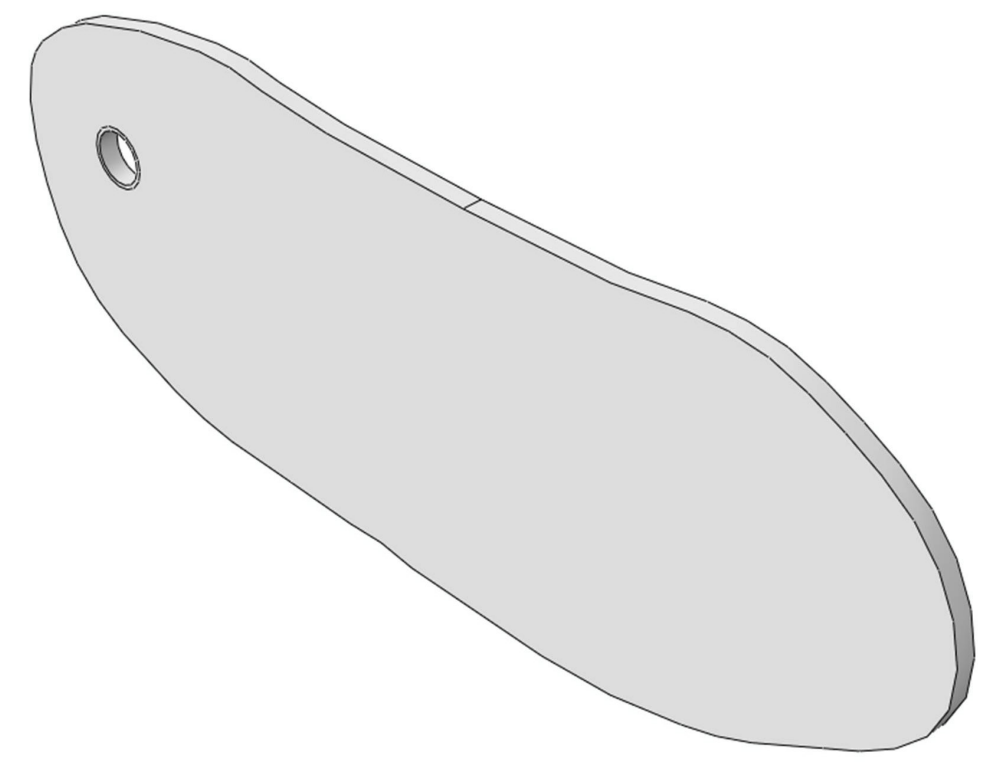

Figure 4.4 3 Dimensional peroneal nerve model in Abaqus 6.9 (Screenshot from Abaqus 6.9)

\subsubsection{Assembling and merging of instances:}

The nerve was assembled inside the Eulerian box such that the center of the hole of the Eulerian box instance coincides with the center of the hole representing articular branch of the eulerian nerve instance. Figure 4.5 shows the assembled part of Nerve and Eulerian box. The two instances were merged to form a new Part named 'NerveEulerianAssembly'.

\subsubsection{Creating Nerve material:}

A drawback of this method in Abaqus 6.9 is its incapability to support Hyperelastic and anisotropic material behavior in Eulerian approach. Hence, linear elastic material having 


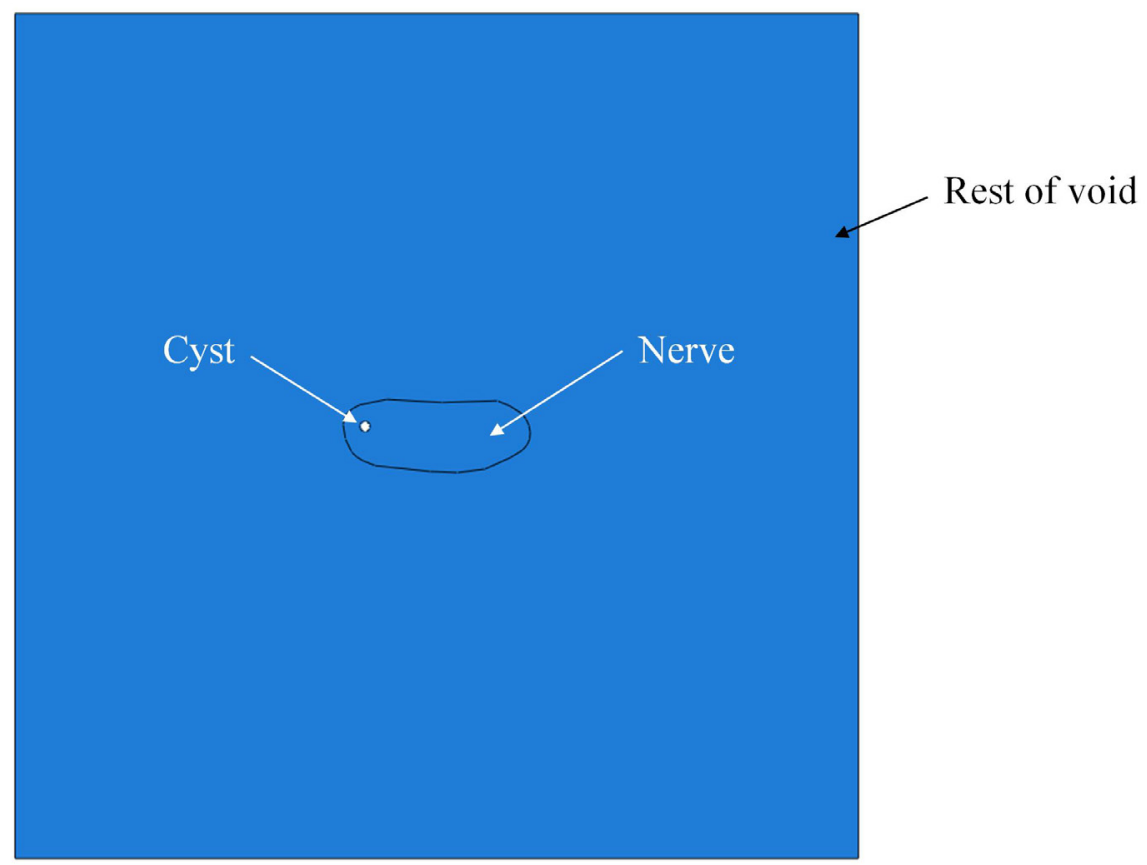

Figure 4.5 Merged part representing different regions for specifying material volume fractions (Screenshot from Abaqus 6.9)

properties of native carotid artery (Refer section 2.2) was preferred for modeling cyst expansion in CPN cross section $\left(\rho=0.76 \mathrm{~g} / \mathrm{cm}^{3} ; \mathrm{E}=4.6 \mathrm{MPa} ; v=0.3\right)$. Two different materials 'Nerve' and 'Peripheral Nerve' were created having the same material properties. These materials were used to define material volume fractions in the Eulerian domain. The significance of creating two different materials having same mechanical properties is explained later in Section 4.2.9.1.

\subsubsection{Creating Eulerian Section Properties:}

The Eulerian section contains all the materials that are included in the Eulerian domain. A material instance was generated for all the materials included in the Eulerian domain. 


\begin{tabular}{|c|c|c|}
\hline \multicolumn{2}{|c|}{ Edit Section } & $x$ \\
\hline \multicolumn{3}{|l|}{ Name: Section-1 } \\
\hline \multicolumn{3}{|l|}{ Type: Eulerian } \\
\hline \multicolumn{3}{|c|}{ Material Instances } \\
\hline $\begin{array}{c}\text { Base } \\
\text { Material }\end{array}$ & $\begin{array}{c}\text { Instance } \\
\text { Name }\end{array}$ & \\
\hline Nerve & nerve-1 & \\
\hline PeripheralNerve & peripheralnerve-1 & \\
\hline \multicolumn{3}{|c|}{$\begin{array}{l}\text { Waming: Changes to material instance } \\
\text { names may invalidate existing } \\
\text { predefined fields. }\end{array}$} \\
\hline OK & Cancel & \\
\hline
\end{tabular}

Figure 4.6 Edit Section tab in Abaqus 6.9 (Screenshot from Abaqus 6.9)

In this case, 'Nerve' and 'Peripheral Nerve' were included in the Eulerian domain and hence, two material instances of 'Nerve-1' and 'Peripheral Nerve-1' were generated after creating the Eulerian section. The material instances were used while defining the material volume fractions in predefined fields. The Eulerian section was assigned to the part 'NerveEulerianAssembly'.

In Eulerian Analysis, assignment of Eulerian section does not fill the elements with material. Initial conditions are used to specify the initial location of the material in the Eulerian domain using material volume fractions. 


\subsubsection{Creating sets for specifying material volume fractions:}

Sets were created to represent different regions in the Eulerian domain in order to specify initial location of material in the domain. Three sets were created:

i) Cyst: This set specified the articular branch of the Nerve and contained portion surrounding the hole. Peripheral Nerve-1 material instance was used to specify material volume fraction for this set.

ii) Nerve: This set represented the actual Peroneal Nerve. Nerve-1 material instance was used to specify material volume fraction for this set.

iii) Rest of void: Peripheral Nerve-1 was used as a material instance to specify the material volume fraction for this set. It represented the biological tissues surrounding the nerve.

Figure 4.5 shows the different regions for which the above mentioned sets were created.

\subsubsection{Creating an analysis step:}

A dynamic explicit step was created, since Eulerian approach in Abaqus is only supported for dynamic analysis. Density of nerve material was specified equal to 0.76 $\mathrm{g} / \mathrm{cm}^{3}$ (Hashemi, Chandrashekhar and Slauterback 2005) required for dynamic analysis. Output variable EVF (Element Volume Fraction) was requested to the output database file to plot the material location within the Eulerian domain. The field variable was specified at a frequency of 20 intervals. 


\subsubsection{Meshing the merged part:}

The part obtained by merging of eulerian nerve and Eulerian box instances was meshed with 8 node linear brick Eulerian elements with reduced integration and hourglass control. Normally, triangular meshes are used for parts having complicated geometry, but Abaqus Explicit 6.9 is incapable of performing Eulerian analysis using tetrahedral elements. Regular shaped elements were obtained as far as possible because they give more accurate results as compared to distorted elements. It was not required that the eulerian mesh conform to the initial material boundaries as in case of Lagrangian mesh. In Eulerian meshes, elements may be partially filled with material. However, elements were completely filled with material in this case. Different materials were assigned to different regions of the Eulerian part. Eulerian elements influenced the stable time increment size $(\Delta t)$ in the same way as the Lagrangian elements.

$$
\Delta \mathrm{t}=\frac{L^{e}}{c_{d}}
$$

where

$L^{e}=$ element characteristic length

$c_{d}=$ dilatational wave speed

Hence, as the element characteristic length decreases, the stable time increment size increases significantly. This feature imposed a limit on the mesh size used for the analysis. 


\subsubsection{Mesh Sensitivity Analysis}

As described in Section 4.2.8, the eulerian elements affect the stable time increment size $(\Delta t)$ in the same way as Lagrangian elements. In order to use an optimum mesh size for the analysis, mesh sensitivity analysis was performed. Since strain is the parameter of interest, element size of the entire eulerian domain was reduced step by step, i.e. number of elements in the eulerian domain containing the nerve geometry was increased and circumferential strain was calculated for respective mesh sizes. By definition, strain is the ratio of change in length due to deformation over the original length.

In this case, the cyst which represents a circle before deformation expands and simulates a blow out after deformation. Hence, change in circumference of the geometry due to deformation to the original circumference of the cyst was calculated which is also termed as circumferential strain.

Hence,

$$
\text { Strain }=\frac{C_{d^{-}} C}{C}
$$

where, $\mathrm{C}_{\mathrm{d}}=$ Circumference of cyst after deformation

$$
\mathrm{C}=\text { Circumference of cyst before deformation }
$$


Figure 4.7 shows the plot of circumferential strain (\%) against number of elements in the eulerian domain. The plot suggests that in eulerian analysis, as the number of elements increases, the circumferential strain increases. The mesh size cannot be reduced further due to computational limitations. The processor was not able to handle mesh sizes having seed size less than 0.0675 due to limitations on the processor capacities. Hence, seed size of 0.0675 was used which resulted in 155721 elements. Further analysis was carried out using 155721 eulerian elements.

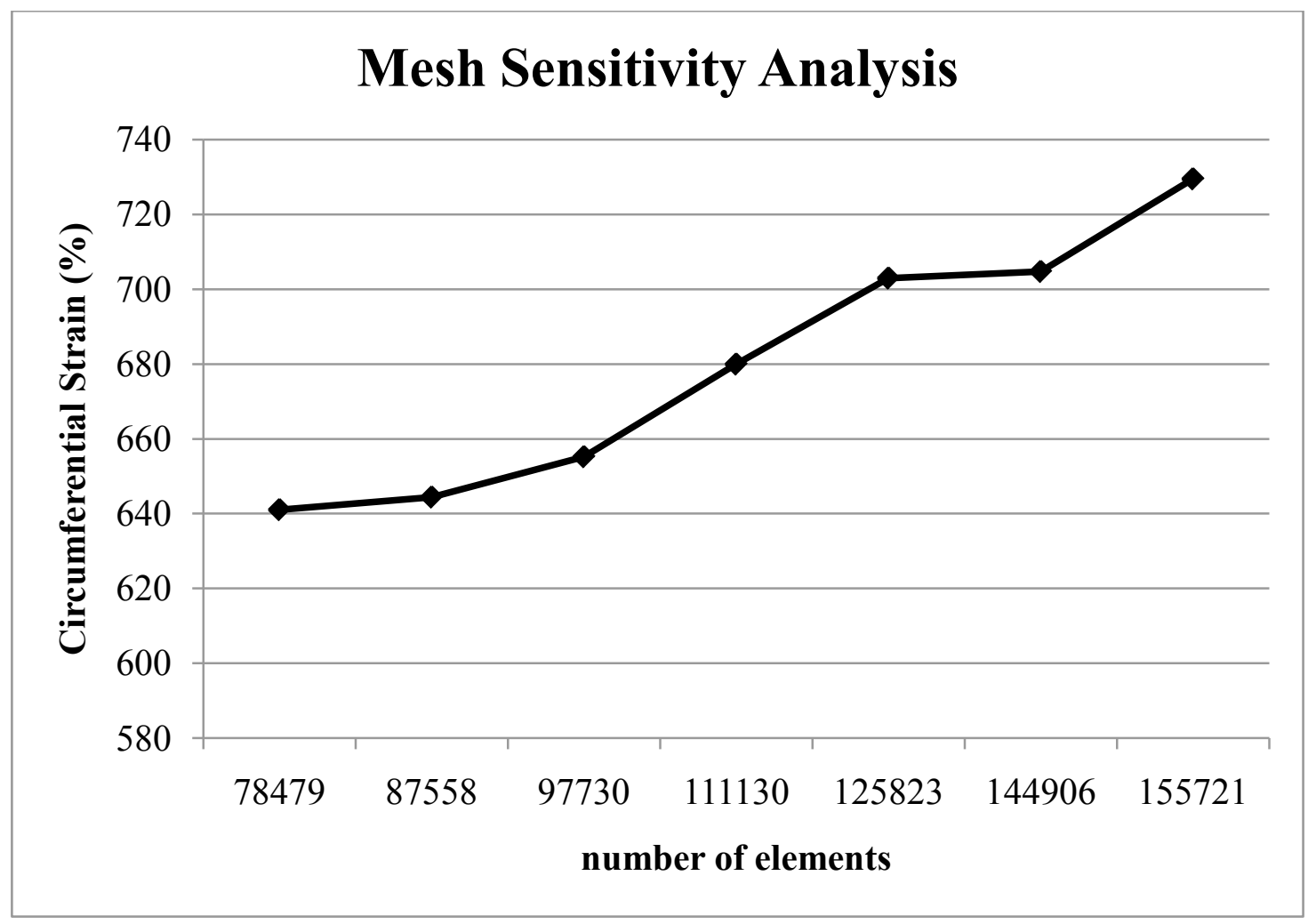

Figure 4.7 Plot of circumferential strain v/s number of elements 


\subsubsection{Defining Initial Conditions:}

Initial conditions were used to specify initial location of the material within the Eulerian domain. Eulerian elements were empty by default having material volume fraction as zero. Predefined fields were used to specify the material volume fractions to different regions in the Eulerian domain. These different regions were represented by sets created in section 4.2.6 and shown in figure 4.5.

Figure 4.8 shows 'Edit Predefined Field' dialog box in Abaqus 6.9. The dialog box contains a table in which each column represents material instance created in the Eulerian section. Each row specifies material volume fraction assigned for a particular region in the domain. Figure 4.8 indicates that Cyst and Rest of void were completely filled with material instance 'Peripheral Nerve-1'. However, the region Nerve was filled with material instance 'Nerve-1'.

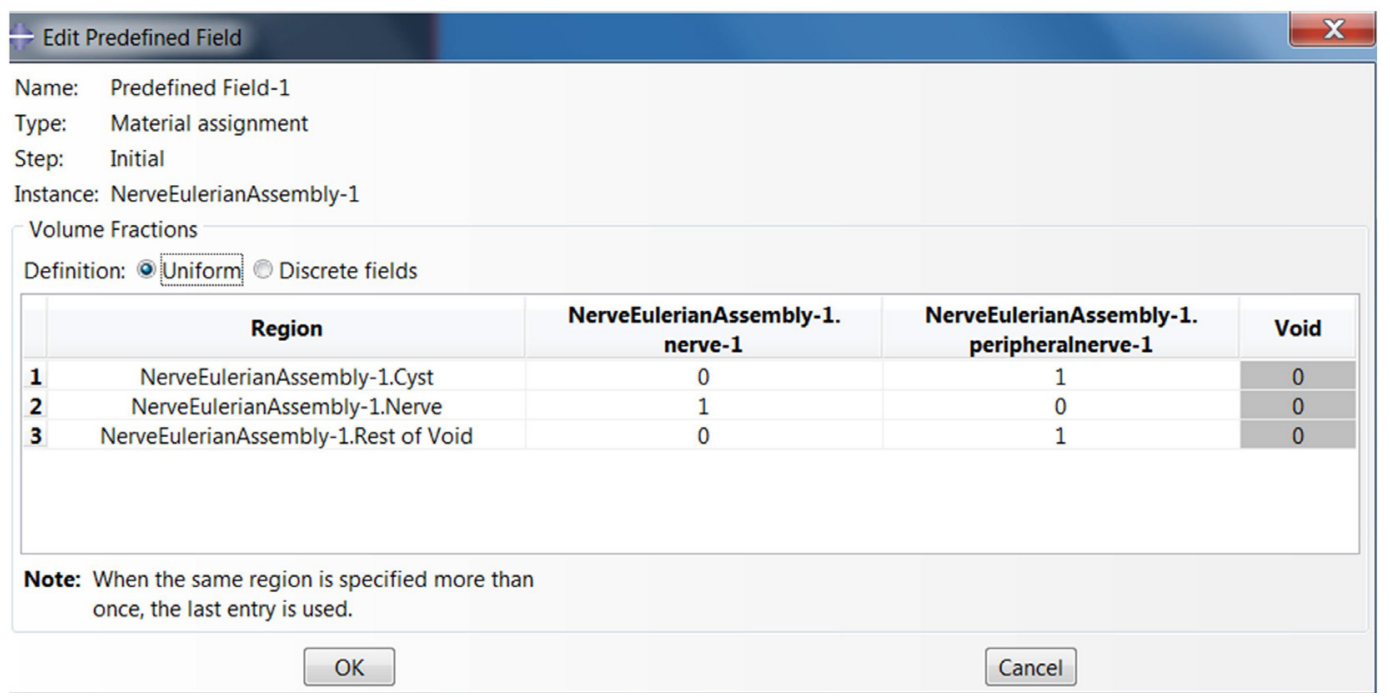

Figure 4.8 Defining material volume fractions in predefined fields (Screenshot from Abaqus) 


\subsubsection{Significance of creating two different materials}

Figure 4.9 (Elangovan et al. 2009) explains the anatomy of CPN and its branches at superior tibiofibular joint in relation to the surrounding tissue. As cyst propagates from the articular branch to sciatic nerve, it is always surrounded by muscles, bones, nervous tissue and soft tissue. In this FEA model, geometry set "nerve" acts as CPN which shows a signet ring appearance at Stage III/IV of cyst propagation as explained in Section 1.1 and figure 1.4. Geometry set 'cyst' acts as mucinous lesions which compress the fascicles in the peroneal nerve due to intraarticular pressures from the joint mechanics. Geometry set 'Rest of void' acts as surrounding material which provides resistance to cyst propagation.

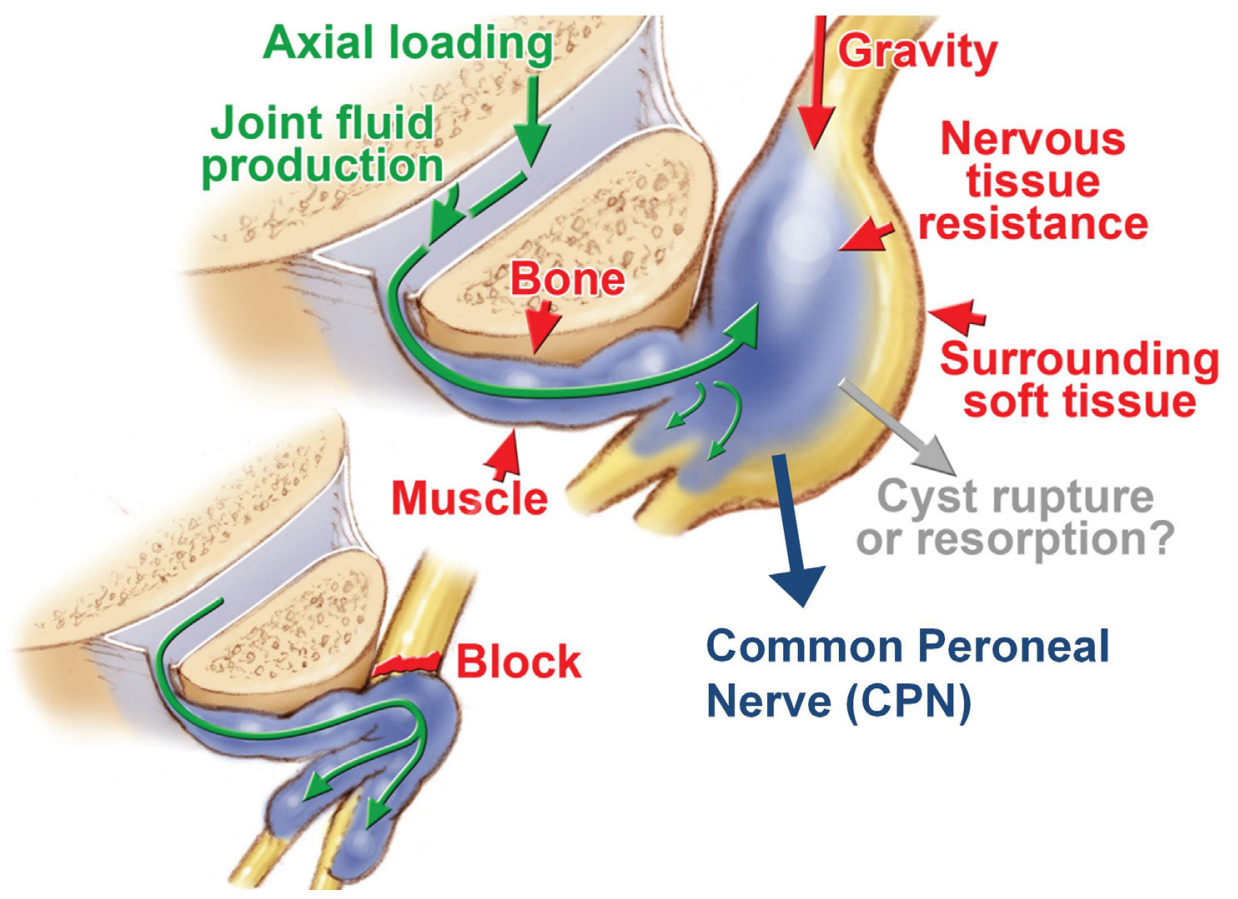

Figure 4.9 Anatomy of Common Peroneal Nerve with its branches at Superior Tibiofibular joint (Figure 4.9 is copyrighted and used with permission of Mayo Foundation for medical education and Research, all rights reserved, see Appendix-A) 
These materials were assumed to be linearly elastic due to inability of Eulerian approach to model Hyperelastic materials. Hence, mechanical properties of native carotid artery were used to model the cyst material, surrounding materials as well as the peroneal nerve. This satisfies the anatomy of the biological problem and also provides a rationale for extreme deformation of fascicles without failure. Thus, the model represents the in vivo condition of the Common Peroneal Nerve subjected to joint fluid pressure and surrounded by muscles, bones, cartilages and other surrounding soft tissues.

\subsubsection{Defining boundary conditions and loads:}

Boundary conditions and loads applied to the Eulerian domain affect the Eulerian material passing through the point of load application. As the articular branch in the CPN is subjected to intraarticular pressure from the superior Tibiofibular joint, the cyst propagates from the articular branch to CPN and finally to the sciatic nerve at Stage IV of cyst propagation.

The physics of the problem can be satisfied by applying a Pressure boundary condition at the periphery of the hole representing an articular branch. Section 3.8 explains that in order to resemble the MRI image of the cyst, strains due to deformation should be greater than $110 \%$. In order to obtain such large strains, excessive pressure forces were required at the periphery of the hole. In addition to it, pressure forces were to be applied to the node sets instead of the surface sets. Abaqus 6.9 is incapable of applying pressure forces 
to node sets and can only be applied to surface sets in Eulerian approach. Since the primary objective of this research is to mechanically model the cyst growth and resemble it with MRI image of the cyst; displacement boundary condition can be used to simulate cyst growth. However, it is not possible to apply prescribed displacement boundary condition in Eulerian analysis because Eulerian nodes do not move with the material and stay fixed in space. Hence, velocity boundary condition is recommended in Eulerian context and was used. Sets were created for applying velocity and zero displacement boundary conditions. A few nodes at right in figure 4.10 were assigned zero displacement boundary condition to simulate the cyst blow out. Radially outward velocity was applied to nodes surrounding the cyst.

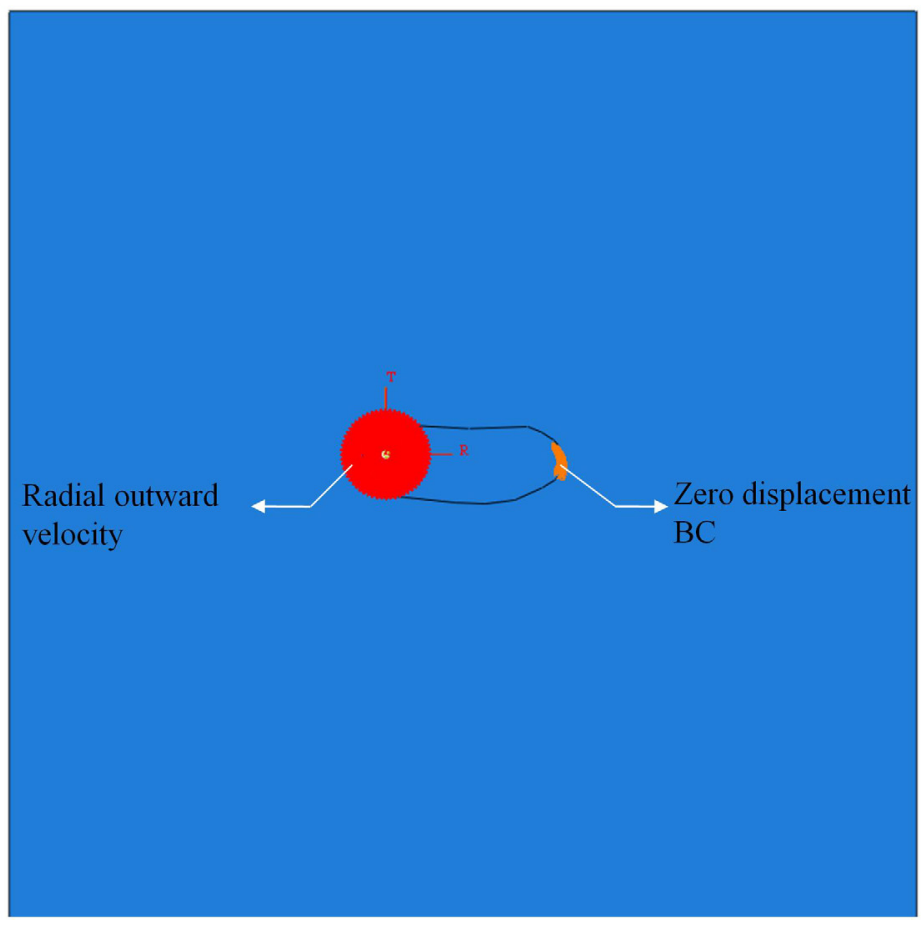

Figure 4.10 Application of Boundary conditions and loads to the Eulerian domain (Screenshot from Abaqus 6.9) 


\subsubsection{Postprocessing:}

Output variable Element Volume Fraction (EVF) was used to visualize material location in the Eulerian domain. Isosurface view cuts were used to remove empty eulerian elements from the plot. All the material instances having zero and non zero material volume fractions in the Eulerian domain were available in the View Cut manager. Figure 4.11 shows the view cut manager dialog box in Abaqus 6.9. Initial conditions illustrated that sets 'Cyst' and 'Rest of void' were filled with material instance Peripheral Nerve-1 and set 'Nerve' was filled with material instance Nerve-1. In this model, geometry set 'Nerve' represented the cross section of CPN; it was considered to be region of interest.

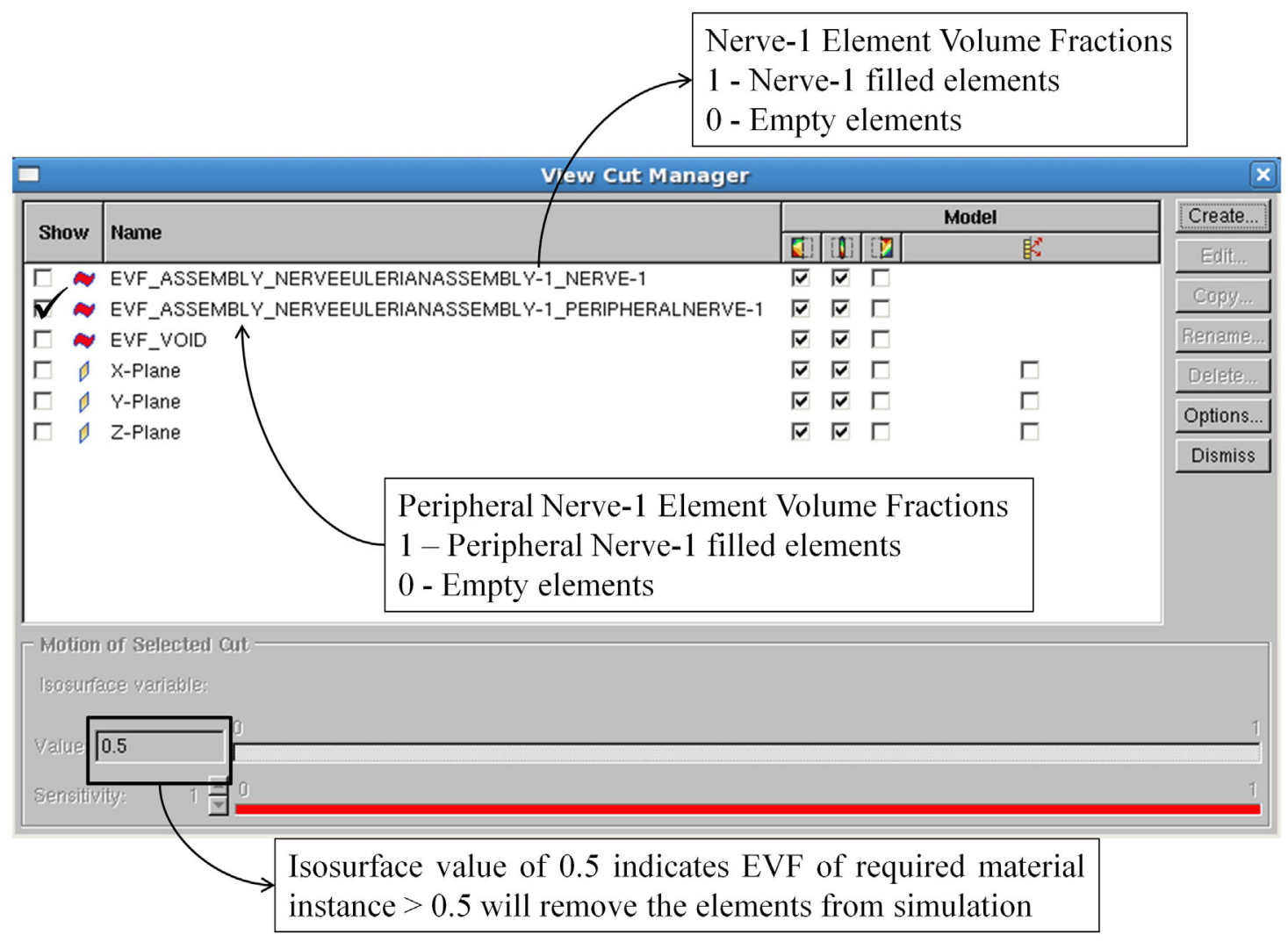

Figure 4.11 Isosurface view cuts dialog box in Abaqus 6.9 (Screenshot from Abaqus 6.9) 
Hence, EVF_ASSEMBLY_PERIPHERAL NERVE-1 was selected as Isosurface view

Cut and Isosurface variable value selected was 0.5 . It meant that elements having EVF of material instance Peripheral Nerve-1 greater than 0.5 were removed from the simulation while elements having EVF of material instance Nerve-1 greater than 0.5 were included in the simulation.

\subsection{Results - Eulerian Analysis:}

The main advantage of Eulerian analysis is the capability of Eulerian mesh to minimize mesh distortions. This enables the Eulerian mesh to simulate problems involving large deformations. Abaqus 6.9 was used to simulate the cyst growth in two dimensions using Eulerian approach. However, Abaqus 6.9 is incapable of performing Eulerian analysis in two dimensions. Hence, a three dimensional Eulerian part having very small thickness was used. Due to limitations in Abaqus 6.9 to apply pressure boundary conditions to nodes in the Eulerian approach, velocity boundary conditions were used to simulate cyst growth. Radially outward velocities were applied to a set of nodes surrounding the cyst. The maximum velocity that the model was able to withstand without termination of analysis was $4.2 \mathrm{~mm} / \mathrm{s}$. Analysis terminated mainly due to an error:

'The ratio of deformation speed to wave speed in an element is less than 1'. This could be avoided by the use of Mass scaling technique. However, mass scaling was not supported 
in Eulerian approach. This error can be avoided by using a fine mesh having seed size less than 0.0675 . However, processor capacity sets a limit on the seed size and hence, this error can be avoided by using processors having larger capacity.

Results were viewed in the visualization module of Abaqus 6.9. The entire Eulerian domain appeared in the main window in visualization module. As mentioned in Section 4.2.11, the actual Nerve model was displayed by toggling ' $\mathrm{ON}$ ' the material volume fraction for Peripheral Nerve-1 in the view cut manager (Refer Fig. 4.11). The nerve model along with the deformation due to the applied boundary conditions was displayed. In order to view the deformation at each time interval, it was animated with time history. Figure 4.12 shows the deformation of CPN due to expansion of cyst. The cyst propagated proximally while displacing the fascicles around it due to expansion of the cyst in radial outward direction. In the Eulerian approach, the mesh stays fixed and material flows through the mesh; volume averaged quantities are obtained in the deformation plot. Hence, in order to obtain strain due to the propagation of a cyst in CPN division of sciatic nerve, the ratio of change in circumference of cyst due to deformation to circumference of cyst before deformation was calculated. As shown in figure 4.12, the cyst appears as a circle in undeformed plot (step time $=0.0$ ) having diameter equal to $0.18 \mathrm{~mm}$. Thus, circumference of cyst before deformation was equal to $0.5655 \mathrm{~mm}$. 

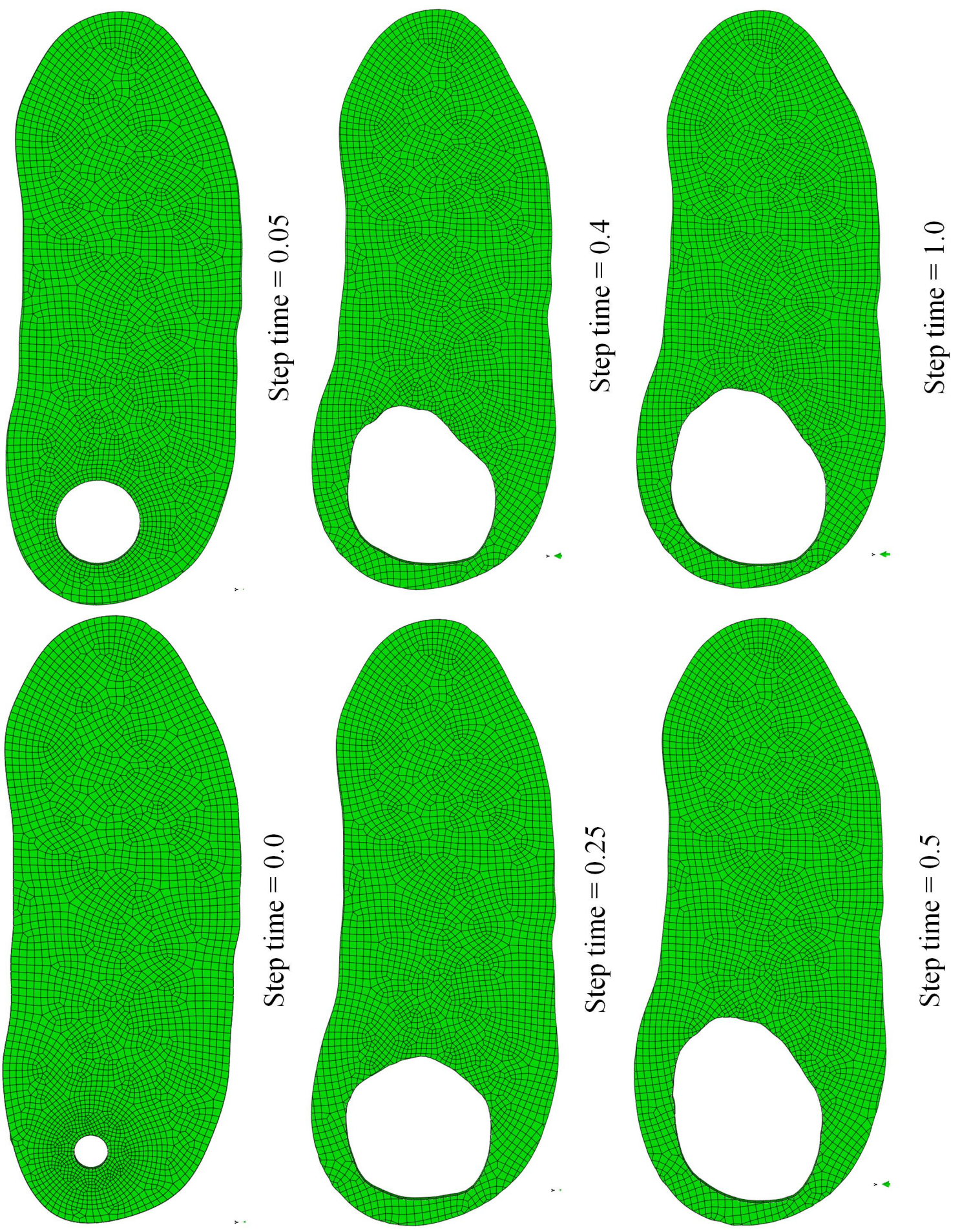

Figure 4.12 Deformation of CPN due to expansion of the IGC for subsequent frequency intervals (Screenshot from Abaqus 6.9) 
In the deformed plot, the cyst appears as an ellipse (step time $=1.0$ ). The major and minor axes of the ellipse were calculated using Abaqus 6.9 tools. The dimensions of the ellipse were as given below:

Major axis of the ellipse: $1.915 \mathrm{~mm}$

Minor axis of the ellipse: $1.52 \mathrm{~mm}$

Using the above data, the circumference of the ellipse was calculated equal to $5.43 \mathrm{~mm}$.

Therefore, Strain due to expansion of cyst in CPN cross section was given as:

$$
\text { Strain }=\frac{\mathrm{C}_{\mathrm{d}}-\mathrm{C}}{\mathrm{C}}
$$

where

$\mathrm{C}_{\mathrm{d}}=$ Circumference of the cyst after deformation

$\mathrm{C}=$ Circumference of the cyst before deformation

$$
\text { Strain }=\frac{4.864}{0.5654}=8.602
$$

Therefore, the strain obtained in Eulerian approach due to cyst blow out was 8.602 i.e. equal to $860.2 \%$. Comparing these results with the results obtained from EFGM in Section 3.9, Strain obtained in Eulerian approach was considerably larger than strain obtained in EFGM showing an increase in strain by $682 \%$. Thus, Eulerian approach has the capability of modeling IGC propagation in CPN division of the sciatic nerve. 


\subsubsection{Signet Ring Correlation}

Articular theory proposed by Spinner et al., 2006 explains that IGC propagates proximally from articular branch to sciatic nerve by expansion due to intraarticular pressures resulting in excessive deformation of the fascicles around it. In the Eulerian approach, the strains of $860.2 \%$ were obtained by expansion of a cyst subjected to prescribed velocities in radial outward direction. Since, intraarticular pressures mainly occur due to cyst fluid pressurizing the articular branch from inside; the phenomenon was approximated as cyst fluid moving at a certain velocity in radially outward direction. As shown in figure 4.12, deformation though does not resemble a signet ring appearance; but it certainly has the capability of modeling cyst propagation by actual deformation of fascicles.

Figure 4.13 (a) shows the MRI image of the cyst at the CPN cross section at fibular neck and figure 4.13 (b) shows the deformed plot obtained in Eulerian approach. The white region in figure 4.13 (a) represents the cyst filled with mucinous fluid. Grey colored material in MRI image represents the eccentrically compressed fascicles due to expansion of the cyst subjected to intraarticular pressures. The appearance of the cyst and its neighboring fascicles resemble a signet ring; hence, the term 'signet ring sign' was coined by Spinner et al. 2006 . 


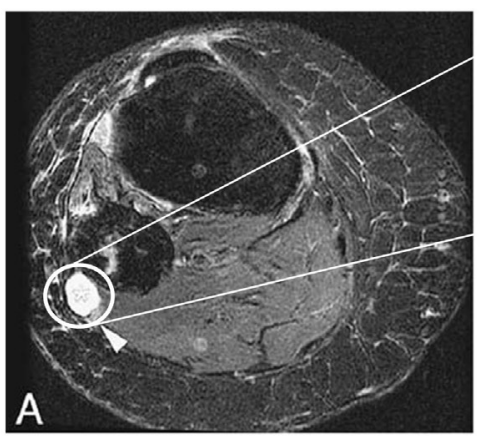

(a) MRI image of cyst

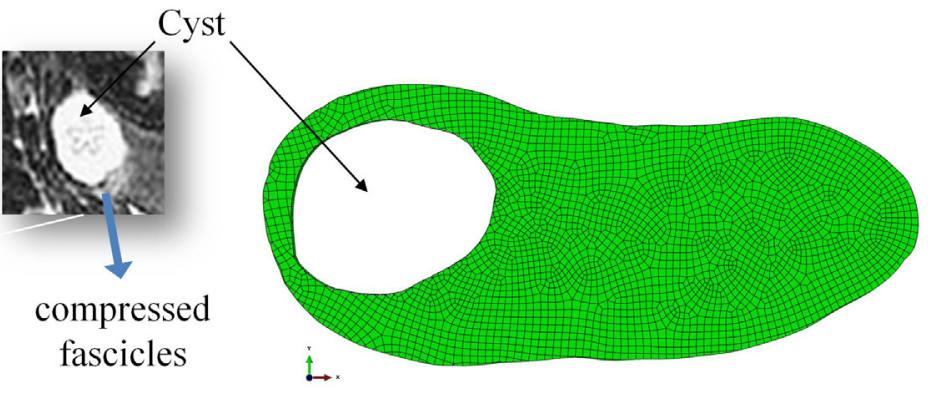

(b) Deformed shape at step time $=1.0$

Figure 4.13. Signet ring sign correlation

(Image 'a' reprinted with kind permission from Springer Science+Business Media: Skeletal Radiology, Coexisting secondary intraneural and vascular adventitial ganglion cysts of joint origin: a causal rather than a coincidental relationship supporting an articular theory, v.35, 2006, p.734-744, Authors - Spinner RJ, Scheithauer BW, Desy NM, Rock MG, Holdt FC and Amrami KK, Fig. 1, see Appendix-A)

Similarly, in Figure 4.13 (b), the white region represents the cyst and the elements surrounding the cyst represent the neighboring fascicles. Correlations between figures (a) and (b) suggest that the simulation results do not resemble the MRI image of the cyst, but large strains obtained certainly show capability of the method to model this neurological deficit.

\subsubsection{Cyst propagation correlation}

Analysis of strain obtained for every time interval gives a clear idea of propagation of cyst in radial direction in the affected nerve cross section. Circumferential strains were 


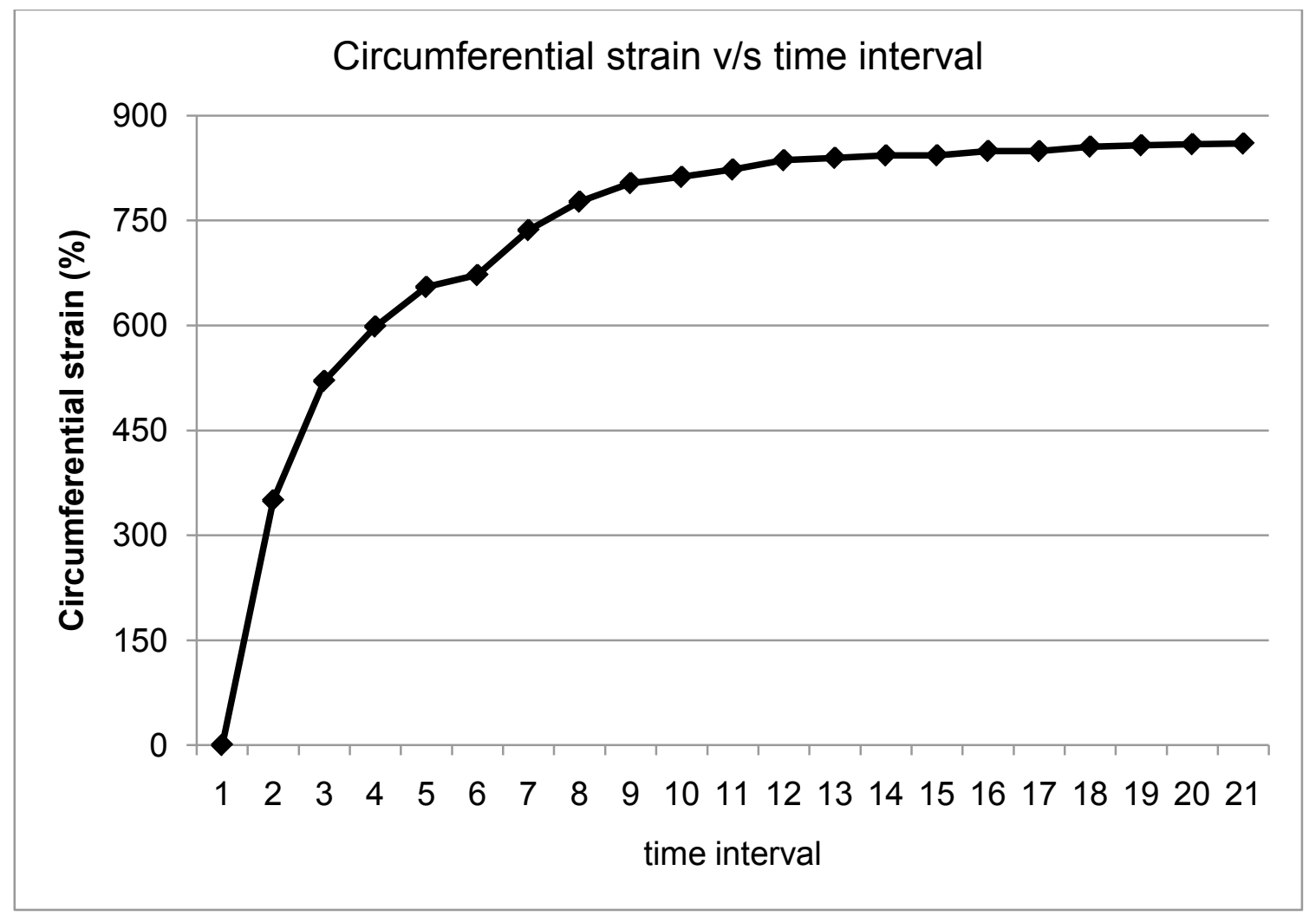

Figure 4.14 Plot of circumferential strain against time interval

obtained from equation 4.3.1 for every time interval and graph of circumferential strains against the respective time interval was plotted. Figure 4.14 shows a plot of circumferential strain against time interval indicating the path of cyst growth. The plot of circumferential strain against time interval shows that initially, strain increases rapidly until time interval 8. However, as time interval further increases, rate of increase of strain reduces. If time interval plotted on X-axis in Figure 4.14, is considered to be analogous to the time required for cyst propagation. The plot shows ganglion cyst propagation in peripheral nerve connected to a joint. Figure 4.9 explains the mechanism behind cyst propagation in Section 4.2.8. The time interval plotted as X-axis can be considered to be 
corresponding to the actual time for which cyst is present inside the nerve. Therefore, it can be concluded that cyst rapidly propagates with time at the beginning. At this stage of cyst propagation, the forces due to intraarticular pressure are greater than the resisting forces. It can be considered as Stage I and Stage II of the cyst propagation. As time progresses, the cyst grows proximally compressing more fascicles around it. However, at this stage, the resisting forces become almost equal to the assisting forces due to intraarticular pressures and the rate of cyst propagation decreases. This can be considered as Stage III/ Stage IV of cyst propagation.

Thus, the Eulerian approach in Abaqus 6.9 was effective enough in modeling large deformations of fascicles due to cyst expansion and simulated a cyst blow out. In addition, it demonstrated good correlation between the growth of cyst in the mechanical model and in reality. The limitations of this approach were its inability to apply pressure boundary conditions to node sets and the incapability to model hyperelastic materials. 


\section{SUMMARY AND CONCLUSIONS}

\subsection{Summary}

The primary objectives of this study were to model IGC propagation in two dimensions and predict the cyst path in the CPN division of the sciatic nerve. The two dimensional FEA model was created using data obtained from clinicians and geometry provided by Sunderland \& Ray 1948. According to the data obtained from clinicians, the cyst was located medial to the nerve with fibers distally branching out into the articular branch. Mechanical modeling of the ganglion cyst was performed using two computational techniques namely: i) Element Free Galerkin Method (EFGM) and ii) Eulerian Analysis.

In EFGM, the nerve model was discretized into nodes and background mesh was used for integration of system equations. Cyst fluid pressure was simulated by forces acting in radial outward direction. Due to absence of mesh, EFGM was able to simulate the deformation of fascicles due to cyst expansion up to $110 \%$ strains. However, it failed to verify the signet ring (Spinner et al. 2006) correlation obtained from MRI image of the cyst. Due to lack of control of LS-DYNA on EFGM parameters, large strain gradients were observed which resulted in inaccuracies and premature termination of the analysis. Hence, the Eulerian approach was used to model the deformation due to expansion of the cyst and compression of fascicles around it. 
In the Eulerian analysis, the mesh stayed fixed and material moved through the mesh. Therefore, large deformations were obtained with minimal mesh distortion. Ganglion cyst propagation was modeled using the Eulerian approach in Abaqus 6.9. Mechanical model represented the in vivo condition of cyst expansion in CPN. Radial outward velocities were assigned to nodes on and around the periphery of the cyst and a few nodes were constrained at the other end to prevent rigid body motion. The cyst propagated proximally deforming fascicles around it demonstrating the physical phenomenon of cyst growth. The cyst was blown out to its maximum extent in this manner. Though the mechanical model failed to exactly resemble the 'signet ring sign' obtained from MRI image of the cyst, it was capable of modeling excessively large deformation of $860 \%$ strain. Hence, correlations were adequately possible. Moreover, the plot of circumferential strain against respective time interval (Fig 4.14) approximated the cyst behavior in the nerve subjected to intraarticular pressures.

\subsection{RESEARCH SIGNIFICANCE}

IGC's have been considered as curiosities for nearly 2 centuries. Due to esoteric nature of these lesions and its tendency to recur postoperatively; clinicians are working to attain a foolproof treatment for this neurological deficit. Different theories without a scientific basis have been proposed in the past. IGC's are believed to originate from joints and 
propagate proximally and radially due to joint fluid pressure pressurizing the nerve forming a blow out. Dye experiments have enabled clinicians to validate the path of cyst propagation. However, they are unable to find answers to the question why cyst propagates in a particular direction i.e. proximally? In this thesis report, advanced computational techniques were used to mechanically model the cyst growth in CPN division of the sciatic nerve in two dimensions located at the fibular neck by actual deformation of fascicles around it. The mechanical model was used to resemble the MRI image of the cyst in the CPN cross section at the same location which reinforces the articular theory (Spinner et al. 2003). This research primarily focused on methods capable of modeling excessively large deformation (strains greater than 100\%) and did not take into consideration the nonlinear material behavior of the nerve material. It tested two novel numerical methods capable of modeling excessively large deformations. Based on the results and correlation obtained with MRI image of the cyst, it was concluded that the Eulerian mesh approach is capable of modeling excessively large deformations (order of $860 \%$ strain) and can be used to model ganglion cyst propagation in the sciatic nerve using a three dimensional model.

FEA model was created using data from clinicians and geometry obtained from Sunderland \& Ray 1948 in Chapter 2. Objective of Chapter 3 was to develop a mechanical approach for simulating excessively large strains in a problem having simple 
geometry and applying the same to the nerve geometry. EFGM, a meshfree method having capability of modeling excessively large deformations was used to simulate this deformation. Maximum strain obtained due to expansion of cyst subjected to pressures from joint fluid was approx $110 \%$ which was substantial. However, it failed to resemble the MRI image of the cyst showing a signet ring like appearance. Hence, computational tool capable of modeling strains greater than $110 \%$ was required.

Chapter 4's objective was to model the nerve cross section to strains greater than $110 \%$ in order to resemble MRI image of the cyst using eulerian approach. Eulerian approach in Abaqus 6.9 was used to model the nerve cross section. A three dimensional Eulerian model having very small thickness was created due to incapability of Abaqus 6.9 to analyze two dimensional models using Eulerian approach. Due to limitations in applying pressure loads to the nodes in Eulerian approach, velocity boundary conditions were used to simulate cyst blow out. Results showed the deformation of elements up to $860 \%$ strains and it adequately resembled the MRI image of the cyst. The plot of strain against time interval closely resembled the propagation of cyst in the sciatic nerve. Also, the model exactly represented the in vivo condition of the nerve in human body with the nerve being surrounded by biological tissues namely bones, muscles and soft tissues.

The above analyses verified the capability of these techniques to mechanically model this neurological deficit. Eulerian approach was especially a promising technique to model 
such large deformations and accordingly, this neurological deficit. However, Study of stresses occurring in the fascicles due to cyst expansion required the need for accurate representation of material microstructure, material behavior between the model and actual nerve material.

\subsection{Future Work}

Current work has produced valuable interpretations which can be used in future for better prediction of the actual phenomenon. The primary constraints observed in FE modeling of ganglion cyst expansion include modeling excessively large deformation of fascicles and use of incompressible Hyperelastic material. Current work focused on techniques capable of modeling large deformations of elements which presented an insight into these advanced methods.

EFGM in LS-DYNA was used as an effective technique to model the cyst expansion in two dimensions subjected to radial outward forces at the periphery of the cyst. However, LS-DYNA had less control over EFGM due to which the simulation results showed large strain gradients resulting in premature termination of the analysis. The solution to this problem could be the development of a user defined algorithm based on EFGM enabling the user to select the support domain of the point of interest and maintaining optimum ratio of quadrature points to the local support nodes as discussed in section 3.6.1. 
Moreover, use of incompressible hyperelastic material as the nerve material will exactly resemble the actual cyst growth phenomenon. Use of other forms of meshless methods namely: Diffuse Element method (DEM), Smooth Particle Hydrodynamics (SPH), Natural Element Method (NEM), Reproducing Kernel Particle Method (RKPM) etc. which have shown capability to model large deformations in biological tissues can be effective enough to model this neurological deficit.

Eulerian analysis in Abaqus 6.9 demonstrated fairly good correlation between the results obtained from the mechanical model and the MRI image of the cyst. However, Velocity boundary conditions were applied to model the blow out. In reality, pressures from the joint fluid deform the cyst compressing the fascicles around it. Hence, use of pressure boundary conditions at the edges of the cyst will simulate the actual phenomenon and the correlation between the mechanical model and the MRI image of the cyst can be exactly made. An additional limitation of this approach is the incapability of Abaqus 6.9 to model hyperelastic and anisotropic materials. Hence, compressible linear elastic material having elastic properties of native carotid artery was used. In order to fairly approximate the actual phenomenon, incompressible material in $\mathrm{U}_{\mathrm{S}}-\mathrm{U}_{\mathrm{P}}$ formulation can be used. This method will result in reduction of computational efficiency, but is the only material model currently available that can be used for modeling this neurological deficit in Eulerian approach in Abaqus. 
Thus, this Thesis report mainly focused on the methods capable of modeling the large strain deformation of the elements required in modeling the IGC propagation in two dimensions. It proposed two novel advanced techniques capable of modeling excessively large strain deformations. EFGM was capable of modeling $110 \%$ strain in complicated nerve geometry and $140 \%$ strain in simple plate geometry before the termination of analysis. Eulerian analysis in Abaqus 6.9 was used as another method to model the complicated nerve geometry. It demonstrated deformations of $860 \%$ strain and was verified to be more capable of modeling large strain deformations than EFGM. Hence, Eulerian method can be considered to be an efficient and capable method to model the cyst propagation path from the articular branch to the sciatic nerve passing via the trifurcation of articular branch, Deep Peroneal Nerve and Superficial Peroneal Nerve and corroborate the proximal predilection of the Intraneural Ganglion Cyst as mentioned in the articular theory proposed by Spinner et al. 2003 . 


\section{REFERENCES}

Belytschko, L, Y Lu, and L Gu. "Element Free Galerkin Methods." International Journal of Numerical Methods, 37, 1994: 229-256.

Benson, D. "Computational Methods in Lagrangian and Eulerian Hydrocodes." Computer Methods in Applied Mechanics and Engineering, 99, 1992: 235-394.

"Coupled Eulerian Lagrangian (CEL) Analysis with Abaqus/Explicit." Dassault Systems.

Providence, RI: Dassault Systems, 2010.

Desy, N. M., K. K. Amrami, and R. J Spinner. "Ganglion cysts and nerves." . Neurosurgery Quarterly, 16(4),, 2006: 187-194.

Dheeravongkit, A, and K Shimda. "Inverse Pre-Deformation of Finite Element Mesh for Large Deformation Analysis." Journal of Computer Aided Design and Applications, 2, 2005: 805-814.

Doblare, M, E Cueto, B Calvo, A Martinez, J Garcia, and J Cegonino. "On the employ of meshless methods in biomechanics." Computer Methods in applied mechanics and engineering, 194, 2004: 801-821.

Elangovan, S. Advanced Mechanics of Materials with Microstructure. Houghton, MI: Michigan Technological University, 2010.

Elangovan, S, G Odegard, D Morrow, H Wang, M Herbert-Blouin, and R Spinner. "Intraneural Ganglia: a clinical problem deserving a mechanistic explanation and model." Neurosurgical Focus, 26(2), 2009: 1-7.

Gadala, M, and J Wang. "ALE formulation and its applications in solid mechanics." Computer Methods in Applied Mechanics and Engineering, 167, 1998: 33-55. 
Gallagher, T C, R H Gross, T C Simon, and B R Johnson. Finite Elements in Biomechanics. John Wiley and Sons, 2006.

Hashemi, J, N Chandrashekhar, and J Slauterback. "The mechanical properties of the human patellar tendon are correlated to its mass density and are independent of sex." Clinical Biomechanics, 20, 2005: 645-652.

Horton, A, A Wittek, and K Miller. "Subject Specific Biomechanical Simulation of Brain Indentation using Meshless Method." MICCAI Proceedings if 10th International Conference on medical image computing and computer assisted interventior. Berlin: Universitat Trier, 2007. 541-548.

Huang, $\mathrm{J}$ M, and $\mathrm{J}$ T Black. "An evaluation of chip separation criteria for the fem simulation of machining." ASME Journal of Manufacturing Science and Engineering, 118, 1996: 545-553.

Kawashima, Y, and Y Sakai. "Large Deformation Analysis of Hyperelastic materials using SPH Method." Journal of Soft Materials, 3, 2007: 21-28.

Lee, S, K Darvish, and L Lobovsky. "Modeling of the Material properties and Fluid Structure Interaction in the Traumatic Rupture of Aorta." ESV Conference . 2005. 1-6.

Liu, G. Meshfree Methods: Moving Beyond Finite Element Method. CRC Press, 2003.

LS-DYNA Keyword User's Manual, 1. Livermore Software Technology Corporation, 2007.

Raczy, A, M Elmadagli, W Altenhof, and A Alpas. "An Eulerian Finite Element Model for determination of a Copper subjected to orthogonal cutting." Metallurgical and Materials Transactions, 35A, 2004: 2393-2400. 
Sidorov, Sergey. Finite Element Modeling of Human Artery Tissue with a NonLinear Multi-mechanism inelastic material. Pittsburgh: University of Pittsburgh, 2007.

Spinner, R, B Scheithauer, N Desy, M Rock, F Holdt, and K Amrami. "Coexisting Secondary intraneural and vascular adventitial ganglion cysts of joint origin: a causal rather than a coincidental relationship supporting articular theory." Skeletal Radiology, 35, 2006: 734-744.

Spinner, R, B Scheithauer, N Desy, M Rock, F Holdt, and K Amrami. "Coexisting Secondary intraneural and vascular adventitial ganglion cysts of joint origin: a causal rather than a coincidental relationship supporting articular theory." Skeletal Radiology, 35, 2006: 734-744.

Spinner, R, et al. "Peroneal Intraneural Ganglia: the importance of articular branch. clinical series." Journal of Neurosurgery, 99, 2003: 319-329.

Spinner, R, H Wang, S Carmichael, K Amrami, and B Scheithauer. "Epineurial Compartments and their role in Intraneural Ganglion Cyst propagation: An experimental study. ." Clinical anatomy, 20, 2007: 826-833.

Spinner, Robert, John Atkinson, and Robert Tiel. "Peroneal Intraneural Ganglia: the importance of the articular branch. A unifying theory." Journal of Neurosurgery, Volume 99, 2003: 330-343.

Sunderland, S, and L Ray. "The intraneural topography of the sciatic nerve and its popliteal divisions in man." Brain: a journal of neurology , 1948: 242-273.

Wu, C, A Bazar, C Campbell, and K Gregory. "Longitudinal Tensile Properties of Elastin, Cured Elastin and Native Carotid Artery." American Society of Biomechanics Annual Meeting. 2004. 


\section{APPENDIX A - COPYRIGHTS/PERMISSIONS}

\subsection{Licenses for Chapter - 1}

\subsubsection{License for figure 1.1, 1.3:}

December 13, 2011

Puneet S. Soman

Department of Mechanical Engineering

Michigan Technology University

Mr. Soman,

RE: Permission to reproduce Figures 3, 6, 14

200 First Street SW

Rochester Minnesota 55905

507-284-251 1

\section{Section of Scientific Publications}

In your thesis entitled, "Mechanical Modeling of intraneural Ganglion Cyst."

Copyright of the above-mentioned artwork is held by Mayo Foundation. Thus, for a $\mathrm{n}$ y appearance of this artwork, the credit line should include "By permission of Mayo Foundation for Medical Education and Research. All rights reserved."

As an authorized agent for the Foundation in these matters, I hereby grant permission for the use of these illustrations in your thesis.

Mayo Foundation does not hold the copyright for Figure1A and Figure 2B. Permission will need to be obtained from the Joumal of Neurosurgery or from the publisher.

Sincerely yours,

Mr. Soman,

Your permission letter is attached.

Rosemary Perry

Agent, Mayo Foundation for Medical Education and Research 
-----Original Message-----

From: prvs=3212e5927=pssoman@mtu.edu

[mailto:prvs=3212e5927=pssoman@mtu.edu] On Behalf Of Puneet Soman

Sent: Tuesday, December 13, 2011 10:18 AM

To: Perry, Rosemary

Cc: Gregory Odegard

Subject: Re: Permission required for images

Hello Ms. Perry,

Thank you for your reply. Please find the attachment containing the images which require permissions.

Also the title of my thesis: "Mechanical Modeling of Intraneural Ganglion Cyst" which is also mentioned in the attachment.

Thanks and Regards,

Puneet S Soman

Graduate Student (M.S)

Department of Mechanical Engineering Engineering Mechanics

Michigan Technological University, (980)-254-7626

Mailme at:pssoman@mtu.edu

\subsubsection{LICENSE FOR FIGURE 1.2:}

Thank you very much for your order.

This is a License Agreement between Puneet S Soman ("You") and John Wiley and Sons ("John Wiley and Sons"). The license consists of your order details, the terms and conditions provided by John Wiley and Sons, and the payment terms and conditions.

THIS DIGITAL LICENSING AND REPRINT SERVICE IS ADMINISTERED BY COPYRIGHT CLEARANCE CENTER, INC. ("CCC" or "Us").

General Payment Terms: You may pay by credit card or through an account with us payable at the end of the month. If you and we agree that you may establish a standing account with CCC, then the following terms apply:

Remit Payment to: Copyright Clearance Center, Dept 001, P.O. Box 843006, Boston, MA 02284-3006

Payments Due: Invoices are payable upon their delivery to you (or upon our notice to you that they are available to you for downloading). After 30 days, outstanding amounts 
will be subject to a service charge of $1-1 / 2 \%$ per month or, if less, the maximum rate allowed by applicable law.

Please note that, while you may exercise the rights licensed immediately, the license will be automatically void (as if it never existed) in the event that we do not receive payment for the license on a timely basis. Also please note that you are responsible for any transactions that use your user name and password; please protect the secrecy of those pieces of information.

THE FOLLOWING TERMS AND CONDITIONS APPLY TO ALL TRANSACTIONS THAT YOU ENTER INTO THROUGH THIS DIGITAL LICENSING AND REPRINT SERVICE, REGARDLESS OF THE WEBSITE FROM WHICH YOU ENTER IT. BECAUSE YOU ARE IN THE PROCESS OF OPENING A NEW ACCOUNT WITH US, YOU MUST INDICATE YOUR CONSENT TO THESE TERMS AND CONDITIONS AT THIS TIME. IN THE FUTURE, YOU MAY ALSO SEE THESE TERMS AND CONDITIONS AT ANY TIME OR IN CONNECTION WITH ANY TRANSACTION AT myaccount.copyright.com.

ANY LICENSE CREATED IS SUBJECT TO THE TERMS AND CONDITIONS THAT FOLLOW AS WELL AS ANY TERMS AND CONDITIONS ESTABLISHED BY THE RIGHTSHOLDER ON WHOSE WEBSITE YOU FIND THE MATERIAL YOU SEEK TO LICENSE, AND USE OF ANY MATERIALS CONSTITUTES ACCEPTANCE OF ALL SUCH TERMS AND CONDITIONS.

Terms and Conditions That Apply to All Transactions:

1. This digital licensing and reprint service enables you, the "User", to obtain licenses to make certain uses of the online content of many copyright holders (each a "Rightsholder"). Licenses granted through this service are granted by the Rightsholder in the content for which you are seeking a license and from whose Website (containing the content) you reached this service. This service is administered by Copyright Clearance Center, Inc. ("CCC") and your use of the content is governed by these terms and conditions, BUT your use will ALSO be governed by the terms and conditions which are set individually by the Rightsholder whose material you seek to use; the Rightsholder's terms and conditions will be made available to you in the course of the licensing process for each transaction. You, as User, will be deemed to have accepted and agreed to all of those terms and conditions, as well as these terms and conditions, if you use the Rightsholder's copyrighted material in any fashion. CCC reserves the right to send electronic mail to you for the purpose of informing you of changes or additions to this service.

2. User hereby acknowledges and agrees that User is responsible for any transaction entered into through this digital licensing and reprint service and identified with User's user name and password (if on account) or User's credit card information (if by credit card). It is User's responsibility to maintain the secrecy of such information, to notify CCC immediately upon learning of any transaction entered into through this service that 
was done so without User's authorization, and to use the appropriate automated services within this digital licensing and reprint service to alter passwords and standing payment information whenever necessary to preserve secrecy. User represents and warrants that User is at least 18 years old if User is a person (as opposed to a company or other organization); that in any event User is legally capable in User's place of residence or business of entering into the agreement created by these terms and conditions and Rightsholder's terms and conditions; and that the individual opening an account or seeking transactions under this digital licensing and reprint service on behalf of any User that is a business, corporate entity or other organization is duly authorized by User to do so.

3. Use of User-related information collected by this licensing service is governed by CCC's privacy policy. CCC's privacy policy is accessible through CCC's website www.copyright.com and from numerous locations throughout the webpages comprising this licensing service.

4. As among User, CCC and the Rightsholder, all materials available for licensing, as well as all rights therein, including copyright rights, remain the sole and exclusive property of the Rightsholder. All trademarks not belonging to the Rightsholder, as well as all software and other elements that you encounter in the course of using this digital licensing and reprint service, as well as all intellectual property rights therein, remain the sole and exclusive property of CCC and are not licensed to User in any way. While User may exercise the rights licensed immediately upon issuance of the license at the end of the licensing process for the transaction, the license is automatically revoked, and is null and void as if it had never been issued, if complete payment for the license is not received on a timely basis either from User directly or through a payment agent, such as a credit card company. All rights not expressly granted are reserved; any license granted may be further limited (on a Work-by-Work basis) as set forth in any restrictions included in the Rightsholder's terms and conditions applicable to the transaction (which will be provided at the end of the licensing process, at User's option, on paper or electronically).

5. User hereby indemnifies and agrees to defend CCC and its employees, agents, representatives, officers and directors, against all claims, liability, damages, costs and expenses, including legal fees and expenses, arising out of any use of licensed material beyond the scope of the rights granted, or any use of any licensed material which has been altered in any way by User, including claims for defamation or infringement of or damage to rights of copyright, publicity, privacy or other tangible or intangible property.As a digital licensing and reprint service on behalf of the Rightsholders, CCC has no duty to indemnify User. Notice of such indemnification as may be available can be found in the Terms and Conditions of the individual Rightsholders.

6. LIMITATION OF LIABILITY OF CCC. UNDER NO CIRCUMSTANCES WILL CCC BE LIABLE FOR ANY DIRECT, INDIRECT, CONSEQUENTIAL OR INCIDENTAL DAMAGES (INCLUDING WITHOUT LIMITATION DAMAGES FOR LOSS OF BUSINESS PROFITS OR INFORMATION, OR FOR BUSINESS INTERRUPTION) ARISING OUT OF (i) THE USE OR INABILITY TO USE ANY 
LICENSED MATERIAL OR (ii) THE INABILITY TO OBTAIN ADDITIONAL RIGHTS TO LICENSED MATERIALS, EVEN IF CCC HAS BEEN ADVISED OF THE POSSIBILITY OF SUCH DAMAGES. In any event, the total liability of CCC (including its employees, agents, representatives, officers and directors) shall not exceed the total amount actually paid by User for the applicable license. User assumes full liability for the actions and omissions of its principals, employees, agents, affiliates, successors and assigns.

7. NO WARRANTIES FROM CCC. CCC DISCLAIMS ALL WARRANTIES RELATING TO THE COPYRIGHTED MATERIALS OF RIGHTSHOLDER, EITHER EXPRESS OR IMPLIED, INCLUDING WITHOUT LIMITATION IMPLIED WARRANTIES OF MERCHANTABILITY OR FITNESS FOR A PARTICULAR PURPOSE. IN ADDITION, THIS LICENSING SERVICE AND ALL SOFTWARE USED IN CONNECTION THEREWITH ARE DISTRIBUTED ON AN "AS IS" BASIS WITHOUT WARRANTIES OF ANY KIND, EITHER EXPRESS OR IMPLIED, INCLUDING, WITHOUT LIMITATION, WARRANTIES OF TITLE OR IMPLIED WARRANTIES OF MERCHANTABILITY OR FITNESS FOR A PARTICULAR PURPOSE. USER HEREBY ACKNOWLEDGES THAT USE OF THE SERVICE IS AT USER'S SOLE RISK.

8. (a) The term "License Grant" is used in these terms and conditions to describe (i) the entire set of details (including User's name as licensee, the nature of the use for which User seeks a license, and the price of the license), as well as (ii) the Rightsholder's terms and conditions applicable to that licensing transaction and governing the particular use User may make of that copyrighted material, and (iii) CCC's general terms and conditions relating to billing and payment that are applicable to ALL transactions. All elements of the License Grant are printed out or referred to in the license document that is delivered to User at the conclusion of each transaction under this digital licensing and reprint service, and are generally available within the service's Website at any time.

(b) Any failure by User to pay any amount when due, or any use by User of any licensed material beyond the scope of the License Grant, shall be a material breach of the License Grant. Any breach not cured within ten (10) days of notice thereof shall result in immediate termination of such license without further notice. Invoices are due and payable upon their delivery to User (or upon CCC's notice to User that they are available to User for downloading from the Internet); amounts overdue will be subject to a service charge of $1-1 / 2 \%$ per month or, if less, the maximum interest rate allowed by applicable law in User's place of business, such service charge to begin running 30 days after delivery of, or notice of availability of, invoice.

9. CCC hereby objects to any terms contained in any writing prepared by User or its principals, employees, agents or affiliates and purporting to govern or otherwise relate to any licensing transaction, which terms are in any way inconsistent with any of these terms or the Rightsholder's standard terms or with any standard operating procedures of Rightsholder or CCC, whether such writing is prepared prior to, simultaneously with or subsequent to the License Grant, and whether such writing appears on any paper or 
electronic version of the License Grant or in a separate paper or electronic instrument, unless such writing is countersigned by CCC.

10. User may terminate its account at any time by sending e-mail to: customercare@copyright.com. Upon termination, User will receive a confirmation via email that the request was received, and access to the licensing service from User's account will be suspended within one business day. User is responsible for all charges incurred up to the time the account is deactivated.

11. Unless the Rightsholder's own terms and conditions for the License Grant designate different terms for governing law, venue and jurisdiction and those terms and conditions are determined by a competent court to apply to a particular dispute, (a) the License Grant shall be governed by and construed under the law of the State of New York, USA, without regard to the principles thereof of conflicts of law, (b) any case, controversy, suit, action, or proceeding arising out of, in connection with, or related to the License Grant shall be brought, at CCC's sole discretion, in any federal or state court located in the County of New York, State of New York, USA, or in any U.S. federal or state court whose geographical jurisdiction covers the principal place of business of the Rightsholder, and (c) the parties expressly submit to the personal jurisdiction and venue of each such U.S. federal or state court.

12. User acknowledges and agrees that $\mathrm{CCC}$ may alter these terms and conditions in any fashion and at any time, effective immediately, provided that CCC posts notice of any material alteration hereof to the location at which User's monthly invoice is made available by $\mathrm{CCC}$ on the Internet and any such material alteration will be effective on the date set forth in the notice (and which effective date will be at least 30 days following CCC's first posting thereof). User also acknowledges and agrees that CCC may, on notice to User at the time of invoicing or at the time of any re-invoicing of a past-due amount, assign accounts and/or amounts due either to the applicable Rightsholder or to a financial institution; and that $\mathrm{CCC}$ may at any time assign all its rights, duties and responsibilities hereunder or under any License Grant to any other person who shall take responsibility for this licensing facility. Finally, User acknowledges and agrees that CCC may, in its sole discretion, terminate or suspend User's access to all or part of the licensing service for any reason, including without limitation breach of this Agreement or persistent failure to pay license fees on a timely basis.

\subsubsection{License for Figure 1.4:}

Permission to reproduce the requested material is granted without charge by the copyright owner, AANS, provided that full acknowledgment is given to Journal of Neurosurgery.

Best of luck on your thesis,

Thank you,

Gillian 
Gillian Shasby

Director of Publications - Operations

The JNS Publishing Group

— Journal of Neurosurgery

— Journal of Neurosurgery: Spine

— Journal of Neurosurgery: Pediatrics

-Neurosurgical Focus

1224 Jefferson Park Ave

Suite 450

Charlottesville, VA 22903

434-924-5503 - main

434-924-5555 - direct

Begin forwarded message:

From: "subscriptions@thejns.org" < subscriptions@thejns.org>

From: "pssoman@mtu.edu" <pssoman@mtu.edu>

Date: December 14, 2011 1:38:58 PM EST

To: permissions@thejns.org

Cc: "patrick@thejns.org" < patrick@thejns.org>

Ce: "eevans@atypon.com"<eevans@atypon.com>

Cc: "jjoanani@atypon.com" <jjoanani@atypon.com>

\section{Subject: Mail from Reprints/Permissions Form}

Reply-To: subscriptions@thejns.org

Reply-To: <pssoman@mtu.edu>

Request to reprint the following

Peroneal intraneural ganglia: the importance of articular branch. Clinical series Authors: Robert J Spinner

Publication: Journal of Neurosurgery

Month: Aug

Year: 2003

Volume: 99

Issue:

Pages: $\quad 319-29$

Permission Category:

Original Author Seeking Permission to Use Content in non-AANS Publication 
Reprint Material Specifics:

Figure 1 B: Axial FSEIR image obtained just below the level shown in A, demonstrating the mass to be hyperintense which is consistent with the cyst

Media Type: $\quad$ Print and Electronic

Media: Not listed/other

Language: $\quad$ English (as originally published)

Title and Edition of New Mechanical Modeling of Intraneural Ganglion Cyst: Work: Master's Thesis

Anticipated Republication Jan 2012

Date:

Quantity: 1

Publisher of New Work: Michigan Technological University

Other Notes or Comments:

Request from:

Puneet S Soman, Graduate Student

Company: Michigan Technological University

1400, Townsend Drive

Houghton MI 49931

United States

pssoman@mtu.edu

Phone: 980-254-7626

Fax:

Reference Number:

Company Web Site: www.mtu.edu

Request On Behalf Of:

\subsection{Licenses for Chapter 2:}

\subsubsection{Licenses for Figure 2.1:}

Thank you very much for your order.

This is a License Agreement between Puneet S Soman ("You") and Oxford University Press ("Oxford University Press"). The license consists of your order details, the terms 
and conditions provided by Oxford University Press, and the payment terms and conditions.

THIS DIGITAL LICENSING AND REPRINT SERVICE IS ADMINISTERED BY COPYRIGHT CLEARANCE CENTER, INC. ("CCC" or "Us").

General Payment Terms: You may pay by credit card or through an account with us payable at the end of the month. If you and we agree that you may establish a standing account with CCC, then the following terms apply:

Remit Payment to: Copyright Clearance Center, Dept 001, P.O. Box 843006, Boston, MA 02284-3006

Payments Due: Invoices are payable upon their delivery to you (or upon our notice to you that they are available to you for downloading). After 30 days, outstanding amounts will be subject to a service charge of $1-1 / 2 \%$ per month or, if less, the maximum rate allowed by applicable law.

Please note that, while you may exercise the rights licensed immediately, the license will be automatically void (as if it never existed) in the event that we do not receive payment for the license on a timely basis. Also please note that you are responsible for any transactions that use your user name and password; please protect the secrecy of those pieces of information.

THE FOLLOWING TERMS AND CONDITIONS APPLY TO ALL TRANSACTIONS THAT YOU ENTER INTO THROUGH THIS DIGITAL LICENSING AND REPRINT SERVICE, REGARDLESS OF THE WEBSITE FROM WHICH YOU ENTER IT. BECAUSE YOU ARE IN THE PROCESS OF OPENING A NEW ACCOUNT WITH US, YOU MUST INDICATE YOUR CONSENT TO THESE TERMS AND CONDITIONS AT THIS TIME. IN THE FUTURE, YOU MAY ALSO SEE THESE TERMS AND CONDITIONS AT ANY TIME OR IN CONNECTION WITH ANY TRANSACTION AT myaccount.copyright.com.

ANY LICENSE CREATED IS SUBJECT TO THE TERMS AND CONDITIONS THAT FOLLOW AS WELL AS ANY TERMS AND CONDITIONS ESTABLISHED BY THE RIGHTSHOLDER ON WHOSE WEBSITE YOU FIND THE MATERIAL YOU SEEK TO LICENSE, AND USE OF ANY MATERIALS CONSTITUTES ACCEPTANCE OF ALL SUCH TERMS AND CONDITIONS.

Terms and Conditions That Apply to All Transactions:

1. This digital licensing and reprint service enables you, the "User", to obtain licenses to make certain uses of the online content of many copyright holders (each a "Rightsholder"). Licenses granted through this service are granted by the Rightsholder in the content for which you are seeking a license and from whose Website (containing the content) you reached this service. This service is administered by Copyright Clearance Center, Inc. ("CCC") and your use of the content is governed by these terms and conditions, BUT your use will ALSO be governed by the terms and conditions which are 
set individually by the Rightsholder whose material you seek to use; the Rightsholder's terms and conditions will be made available to you in the course of the licensing process for each transaction. You, as User, will be deemed to have accepted and agreed to all of those terms and conditions, as well as these terms and conditions, if you use the Rightsholder's copyrighted material in any fashion. CCC reserves the right to send electronic mail to you for the purpose of informing you of changes or additions to this service.

2. User hereby acknowledges and agrees that User is responsible for any transaction entered into through this digital licensing and reprint service and identified with User's user name and password (if on account) or User's credit card information (if by credit card). It is User's responsibility to maintain the secrecy of such information, to notify CCC immediately upon learning of any transaction entered into through this service that was done so without User's authorization, and to use the appropriate automated services within this digital licensing and reprint service to alter passwords and standing payment information whenever necessary to preserve secrecy. User represents and warrants that User is at least 18 years old if User is a person (as opposed to a company or other organization); that in any event User is legally capable in User's place of residence or business of entering into the agreement created by these terms and conditions and Rightsholder's terms and conditions; and that the individual opening an account or seeking transactions under this digital licensing and reprint service on behalf of any User that is a business, corporate entity or other organization is duly authorized by User to do so.

3. Use of User-related information collected by this licensing service is governed by CCC's privacy policy. CCC's privacy policy is accessible through CCC's website www.copyright.com and from numerous locations throughout the webpages comprising this licensing service.

4. As among User, $\mathrm{CCC}$ and the Rightsholder, all materials available for licensing, as well as all rights therein, including copyright rights, remain the sole and exclusive property of the Rightsholder. All trademarks not belonging to the Rightsholder, as well as all software and other elements that you encounter in the course of using this digital licensing and reprint service, as well as all intellectual property rights therein, remain the sole and exclusive property of CCC and are not licensed to User in any way. While User may exercise the rights licensed immediately upon issuance of the license at the end of the licensing process for the transaction, the license is automatically revoked, and is null and void as if it had never been issued, if complete payment for the license is not received on a timely basis either from User directly or through a payment agent, such as a credit card company. All rights not expressly granted are reserved; any license granted may be further limited (on a Work-by-Work basis) as set forth in any restrictions included in the Rightsholder's terms and conditions applicable to the transaction (which will be provided at the end of the licensing process, at User's option, on paper or electronically).

5. User hereby indemnifies and agrees to defend CCC and its employees, agents, representatives, officers and directors, against all claims, liability, damages, costs and 
expenses, including legal fees and expenses, arising out of any use of licensed material beyond the scope of the rights granted, or any use of any licensed material which has been altered in any way by User, including claims for defamation or infringement of or damage to rights of copyright, publicity, privacy or other tangible or intangible property.As a digital licensing and reprint service on behalf of the Rightsholders, CCC has no duty to indemnify User. Notice of such indemnification as may be available can be found in the Terms and Conditions of the individual Rightsholders.

6. LIMITATION OF LIABILITY OF CCC. UNDER NO CIRCUMSTANCES WILL CCC BE LIABLE FOR ANY DIRECT, INDIRECT, CONSEQUENTIAL OR INCIDENTAL DAMAGES (INCLUDING WITHOUT LIMITATION DAMAGES FOR LOSS OF BUSINESS PROFITS OR INFORMATION, OR FOR BUSINESS INTERRUPTION) ARISING OUT OF (i) THE USE OR INABILITY TO USE ANY LICENSED MATERIAL OR (ii) THE INABILITY TO OBTAIN ADDITIONAL RIGHTS TO LICENSED MATERIALS, EVEN IF CCC HAS BEEN ADVISED OF THE POSSIBILITY OF SUCH DAMAGES. In any event, the total liability of CCC (including its employees, agents, representatives, officers and directors) shall not exceed the total amount actually paid by User for the applicable license. User assumes full liability for the actions and omissions of its principals, employees, agents, affiliates, successors and assigns.

7. NO WARRANTIES FROM CCC. CCC DISCLAIMS ALL WARRANTIES RELATING TO THE COPYRIGHTED MATERIALS OF RIGHTSHOLDER, EITHER EXPRESS OR IMPLIED, INCLUDING WITHOUT LIMITATION IMPLIED WARRANTIES OF MERCHANTABILITY OR FITNESS FOR A PARTICULAR PURPOSE. IN ADDITION, THIS LICENSING SERVICE AND ALL SOFTWARE USED IN CONNECTION THEREWITH ARE DISTRIBUTED ON AN "AS IS" BASIS WITHOUT WARRANTIES OF ANY KIND, EITHER EXPRESS OR IMPLIED, INCLUDING, WITHOUT LIMITATION, WARRANTIES OF TITLE OR IMPLIED WARRANTIES OF MERCHANTABILITY OR FITNESS FOR A PARTICULAR PURPOSE. USER HEREBY ACKNOWLEDGES THAT USE OF THE SERVICE IS AT USER'S SOLE RISK.

8. (a) The term "License Grant" is used in these terms and conditions to describe (i) the entire set of details (including User's name as licensee, the nature of the use for which User seeks a license, and the price of the license), as well as (ii) the Rightsholder's terms and conditions applicable to that licensing transaction and governing the particular use User may make of that copyrighted material, and (iii) CCC's general terms and conditions relating to billing and payment that are applicable to ALL transactions. All elements of the License Grant are printed out or referred to in the license document that is delivered to User at the conclusion of each transaction under this digital licensing and reprint service, and are generally available within the service's Website at any time.

(b) Any failure by User to pay any amount when due, or any use by User of any licensed material beyond the scope of the License Grant, shall be a material breach of the License Grant. Any breach not cured within ten (10) days of notice thereof shall result in 
immediate termination of such license without further notice. Invoices are due and payable upon their delivery to User (or upon CCC's notice to User that they are available to User for downloading from the Internet); amounts overdue will be subject to a service charge of $1-1 / 2 \%$ per month or, if less, the maximum interest rate allowed by applicable law in User's place of business, such service charge to begin running 30 days after delivery of, or notice of availability of, invoice.

9. CCC hereby objects to any terms contained in any writing prepared by User or its principals, employees, agents or affiliates and purporting to govern or otherwise relate to any licensing transaction, which terms are in any way inconsistent with any of these terms or the Rightsholder's standard terms or with any standard operating procedures of Rightsholder or CCC, whether such writing is prepared prior to, simultaneously with or subsequent to the License Grant, and whether such writing appears on any paper or electronic version of the License Grant or in a separate paper or electronic instrument, unless such writing is countersigned by CCC.

10. User may terminate its account at any time by sending e-mail to: customercare@copyright.com. Upon termination, User will receive a confirmation via email that the request was received, and access to the licensing service from User's account will be suspended within one business day. User is responsible for all charges incurred up to the time the account is deactivated.

11. Unless the Rightsholder's own terms and conditions for the License Grant designate different terms for governing law, venue and jurisdiction and those terms and conditions are determined by a competent court to apply to a particular dispute, (a) the License Grant shall be governed by and construed under the law of the State of New York, USA, without regard to the principles thereof of conflicts of law, (b) any case, controversy, suit, action, or proceeding arising out of, in connection with, or related to the License Grant shall be brought, at CCC's sole discretion, in any federal or state court located in the County of New York, State of New York, USA, or in any U.S. federal or state court whose geographical jurisdiction covers the principal place of business of the Rightsholder, and (c) the parties expressly submit to the personal jurisdiction and venue of each such U.S. federal or state court.

12. User acknowledges and agrees that $\mathrm{CCC}$ may alter these terms and conditions in any fashion and at any time, effective immediately, provided that CCC posts notice of any material alteration hereof to the location at which User's monthly invoice is made available by $\mathrm{CCC}$ on the Internet and any such material alteration will be effective on the date set forth in the notice (and which effective date will be at least 30 days following CCC's first posting thereof). User also acknowledges and agrees that CCC may, on notice to User at the time of invoicing or at the time of any re-invoicing of a past-due amount, assign accounts and/or amounts due either to the applicable Rightsholder or to a financial institution; and that CCC may at any time assign all its rights, duties and responsibilities hereunder or under any License Grant to any other person who shall take responsibility for this licensing facility. Finally, User acknowledges and agrees that CCC may, in its sole discretion, terminate or suspend User's access to all or part of the 
licensing service for any reason, including without limitation breach of this Agreement or persistent failure to pay license fees on a timely basis.

\subsection{Licenses for Chapter 4}

\subsubsection{Licenses for Figure 4.9}

December 13, 2011

Puneet S. Soman

Department of Mechanical Engineering

Michigan Technology University

Mr. Soman,

RE: Permission to reproduce Figures 3, 6, 14

200 First Street SW

Rochester Minnesota 55905

507-284-251 1

\section{Section of Scientific Publications}

In your thesis entitled, "Mechanical Modeling of Intraneural Ganglion Cyst."

Copyright of the above-mentioned artwork is held by Mayo Foundation. Thus, for a $\mathrm{n}$ appearance of this artwork, the credit line should include "By permission of Mayo Found ation for Medical Education and Research. All rights reserved."

As an authorized agent for the Foundation in these matters, I hereby grant permission for the use of these illustrations in your thesis.

Mayo Foundation does not hold the copyright for Fi gure1A and Figure 2B. Permission will need to be obtained from the Joumal of Neurosurgery or from the publisher.

Sincerely yours,

\subsubsection{Licenses for Figure 4.13 (a)}

This is a License Agreement between Puneet S Soman ("You") and Springer ("Springer") provided by Copyright Clearance Center ("CCC"). The license consists of your order details, the terms and conditions provided by Springer, and the payment terms and conditions.

All payments must be made in full to CCC. For payment instructions, please see information listed at the bottom of this form. 
License Number

2807751060646

License date

Dec 14, 2011

Licensed content publisher

Springer

Licensed content publication

Skeletal Radiology

Licensed content title

Coexisting secondary intraneural and vascular adventitial ganglion cysts of joint origin: a causal rather than a coincidental relationship supporting an articular theory

Licensed content author

Robert J. Spinner

Licensed content date

Jan 1, 2006

Volume number

35

Issue number

10

Type of Use

Thesis/Dissertation

Portion

Figures

Author of this Springer article

No

Order reference number

Title of your thesis / dissertation

Mechanical Modeling of Intraneural Ganglion Cyst

Expected completion date

Jan 2012

Introduction 
The publisher for this copyrighted material is Springer Science + Business Media. By clicking "accept" in connection with completing this licensing transaction, you agree that the following terms and conditions apply to this transaction (along with the Billing and Payment terms and conditions established by Copyright Clearance Center, Inc. ("CCC"), at the time that you opened your Rightslink account and that are available at any time at http://myaccount.copyright.com).

\section{Limited License}

With reference to your request to reprint in your thesis material on which Springer Science and Business Media control the copyright, permission is granted, free of charge, for the use indicated in your enquiry. Licenses are for one-time use only with a maximum distribution equal to the number that you identified in the licensing process.

This License includes use in an electronic form, provided it is password protected or on the university's intranet, destined to microfilming by UMI and University repository. For any other electronic use, please contact Springer at (permissions.dordrecht@springer.com or permissions.heidelberg@springer.com)

The material can only be used for the purpose of defending your thesis, and with a maximum of 100 extra copies in paper.

Although Springer holds copyright to the material and is entitled to negotiate on rights, this license is only valid, provided permission is also obtained from the (co) author (address is given with the article/chapter) and provided it concerns original material which does not carry references to other sources (if material in question appears with credit to another source, authorization from that source is required as well). Permission free of charge on this occasion does not prejudice any rights we might have to charge for reproduction of our copyrighted material in the future.

Altering/Modifying Material: Not Permitted

However figures and illustrations may be altered minimally to serve your work. Any other abbreviations, additions, deletions and/or any other alterations shall be made only with prior written authorization of the author(s) and/or Springer Science + Business Media. (Please contact Springer at permissions.dordrecht@springer.com or permissions.heidelberg@springer.com)

Reservation of Rights

Springer Science + Business Media reserves all rights not specifically granted in the combination of (i) the license details provided by you and accepted in the course of this licensing transaction, (ii) these terms and conditions and (iii) CCC's Billing and Payment terms and conditions.

Copyright Notice:

Please include the following copyright citation referencing the publication in which the material was originally published. Where wording is within brackets, please include verbatim. 
"With kind permission from Springer Science+Business Media: <book/journal title, chapter/article title, volume, year of publication, page, name(s) of author(s), figure number(s), and any original (first) copyright notice displayed with material>."

Warranties: Springer Science + Business Media makes no representations or warranties with respect to the licensed material.

Indemnity

You hereby indemnify and agree to hold harmless Springer Science + Business Media and $\mathrm{CCC}$, and their respective officers, directors, employees and agents, from and against any and all claims arising out of your use of the licensed material other than as specifically authorized pursuant to this license.

No Transfer of License

This license is personal to you and may not be sublicensed, assigned, or transferred by you to any other person without Springer Science + Business Media's written permission.

No Amendment Except in Writing

This license may not be amended except in a writing signed by both parties (or, in the case of Springer Science + Business Media, by CCC on Springer Science + Business Media's behalf).

Objection to Contrary Terms

Springer Science + Business Media hereby objects to any terms contained in any purchase order, acknowledgment, check endorsement or other writing prepared by you, which terms are inconsistent with these terms and conditions or CCC's Billing and Payment terms and conditions. These terms and conditions, together with CCC's Billing and Payment terms and conditions (which are incorporated herein), comprise the entire agreement between you and Springer Science + Business Media (and CCC) concerning this licensing transaction. In the event of any conflict between your obligations established by these terms and conditions and those established by CCC's Billing and Payment terms and conditions, these terms and conditions shall control.

Jurisdiction

All disputes that may arise in connection with this present License, or the breach thereof, shall be settled exclusively by the country's law in which the work was originally published.

Other terms and conditions:

\section{v1.2}

If you would like to pay for this license now, please remit this license along with your payment made payable to "COPYRIGHT CLEARANCE CENTER" otherwise you will be invoiced within 48 hours of the license date. Payment should be in the form of a check 
or money order referencing your account number and this invoice number RLNK500683937.

Once you receive your invoice for this order, you may pay your invoice by credit card. Please follow instructions provided at that time.

Make Payment To:

Copyright Clearance Center

Dept 001

P.O. Box 843006

Boston, MA 02284-3006

For suggestions or comments regarding this order, contact RightsLink Customer Support: customercare@copyright.com or +1-877-622-5543 (toll free in the US) or +1-978-6462777.

Gratis licenses (referencing $\$ 0$ in the Total field) are free. Please retain this printable license for your reference. No payment is required. 